PAULO VINÍCIUS MIYUKI YAMABE

Study of a methodology to evaluate the severity of obstructed coronary arteries with the aid of computer simulations 
PAULO VINÍCIUS MIYUKI YAMABE

\section{Study of a methodology to evaluate the severity of obstructed coronary arteries with the aid of computer simulations}

Submitted in partial fulfilment of the requirements for the degree of Master of Science in Mechanical Engineering 
PAULO VINÍCIUS MIYUKI YAMABE

\section{Study of a methodology to evaluate the severity of obstructed coronary arteries with the aid of computer simulations}

Submitted in partial fulfilment of the requirements for the degree of Master of Science in Mechanical Engineering

Field of Study:

Control and Mechanical Automation Engineering (3152)

Supervised by:

Prof. Dr. Emílio Carlos Nelli Silva 
Este exemplar foi revisado e corrigido em relação à versão original, sob responsabilidade única do autor e com a anuência de seu orientador.

São Paulo, de de

Assinatura do autor:

Assinatura do orientador:

Catalogação-na-publicação

Yamabe, Paulo Vinicius Miyuki

Study of a methodology to evaluate the severity of obstructed coronary arteries with the aid of computer simulations / P. V. M. Yamabe -- versão corr. - São Paulo, 2016.

$94 \mathrm{p.}$

Dissertação (Mestrado) - Escola Politécnica da Universidade de São Paulo. Departamento de Engenharia Mecatrônica e de Sistemas Mecânicos.

1.Dinâmica dos Fluidos (Simulação) 2.Método dos Elementos Finitos 3.Hemodinâmica 4.Bioengenharia 5.Artérias (Sistemas) I.Universidade de São Paulo. Escola Politécnica. Departamento de Engenharia Mecatrônica e de Sistemas Mecânicos II.t. 


\section{ACKNOWLEDGEMENTS}

Gostaria de agrader todos amigos e familiares que estiveram presentes nessa jornada acadêmica, especialmente meus pais, Edna e Marcio, minha irmã, Alyne, e minha namorada Mariana. Vocês me deram todo o suporte necessário para a realização desta etapa, e sempre acreditaram em mim. Muito obrigado, de coração.

Um muito obrigado à todos os professores com os quais eu tive contato durante a realização do mestrado, pela dedicação e paciência no nobre ato de ensinar, e por me mostrar diferentes alternativas e soluções para os problemas encontrados durante a elaboração desta dissertação.

Ao Instituto Dante Pazzanesse de Cardiologia e ao médico Tiago Senra, pelo apoio e pela colaboração na parte médica do trabalho, esta dissertação só foi possível pela troca de informações e ideias que aconteceu na elaboração da mesma.

Deixo aqui também, um agradecimento especial à ONG TETO-Brasil e à todos os voluntários que participam deste projeto incrível, por me fazerem acreditar na busca por uma sociedade mais justa e menos desigual.

Por último, mas não menos importante, agradeço a Fundação de Pesquisas Aquáticas (FUNDESPA), a Coordenação de Aperfeiçoamento de Pessoal de Nível Superior (Capes) e o Conselho Nacional de Desenvolvimento Científico e Tecnológico (CNPq), pela bolsa de estudos concedida, que viabilizou financeiramente a elaboração desse projeto. 
"If you want to go fast, go alone.

If you want to go far, go together." African proverb 


\section{ABSTRACT}

Computer simulations have become a great tool to assist the medical field. The present work is a study of a non-invasive patient-specific methodology to evaluate the hemodynamic importance of coronary stenosis using computer simulations. The severity of the lesion is evaluated by the Fractional Flow Reserve, calculated by the pressure gradient before and after the lesion. The geometry models are obtained from medical images of Computed Tomography Angiography exams, and the simulations considers the pulsatile flow and the blood as a non-Newtonian fluid. The governing equations of the blood flow are solved by using Finite Element Method applied to the numerical method called Incremental Pressure Correction Scheme, and with the aid of the libraries from the open-source software FEniCS. Computer simulations of three different patients are performed and the results are compared with the invasive FFR measurements. The methodology proposed shows to be feasible in the study and analysis of stenosed coronaries.

Keywords: Biomedical Engineering. Hemodynamics. Computer Simulations. Finite Element Method. Fractional Flow Reserve. 


\section{RESUMO}

Simulações computacionais tornaram-se uma excelente ferramenta para auxiliar a área médica. O presente trabalho é um estudo de uma metodologia não invasiva para avaliar a importância hemodinâmica de artérias coronárias com estenose através do uso de simulações computacionais. A severidade da lesão da artéria é avaliada através do Fractional Flow Reserve, calculado pelo gradiente de pressão antes e depois da lesão. Os modelos geométricos computacionais foram obtidos a partir de imagens médicas de exames de Angiografia por Tomografia Computadorizada e as simulações consideram o fluxo pulsátil e as propriedades não-Newtonianas do sangue. As equações governantes do fluxo de sangue são resolvidas utilizando o Método dos Elementos Finitos aplicado ao método numérico chamado Incremental Pressure Correction Scheme, e com o uso de bibliotecas do programa em código aberto FEniCS. Foram realizados simulações de três pacientes e os resultados foram confrontados com as medidas invasivas do FFR. A metodologia proposta mostrou-se viável para o estudo e análise de coronárias com estenose.

Palavras-chave: Engenharia Biomédica. Hemodinâmica. Simulações Computacionais. Método dos Elementos Finitos. Fractional Flow Reserve. 


\section{LIST OF FIGURES}

Figure 1.1 - Coronary Arteries and the Atherosclerosis . . . . . . . . . . . . . 15

Figure 1.2 - Progression of the Atherosclerosis . . . . . . . . . . . . . . . 16

Figure 1.3 - Blood Clot Thrombosis . . . . . . . . . . . . . . . . . . . . . . 16

Figure 1.4 - Medical procedures for treating coronary atherosclerosis . . . . . . . . 18

Figure 1.5 - Artery wall composition . . . . . . . . . . . . . . . . . 22

Figure 2.1 - Comparison of different viscosity models . . . . . . . . . . . . . . . 31

Figure 3.1 - Tetrahedral Elements . . . . . . . . . . . . . . . . . . . . . 36

Figure 3.2 - Transient flow profile . . . . . . . . . . . . . . . . . . . . . . . . . . 40

Figure 3.3 - Boundary condition locations . . . . . . . . . . . . . . . . . . 41

Figure 4.1 - Flowchart sequence of the method implemented . . . . . . . . . . . . 42

Figure 4.2 - Sequence of CTA images . . . . . . . . . . . . . . . . . . . 43

Figure 4.3 - DeVIDE environment . . . . . . . . . . . . . . . . . . . . 44

Figure 4.4 - DeVIDE modules . . . . . . . . . . . . . . . . . . . . 44

Figure 4.5 - Rigth coronary model obtained using the DeVIDE . . . . . . . . . . . 45

Figure 4.6 - Right coronary model obtained using DeVIDE and MeshLab . . . . . 46

Figure 4.7 - Right coronary geometry model using the VMTK . . . . . . . . . . 47

Figure 4.8 - FEniCS components overview . . . . . . . . . . . . . . . . . 48

Figure 4.9 - Pressure monitor . . . . . . . . . . . . . . . . . . . . . . . . 55

Figure 5.1 - Schematic representation of flow inside cylinder . . . . . . . . . . . . 57

Figure 5.2 - Schematic representation of the area error . . . . . . . . . . . . . . . 58

Figure 5.3 - Different refinement level of the meshes . . . . . . . . . . . . 58

Figure 5.4 - Graphic of the norm pressure error against the mesh size . . . . . . . . 59

Figure 5.5 - Comparison of the pressure error for P2P1 and P1P1 . . . . . . . . . 61

Figure 5.6 - Comparison of the volumetric flow rate error for P2P1 and P1P1 . . . 61

Figure 5.7 - Comparison of the simulation time for P2P1 and P1P1 . . . . . . . 62

Figure 5.8 - Stenosed right coronary geometry model . . . . . . . . . . . . . . . . 63

Figure 5.9 - Blood flow transient profile of four cardiac cycles . . . . . . . . . . . 63

Figure 5.10 -Location where the pressure is analysed . . . . . . . . . . . . . . 64

Figure 5.11 - Different refinement level of the meshes . . . . . . . . . . . . 65

Figure 5.12 - Left coronary model . . . . . . . . . . . . . . . . . . . . 68

Figure 5.13-Locations analysed in the left coronary model . . . . . . . . . . . . . 69

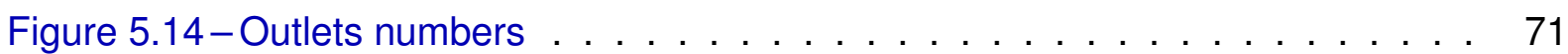

Figure 6.1 - First model used in the non-invasive FFR evaluation . . . . . . . . . . . 74

Figure 6.2 - Calcifications present in the first model . . . . . . . . . . . . . . 74

Figure 6.3 - First model locations used in the ni-FFR evaluation . . . . . . . . . . . 75

Figure 6.4 - Invasive FFR results measured in the LAD . . . . . . . . . . . . . . 75 
Figure 6.5 - Invasive FFR results measured in the LCX . . . . . . . . . . . . . 76

Figure 6.6 - Second model used in the ni-FFR evaluation . . . . . . . . . . . . . 77

Figure 6.7 - Detail of the geometry irregularities of the second model . . . . . . . 77

Figure 6.8 - Second model with the calcifications . . . . . . . . . . . . . . . . . . . . . . . . . .

Figure 6.9 - Third model used in the ni-FFR evaluation . . . . . . . . . . . . . 79

Figure $6.10-$ Third model with calcifications . . . . . . . . . . . . . . . . 79 


\section{LIST OF TABLES}

Table 2.1 - Non-Newtonian models . . . . . . . . . . . . . . . . . 30

Table 5.1 - Number of elements and geometrical error for different meshes . . . . 58

Table 5.2 - Comparison of the numerical solution with the analytical solution . . . 59

Table 5.3 - Error evaluation of the volumetric flow rate . . . . . . . . . . 60

Table 5.4 - Comparison of $\mathrm{P} 2 \mathrm{P} 1$ for $\mathrm{N}=7$ and $\mathrm{P} 1 \mathrm{P} 1$ for $\mathrm{N}=15 \ldots \ldots . \ldots 62$

Table 5.5 - Pressure comparison for each cycle . . . . . . . . . . . . . . 64

Table 5.6 - Number of elements of each mesh . . . . . . . . . . . . . . 65

Table 5.7 - Average Pressure for the different meshes . . . . . . . . . . 66

Table 5.8 - Pressure and ni-FFR results for different blood models . . . . . . . . 66

Table 5.9 - Pressure and ni-FFR results for different blood models with lower blood flow 67

Table 5.10 - Pressure and ni-FFR results considering different blood flow at the inlet 67

Table 5.11 - Pressure and ni-FFR for different outlet boundary condition . . . . . 68

Table 5.12 - Pressure and ni-FFR results for the LMCA . . . . . . . . . . . 70

Table 5.13 - ni-FFR results considering different blood flow at the inlet for the multiple outlets case . . . . . . . . . . . . . . . . . 70

Table $5.14-$ ni-FFR results considering the same pressure at the outlets . . . . . 71

Table 5.15 - ni-FFR results for different pressure in outlets 1 and $2 \ldots \ldots 72$

Table 6.1 - ni-FFR comparison of the first model . . . . . . . . . . . 76

Table 6.2 - ni-FFR comparison of the second model . . . . . . . . . . . 78

Table 6.3 - ni-FFR comparison of the third model . . . . . . . . . . 80

Table 6.4 - ni-FFR results of all patients . . . . . . . . . . . . . . 80

Table 7.1 - Comparison of the Models . . . . . . . . . . . . . . . . . 83 


\section{LIST OF CODES}

4.1 Importing the DOLFIN package . . . . . . . . . . . . . . . . 48

4.2 Importing the mesh file . . . . . . . . . . . . . . . . . 49

4.3 Poisson's problem . . . . . . . . . . . . . . . . . . . . . . . . 49

4.4 Solving linear systems $\ldots \ldots \ldots \ldots$. . . . . . . . . . . . . . 50

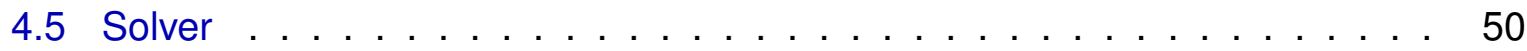

4.6 Solver and preconditioner parameters . . . . . . . . . . . . . . . 51

4.7 Definition of the function spaces $\ldots \ldots \ldots \ldots \ldots$

4.8 Definition of the trial and test functions $\ldots \ldots \ldots \ldots \ldots$

4.9 Definition of the boundary conditions . . . . . . . . . . . . . . 51

4.10 Definition of the initial conditions . . . . . . . . . . . . . . 52

4.11 IPCS implementation . . . . . . . . . . . . . . . . 52

4.12 Assembling the matrices . . . . . . . . . . . . . . . . . 52

4.13 Time loop for the transient solution . . . . . . . . . . . . . 53

A.1 Entire Code used in the computer simulations . . . . . . . . . . . . . 90 


\section{ACRONYMS}

CTA Computed Tomography Angiography

FC Form Compiler

FEM Finite Element Method

FFC FEniCS Form Compiler

FFR Fractional Flow Reserve

FIAT FInite element Automatic Tabulator

IPCS Incremental Pressure Correction Scheme

LAD Left Anterior Descending Coronary Artery

LCX Left Circumflex Coronary Artery

LMCA Left Main Coronary Artery

PDEs Partial Differential Equations

RCA Right Coronary Artery

UFC Unified Form-Assembly Code

UFL Unified Form Language

WSS Wall Shear Stress 
NOTATIONS

$\begin{array}{ll}\mathbf{u} & \text { Velocity } \\ p & \text { Pressure } \\ \mu & \text { Dynamic Viscosity } \\ \nu & \text { Kinematic Viscosity } \\ \rho & \text { Density } \\ t & \text { Time } \\ \Delta t & \text { Time increment } \\ \dot{\gamma} & \text { Shear Rate }\end{array}$




\section{CONTENTS}

$1 \quad$ INTRODUCTION $\ldots \ldots \ldots \ldots \ldots \ldots \ldots \ldots \ldots$

$1.1 \quad$ Coronary Arteries and the Atherosclerosis . . . . . . . . 15

$1.2 \quad$ Fractional Flow Reserve . . . . . . . . . . . . . . 17

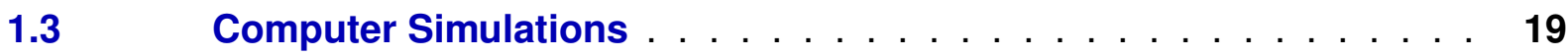

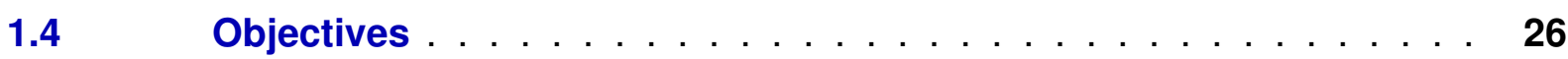

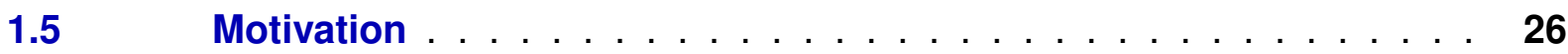

$1.6 \quad$ Document Outline $\ldots \ldots \ldots \ldots \ldots \ldots \ldots$

2 PROBLEM MODELLING $\ldots \ldots \ldots \ldots \ldots \ldots \ldots \ldots \ldots$

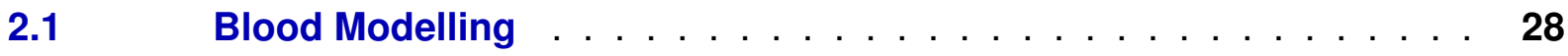

2.1.1 Newtonian and Non-Newtonian Models . . . . . . . . . . . . . . 28

$2.2 \quad$ Governing Equations $\ldots \ldots \ldots \ldots \ldots \ldots \ldots$

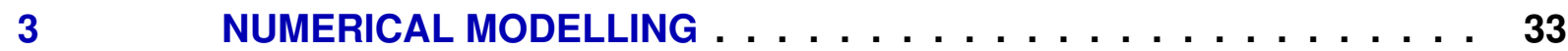

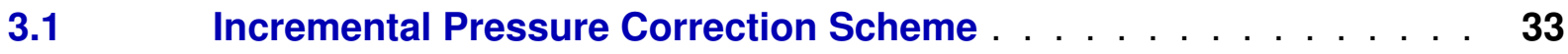

$3.2 \quad$ Finite Element Method $\ldots \ldots \ldots \ldots \ldots \ldots$

$3.3 \quad$ IPCS with FEM $\ldots \ldots \ldots \ldots \ldots$

$3.4 \quad$ Boundary and initial conditions $\ldots \ldots \ldots \ldots$

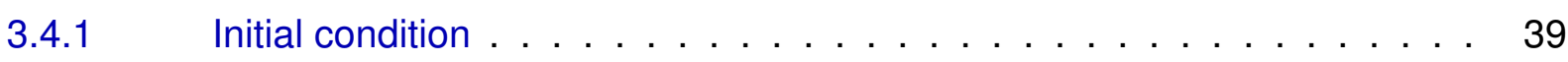

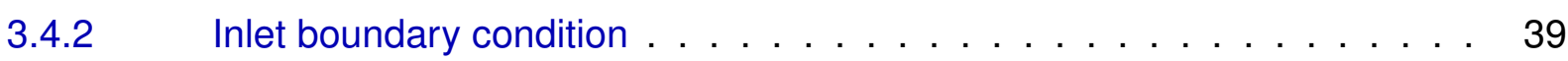

3.4.3 Wall boundary condition . . . . . . . . . . . . . . . . 41

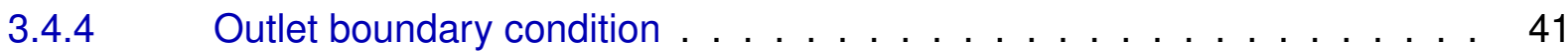

4 METHOD IMPLEMENTATION $\ldots \ldots \ldots \ldots \ldots \ldots \ldots \ldots$

$4.1 \quad$ Medical Images $\ldots \ldots \ldots \ldots \ldots \ldots$

$4.2 \quad$ Acquisition of Geometrical Model . . . . . . . . . . . . 43

4.2.1 Delft Visualization and Image processing Development Environment . . . 44

$4.2 .2 \quad$ Vascular Modelling ToolKit . . . . . . . . . . . . . . 46

$4.3 \quad$ Computer simulations implementation . . . . . . . . . 47

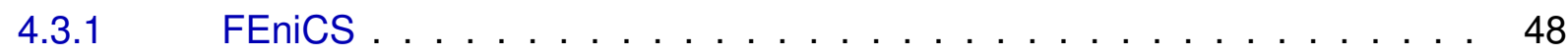

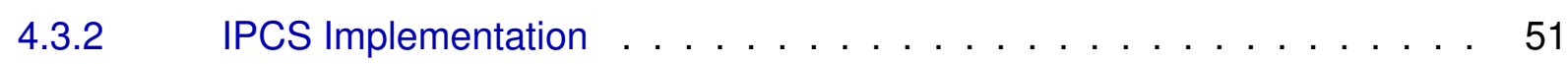

$4.4 \quad$ Paraview . . . . . . . . . . . . . . . . . . 53

$4.5 \quad$ Non-invasive FFR $\ldots \ldots \ldots \ldots \ldots \ldots$

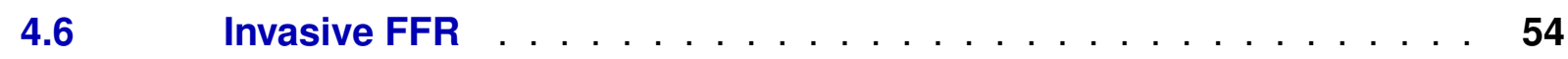

5 EVALUATION OF THE METHOD IMPLEMENTED $\ldots \ldots \ldots \ldots$ 


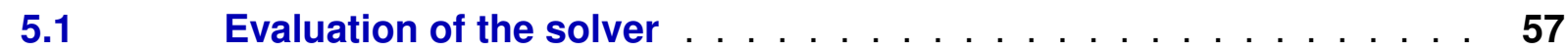

$5.1 .1 \quad$ Convergence analysis . . . . . . . . . . . . . . . 57

5.1 .2 Polynomial order of the base functions . . . . . . . . . . . 61

$5.2 \quad$ Computer simulation tests . . . . . . . . . . . . 63

$5.2 .1 \quad$ Evaluating the number of cycles . . . . . . . . . . . 63

5.2 .2 Mesh convergence test . . . . . . . . . . . . . . 64

$5.2 .3 \quad$ Different blood models . . . . . . . . . . . . . . . . . 66

5.2 .4 Sensitivity analyses of the boundary conditions . . . . . . . . . . . 67

5.2.5 Sensitivity analyses of the boundary conditions for multiple outlets . . . . 68

$6 \quad$ RESULTS . . . . . . . . . . . . . . . . . 73

$6.1 \quad$ Comparison of the ni-FFR with the invasive FFR . . . . . . . 73

$6.1 .1 \quad$ First patient . . . . . . . . . . . . . . . . 73

$6.1 .2 \quad$ Second Patient . . . . . . . . . . . . . . . . . . . . . . . . . . . . . . . . . . .

$6.1 .3 \quad$ Third Patient . . . . . . . . . . . . . . . . . . 79

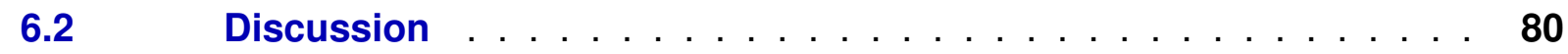

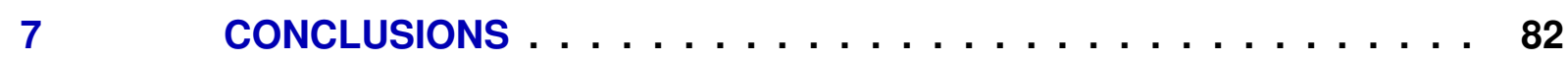

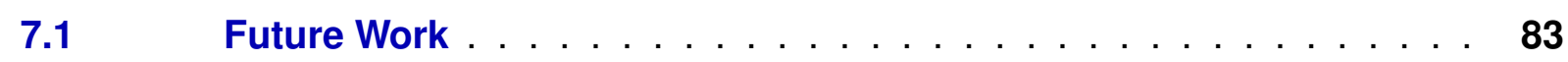

REFERENCES ....................... . . 84

APPENDIX A - CODE IMPLEMENTED . . . . . . . . . . . . . 90 


\section{INTRODUCTION}

According to the World Health Organization (2008) cardiovascular diseases were the major cause of death in the world in 2004, representing roughly 29 percent of deaths worldwide. Of these deaths, an estimated 42 percentage were due to coronary heart disease caused by Atherosclerosis, and this situation tends to be compounded with the increase of the average life expectancy caused by the advances in the medical field.

\subsection{Coronary Arteries and the Atherosclerosis}

The coronary arteries are the vessels responsible for the blood supply of the heart, they are localized in the surface of the heart and have their origin in the aortic sinus, three bulges in the aortic wall also denominated sinuses of Valsalva (HALL; GUYTON, 2006). There are two major branches of coronary arteries, the Right Coronary Artery (RCA) and the Left Main Coronary Artery (LMCA). The LMCA is subdivided in two principal branches, the Left Anterior Descending (LAD) and the Left Circumflex Artery (LCX). The main coronaries and the sinuses of Valsalva can be visualized in Figure 1.1a.

Atherosclerosis is a chronic pathology that causes the abnormal growth of cholesterol rich plaques (atheroma plaque) in the intima, inner layer of the arterial wall, resulting in the partial or total obstruction of the arterial lumen, the inner space or passage of the artery where the blood flow occurs (BARRETT et al., 2010). This restriction caused by the atheroma plaque is also referred as stenosis (Figure 1.1b). Although stenosis is the narrowing of any tubular structure in the human body, in this dissertation the word stenosis is going to refer just to the narrowing of the arterial lumen.

Figure 1.1 - Coronary Arteries and the Atherosclerosis.

(a) Coronary Arteries.

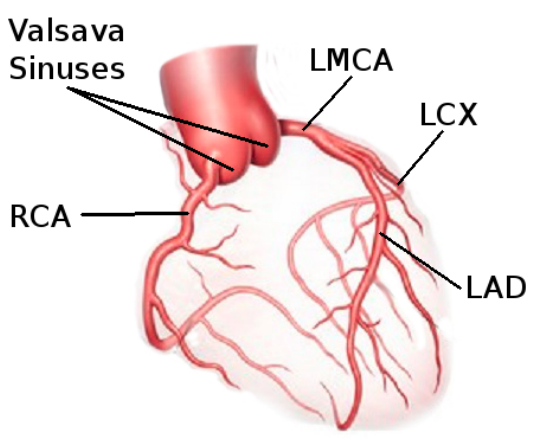

(b) Coronary obstruction.

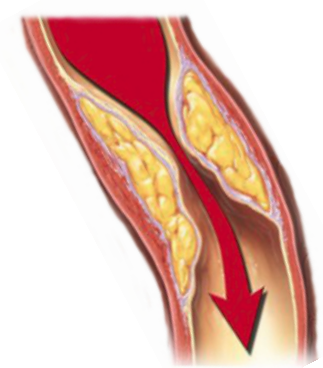


An atheroma is a lump inside the arterial wall, composed by a variable amount of lipids (cholesterol), fibrous connective tissue, calcium and necrosed tissue (HALL; GUYTON, 2006). It has five main stages in its progression: presence of fatty streaks in the arterial wall, appearance of macrophages, development of fibrous plaque, calcification and thrombosis (Figure 1.2).

Figure 1.2 - Progression of the Atherosclerosis: (a) Normal artery (b) fatty streaks (c) macrophages (d) fibrous plaque (e) calcification (f) thrombosis.

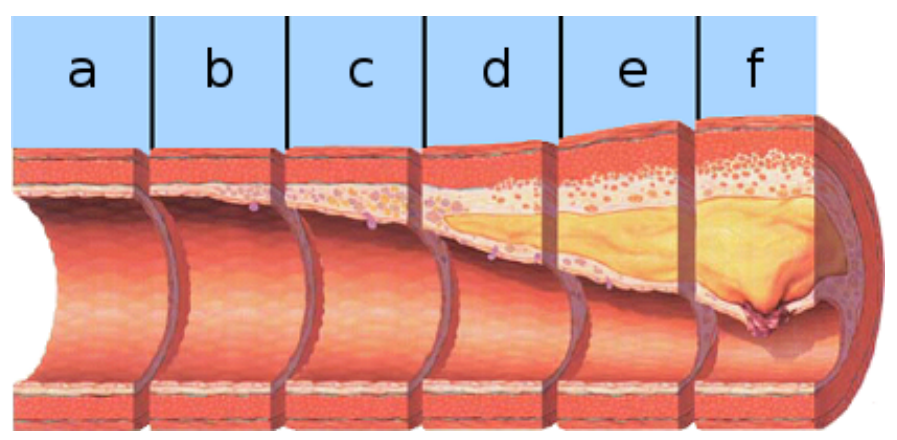

Adapted from Staff Blausen.com (2014).

Atherosclerosis is a silent disease, it take years to develop and to present some clinical complications, however when the artery lumen has been severely obstructed it can cause ischemia, impaired blood supply of a tissue (HALL; GUYTON, 2006). When the atherosclerosis affects the coronary arteries and leads to ischemia of the heart tissue, it normally causes angina (chest pain) that can grow into a myocardial infarction (heart attack) if not treated properly.

Another, and more serious, clinical issue is when the atheroma suffers a rupture, inducing the formation of a thrombus that can enhance the stenosis or break free in the blood stream and get lodge in downstream vessels (Figure 1.3), causing a infarction, commonly known as a heart attack when it occurs in the coronary arteries or stroke if it happens in the brain circulatory system (HALL; GUYTON, 2006).

Figure 1.3 - Blood Clot Thrombosis.

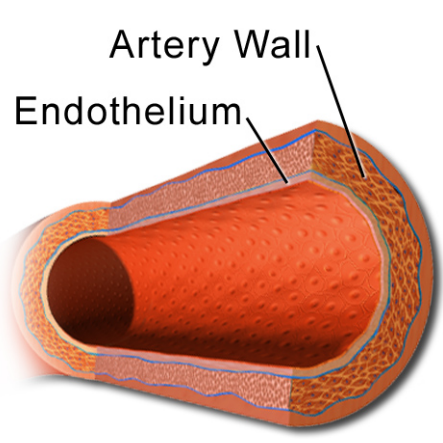

Normal Artery

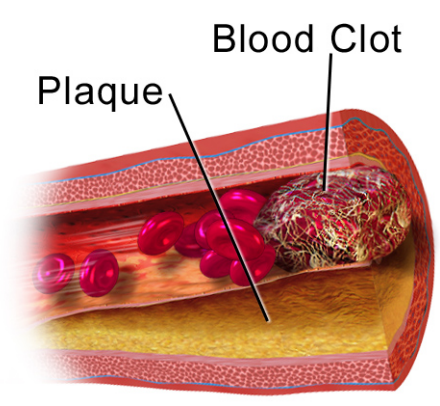

Diseased Artery

Adapted from Staff Blausen.com (2014). 
Atherosclerosis has known risk factors such as high blood cholesterol, obesity, aging, diabetes, smoking and genetics (HALL; GUYTON, 2006), although, it does not affect the entire artery uniformly. It has a predisposition to happen in particular sites, such as bends in tortuous arteries and bifurcations. This focal characteristic of the atherosclerosis, can be explained by the complex blood flows that occurs at these regions.

According to Malek, Alper and Izumo (1999) the propensity of the disease is related to low values of Wall Shear Stress (WSS), the tangential viscous fluid stress that acts in the endothelium cells of the arterial wall, because it causes the wall thickening, raise the cell proliferation and changes the morphology of the endothelium cells.

The first step in the diagnosis of the diseased artery is performed with the assistance of medical images such as Computed Tomography Angiography (CTA) or Magnetic Resonance Angiography (MRA), where the former is the most usual in the clinical practice. From the medical images, the cardiologist can measure the approximate percentage of the obstruction, however can not predict if the diseased vessel can cause ischemia. This can be done by the Fractional Flow Reserve (FFR).

\subsection{Fractional Flow Reserve}

The FFR is the present gold standard in the medical field used to evaluate the functional impact of a stenosed artery (JOHNSON et al., 2014). It is an invasive procedure that uses a catheter with a pressure sensor on its tip, and carries the risk of coronary occlusion, coronary dissection, stroke, aortic dissection, etc.

It is a lesion-specific index that is calculated as the pressure ratio between the distal region (after the stenosis) and the proximal region (before the stenosis) as can been seen in Eq. (1.1) (PIJLS, 2013):

$$
F F R=\frac{P_{\text {distal }}}{P_{\text {proximal }}}
$$

The distal region considered is always the ostia (opening or orifice) of the coronary and the proximal region varies from each patient, because it depends on the readings of the pressure catheter. The surgeon goes to a region where the pressure is more stable and the flow is not turbulent, in some cases the flow after the lesion suffers from turbulent effects.

The FFR is obtained during hyperemia, condition where the arteries are fully dilated, the resistance pressure of the distal region is minimal, and the pressure gradient is maximum. This condition can be achieved by several procedures, being the most usual the intravenous administration of adenosine, because it causes less side effects and creates a stable level of maximum hyperemia. The hyperemia is crucial in the assessment of the FFR, because its value at rest is higher than the hyperemic FFR and do not diagnose ischemia. 
According to Pijls (2013), the FFR presents some major advantages:

1. FFR measurements are easy to perform and are highly reproducible.

2. Measurements are independent of heart rate, blood pressure and heart contractility.

3. FFR has an unequivocal normal unitary value for every lesion.

4. FFR has a cutoff value for discerning the ischemic from non-ischemic lesions.

Lesions with $F F R<0.75$ induce myocardial ischemia in almost $100 \%$ of the lesions, and values of $F F R \geq 0.80$ are related to do not cause ischemia in 95\% of the cases (PIJLS; SELS, 2012). Therefore, patients with $F F R<0.80$ can benefit from a revascularization procedure to improve the blood supply of the ischemic region, where angioplasty and by-pass surgery are the most common procedures.

Figure 1.4 - Medical procedures for treating coronary atherosclerosis.

(a) Stent placement.

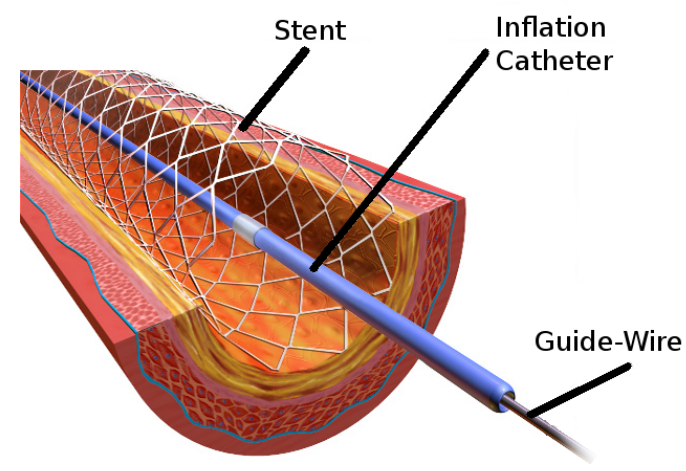

(b) Coronary by-pass.

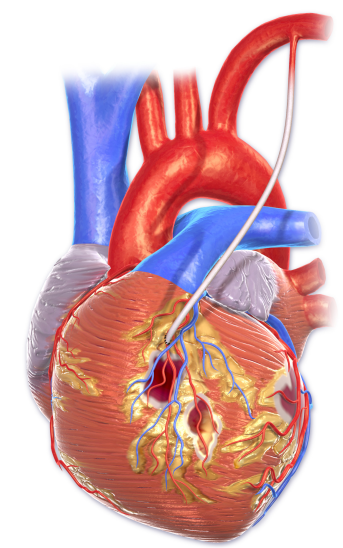

Adapted from Staff Blausen.com (2014).

Angioplasty is a surgical procedure performed to widening the stenosis in order to restore the blood flow of the artery. This is achieved by using a catheter with a balloon on its tip, the balloon is then inflated to expand the stenosis in the radial direction. This can be done with or without a stent placement (Figure 1.4a). Stent is a metallic mesh structure placed inside the artery, to preserve the diameter of the lumen from narrowing again after the angioplasty. Modern drug-eluting stents are embedded with specific drugs, slowly released in the blood flow to prevent restenosis (BARRETT et al., 2010).

The by-pass surgery is performed to enhance the blood supply after the obstructed part (Figure 1.4b), redirecting the blood flow from another vessel. It normally uses a healthy blood vessel from a different part of the body, where the blood vessels with most successful rate are the internal thoracic arteries (mammary arteries) because they have less chance to suffer from atherosclerosis again (BARRETT et al., 2010). 
The focus of this dissertation is to study a methodology to perform a non-invasive prediction of the FFR in stenosed coronary arteries with the aid of computer simulations, more in-depth aspects about the cardiovascular system can be found in physiological books such as "Ganong's Review of Medical Physiology" (BARRETT et al., 2010) or "Guyton and Hall Textbook of Medical Physiology" (HALL; GUYTON, 2006).

\subsection{Computer Simulations}

Computer simulation can be understand as the study of a real world system by using assumptions, mathematical models and numerical methods to describe and predict the system behavior in a computer-based program. The results of a computer simulation are always an approximation of the real problem or system studied, as a consequence of the hypotheses adopted and the numerical methods implemented. Because of these innate errors, all computer simulations should be compared and validated with analytical results, real experiments, literature references or with other already validated software (benchmark), in order to verify the accuracy and efficiency of the program.

The use of computer simulations has increased substantially in almost every field of study in the last decades, mostly because of the undeniable advance of the computational systems to process massive amounts of information, the availability of these high-performance hardware, the improvement of the numerical methods and algorithms, and the benefits these in-silico experiments can provide, for example: cost and time reduction during the design process, possibility of testing multiple case scenarios, difficulty or impossibility to perform a real experiment, easy access to parameters only inferred in real tests, among others.

The use of computer simulations to better understand the arterial system started around the 1950's, where one of the most prominent researchers was Homer R. Warner, one of the pioneers to use analog computers to study the circulation of blood in a closed-loop model (WARNER, 1959). Modern supercomputers are able to simulate full three-dimensional transient models of the whole body, as performed by Xiao, Humphrey and Figueroa (2013) to study the impact of the arterial stiffening caused by aging.

When it comes to use computer simulations of the cardiovascular system, the arterial system can be modelled by using several methods depending on the hypotheses or assumptions adopted, and on the subject of interest. One possible form to subdivide the models in categories, for the sake of simplicity, is:

Space models: Lumped parameters (OD), One-dimensional (1D), Two-dimensional (2D), Three-dimensional (3D) and Multi-scale models

Time models: Steady or Unsteady (Transient) models 
Artery wall models: Rigid walls or Flexible (compliant) walls models

Blood models: Newtonian or non-Newtonian models

Geometry of the vessels models: Fictional or Patient-specific geometries

Each of these models are addressed and explained in the following, with literature examples of applications performed by other authors.

\section{Space Models}

Lumped parameter or zero-dimensional (OD) models focus on evaluating the overall aspects of the blood circulation, such as mean flow and mean pressure. The basic concept of these models is to turn the cardiovascular system into separated unity compartments that reflect the physics of the problem. By doing so, each unity can be expressed by an analogous electrical circuit, where the resistance represents the blood flow viscosity, the inductance the blood inertia and the capacitance the wall compliance of the artery.

These OD models provide an insight on the global hemodynamics and how the system works as a whole, however they do not give information on the local hemodynamics of an artery, such as boundary layer near the vessel walls, flow separation or recirculation zones.

Liang and Liu (2005) used the lumped parameters model to perform a computer simulation of the entire cardiovascular system, subdividing it into seven main subsystems. They have considered a closed-loop system and have obtained reasonable physiological results compared to in-vivo experiments.

Another approach is to use one-dimensional models (1D), where the arteries are subdivided into small tubes, considering the variables of interest axisymmetric and constant in the cross-section. 1D models are good to study the wave propagation of the human pulsatile blood flow because they can simulate the entire arterial tree with a reasonable computational cost, however they also do not account for the local hemodynamics.

Formaggia, Lamponi and Quarteroni (2003) studied the blood flow and pressure wave propagation in the human arteries and addressed the problem of the artery branches with 1D models by using a domain decomposition approach to maintain the stability of the model. They also investigated the importance of using a high-order model for the elasticity of the artery wall.

More recently, Raghu and Taylor (2011) used a 1D model by considering a non-linear viscoelastic model for the arterial wall. They compared the computer simulation with analytical results from linearized equations of the blood flow, and with results from a method of manufactured solutions. The results showed the numerical error decreasing with the refinement of time and space discretization. 
The two-dimensional (2D) or three-dimensional (3D) models are used in studies of hemodynamics when the localized factors are considered important, such as in the analyses of WSS distribution (KANG, 2014) or in the study of complex flows inside aneurysms sacs (FU et al., 2010).

Aneurysms are another serious cardiovascular issue, they are balloon like sacs formed by the rupture of arterial wall and can cause death if not treated properly, however they are not the focus of this dissertation.

Recent studies used a multi-scale modelling, coupling 3D models with 1D or 0D models at the boundaries, to address for both overall and localized hemodynamics of the cardiovascular system. Blanco and Feijóo (2013) used this approach to perform a closed-loop model of the cardiovascular system and studied the sensitivity of the global hemodynamics parameters in a brain aneurysm.

Kim et al. (2009) used a lumped parameter model of the left side of the heart coupled with a 3D aorta to simulate the systemic circulation. They considered two different scenarios, rest and exercise condition, for two models of the human aorta, one normal and one with an aortic coarctation (aorta with stenosis). They have obtained physiological results for the pressure waveforms and aortic flow, showing the pertinence of the method implemented.

\section{Time Models}

Time can be modelled as steady-state or as transient in computer simulations. In fluid flows simulation, the steady-state condition is used when the dependent variables do not depend on time, and, therefore, can be considered constant.

The pulsatile nature of the blood flow normally excludes this hypothesis, however the steady-sate assumption can be used to evaluate the numerical method implemented, as it takes less computational effort to perform the simulation.

Geers et al. (2014) compared the WSS distribution of steady-state and transient 3D simulations of cerebral aneurysms and demonstrated that the steady-state assumption can be used as a good estimation for the WSS field and claims that the use of the steady-state simulations can approximate the numerical solutions to the clinical practice framework because of the low computational cost.

Studying the possible clinical impact of overlapping stents, Rikhtegar et al. (2014) considered the steady-state hypothesis. Their results indicate that the overlap stents can cause unfavorable flow conditions that may worsen clinical outcome.

Most of the computer simulation studies about the cardiovascular system considers the pulsatile flow in order to capture the changing flow rate and the inertia effects during the cardiac cycle. For example, the transient effects can be simulated by trigonometrical functions such as cosine and sine or by the transformation of cardiac signals into functions. 


\section{Artery Wall Models}

The arterial wall can be understand as a laminated composite formed by three different layers named, from inner to outer, intima, media, and adventia (Figure 1.5).

Figure 1.5 - Artery wall composition..

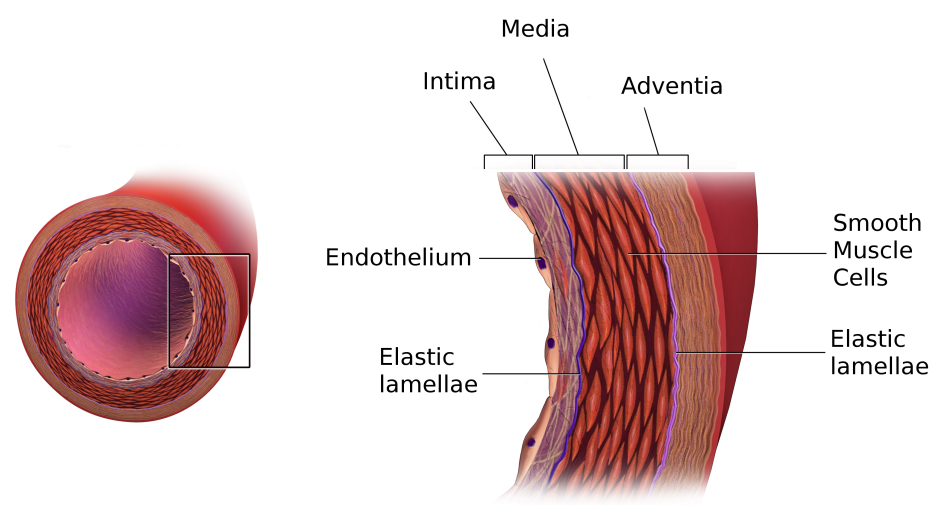

Adapted from Staff Blausen.com (2014).

The intima is the innermost layer formed by endothelium and an elastic membrane. In the middle is the media, which is constituted by smooth muscle cells interspersed by elastic lamellae. The outer layer is called adventia and consists majorly of connective tissue and scattered muscle cells (HALL; GUYTON, 2006). This structure is the same for all arteries. The arteries wall composition only vary in layer thickness depending on the artery diameter and location.

The artery wall has an intrinsic elastic behavior, nevertheless it can be modelled as rigid walls, where they are considered static and undeformable, in order to reduce computational cost. However, when the compliance is taken into account, the model must consider the elastic properties of the artery wall and the Fluid Structure Interaction (FSI) between the blood flow and the artery wall. This normally requires more computational effort and a more robust numerical model, once biofluid FSI numerical models are known to suffer from stability and convergence problems due to the proximity of blood and artery wall density values.

Reymond et al. (2013) compared the rigid wall and the FSI models of a 3D human aorta and showed a significant difference between the models in regarding the WSS distribution. They also compared the wave propagation of the FSI with a 1D model and presented a good correlation between the models with respect to flow waveform and pressure distribution.

\section{Blood Models}

The human blood is a biofluid that is actually a suspension of living cells in a aqueous medium. It is formed mainly by plasma, erythrocytes (red blood cells), leukocytes (white blood cells) and thrombocytes (platelets). 
The plasma is an aqueous polymer solution representing approximately $55 \%$ of the blood volume and is constituted by roughly $92 \%$ of water, where the remaining is made up by electrolytes (such as $\mathrm{Na}^{+}, \mathrm{K}^{+}, \mathrm{Ca}^{2+}, \mathrm{Mg}^{2+}, \mathrm{Cl}^{-}, \mathrm{HCO}_{3}^{-}, \mathrm{HPO}_{4}^{-}, \mathrm{SO}_{4}^{-}$), proteins (where the Albumin is the most important because it has the ability to bind to small molecules that have low water solubility to facilitate their transport) and other small molecules (HALL; GUYTON, 2006).

Leukocytes are part of the human immune system and account for almost $1 \%$ of blood volume. There are five types of leukocytes: neutrophils, lymphocytes, monocytes, eosinophils and basophils, each one of them with specific properties to protect the human body against different infections, bacterias, fungi, viruses, etc (HALL; GUYTON, 2006).

Thrombocytes are the blood elements involved in blood coagulation. In the presence of an injury, they adhere and aggregate to start the coagulation process, ending in the formation of a thrombus (blood clot) (HALL; GUYTON, 2006).

Erythrocytes are anuclear hemoglobin-rich cells responsible for the transport of oxygen and carbon dioxide, they represent almost forty percent $(\sim 40 \%)$ of the total blood volume ${ }^{1}$ and have a shape of an oval biconcave disk that partially determines blood viscosity to vary depending on the conditions of blood flow and, thus, act as a non-Newtonian fluid (ROBERTSON; SEQUEIRA; OWENSE, 2009).

Non-Newtonian fluids do not have a linear relationship between the shear stress and the shear rate and the viscosity is dependent on the shear rate. On the other hand, in Newtonian fluids this relationship is linear and the viscosity is constant for all shear rates (ROBERTSON; SEQUEIRA; OWENSE, 2009).

Blood is considered a shear-thinning (pseudoplastic) fluid, it has a lower apparent viscosity when submitted to higher shear rates. At high shear rates $\left(>10^{3} \mathrm{~s}^{-1}\right)$ the apparent viscosity tends to the Newtonian value, reason why some studies consider the blood as a Newtonian fluid, especially in models of large blood vessels or with high velocity values (ROBERTSON; SEQUEIRA; OWENSE, 2009).

Bernsdorf and Wang (2009) studied the differences between two viscosity models in a 3D aneurysm, and got results indicating the overestimation of the WSS considering the Newtonian model.

More recently, Evju, Valen-Sendstad and Mardal (2013) performed a comparison between the Newtonian model and three different non-Newtonian models in 12 cerebral aneurysm geometries, by considering different boundary conditions. They showed that the geometry of the different aneurysms impact more than the viscosity models in the WSS distribution inside the aneurysm.

\footnotetext{
1 this volume fraction of erythrocytes is known as hematrocit $(\mathrm{Ht})$
} 


\section{Geometry of the Vessels Models}

Modelling the arteries geometry can be performed in two principal manners, by using simplified fictional geometries (tube or cylindrical shapes) or a patient-specific geometry. The latter is obtained by non-invasive exams such as CTA and Magnetic Resonance Angiography (MRA) or by an invasive exam such as Intravascular Ultrasound (IVUS). A complete review on modelling patient-specific geometries can be found in the work of Taylor and Figueroa (2009).

Wang and Bernsdorf (2009) used a 3D generic model of a stenosed artery to study a non-Newtonian blood model by using a particle method called Lattice Boltzmann Method. They compared the Newtonian and the non-Newtonian blood models and reported longer recirculation zones after the stenosis using the former models, due to lower shear rate and thus higher viscosity in these regions.

Auricchio et al. (2014) describes a suitable framework to obtain a 3D patient-specific model from two plane $x$-ray angiographies. The models generated by their implementation can be used to perform computer simulations with patient-specific models.

The models described above allows to study and implement computer simulations of the blood flow in coronary arteries, which is the main focus of this dissertation. Below, some of the work of previous authors are discussed.

To evaluate the impact of the side branches in the coronary tree, Wellnhofer et al. (2010) used a steady-state simulation with a non-Newtonian model for the blood viscosity and compared the results of 17 right coronary arteries models. They demonstrated that the side branches need to be accounted in the WSS profiling. The model without side branches overestimated the mean WSS and the model considering the side branches showed a non-linear relationship in the WSS distribution.

Xie, Wang and Zhou (2013) were interested in how the coronary motion and tortuosity affects the blood flow. They simulated fictional left coronaries with different curvatures and bends, by using the Newtonian hypothesis for the blood viscosity and the rigid wall assumption. They conducted a quantitative hemodynamical analysis and showed that the coronary motion and tortuosity did not affect significantly the pressure drop and the velocity field, although it altered the WSS distribution. In fact, higher bends, and therefore a more tortuous coronary, presented higher WSS magnitudes.

Myers et al. (2001) performed a series of computer simulations of a right coronary artery to examine how changes in the inlet parameters affects the hemodynamic features. They compared different profiles and velocities at the inlet boundary conditions, in steady-state and transient simulations, and concluded that the most important parameter in blood flow simulations are the geometric effects. 
An investigation on the bifurcation angle on left coronary arteries was performed by Chaichana, Sun and Jewkes (2011). They analysed four patient-specific models with different angulations to study the hemodynamic changes caused by the different bifurcation angles. $\mathrm{A}$ low magnitude WSS was observed in the wide-angled bifurcation models, consistent with regions predisposed to suffer from atherosclerosis and stenosis.

Johnston et al. (2004) studied the impact of different viscosity models by considering a steady-state flow in four healthy right coronary artery models. They evaluate the WSS distribution and compared the different blood models concluding that the magnitude of WSS was different for all models, however they all presented the same WSS pattern. More recently they performed a transient analysis (JOHNSTON et al., 2006) by using the same geometry models and showed again that only the magnitude of WSS varied between the models. The same patterns were observed for the Newtonian and non-Newtonian models.

Recent applications focus on the hemodynamics analysis of stenosed coronary arteries, in order to evaluate noninvasively the functional impact of the lesion.

Yamabe and Diana (2013) used a patient-specific model of a right stenosed coronary artery and implemented the 3D coronary flow in a commercial software. They have taken into account the non-Newtonian behavior of the blood, the FSI between the artery wall and the blood and the pulsatile nature of the flow. They have compared the results from the rigid wall assumption with two FSI models, one considering the entire coronary isotropic and another with a different elasticity at the stenosed part.

The American company HeartFlow Inc $^{2}$ performs and commercialize non-invasive calculations of the FFR using computer simulations. They have received, in 2014, the U.S. Food and Drug Administration approval to commercialize their method in the evaluation of the FFR (U.S. Food and Drug Administration, 2014).

HeartFlow already performed clinical trials all around the world, and compared the invasive values of the FFR with the non-invasive FFR derived from CTA. The results were published in three papers: Koo et al. (2011) describes the results of the DISCOVER-FLOW trials, Min et al. (2012) the DeFACTO trials, and Nørgaard et al. (2014) the HeartFlowNXT trials. The results show an average accuracy of $86 \%$ in diagnosing myocardial ischemia in patients with stenosed coronary arteries.

These papers only describe superficially the method used, they focus on information of the patients and on the results of the comparison. The scientific base for the computer simulations used by the HeartFlow is explained in details in Taylor, Fonte and Min (2013) and in Kim et al. (2010), where they consider the pulsatile nature of the blood, a multi-scale coupled model, the blood as a Newtonian fluid and the FSI interaction between blood and artery wall.

<http://heartflow.com/> 
Following the same scope used by the HeartFlow, Morris et al. (2013) performed FFR measures and computer based FFR calculations for pre and post stent placement. They have obtained $97 \%$ of accuracy when comparing the invasive exam and the non-invasive computer-based results. However, in their publication it is not clear the theoretical formulation used, neither how they coupled the 3D and the lumped parameter model.

\subsection{Objectives}

The main objective of this dissertation is to study and implement a method to analyse non-invasively the functional impact of stenosed coronary arteries through the evaluation of the FFR by using the aid of computer simulations with just open-source software.

The three dimensional geometrical models are extracted from Computed Tomography Angiography (CTA) medical images provided by the Dante Pazzanese Institute of Cardiology of São Paulo, to seize the patient-specific idiosyncrasies of each coronary artery.

In order to reduce the computational requirements, such as memory consumption and simulation time, this dissertation is going to consider a few simplifying assumptions that are not used by HeartFlow:

- Consider the artery wall rigid and static (no FSI)

- Constant pressure at the outlet boundary condition (no Multiscale)

The results are compared with real invasive FFR measurements performed at Dante Pazzanese Institute of Cardiology of São Paulo in order to evaluate the developed method.

Also, different blood models are considered in the FFR calculations to evaluate the impact of non-Newtonian fluid models in the FFR calculations.

\subsection{Motivation}

The cardiovascular system, and in particular the coronary arteries, are a complex living system, most of blood flow problems do not have an analytical solution, at least not for real life situations, because of the large amount of variables involved, which is the reason why use approximated solutions using computer simulations are required.

The FFR is an invasive exam and inherits all the medical complications of a surgery, even though it is considered a minor procedure. Computer simulations can overcome this, because the FFR can be evaluated non-invasively from the medical images, as it has been performed by the Heartflow company, reducing all the costs involved with the surgery. 
Up to date, there is no company in Brazil that commercializes the non-invasive FFR exam. The use of only open-source software and the simplifications adopted are an attempt to approximate the Brazilian medical industry to this concept.

Therefore, due to its complexity and importance, the medical community can benefit from engineering tools, to better understand and study how healthy and diseased arteries interacts with the hemodynamics, and to approximate the use of computer simulations to the clinical practice.

\subsection{Document Outline}

In this first chapter, an overview of the medical terms used in the dissertation is presented. It also describes a literature review about computer simulation of cardiovascular systems and of coronary arteries.

The theoretical formulation is presented in Chapter 2, where seven different blood constitutive models and the blood flow motion governing equations are explained.

The numerical methods, the Finite Element Method and the Incremental Pressure Correction Scheme, used for solving the governing equations are explained in Chapter 3.

Chapter 4 describes the open-source computer programs used for implementation of the method studied. This comprises the modelling of the geometry obtained from CTA images, and the numerical implementation in Python using the FEniCS libraries.

The results of the computer simulations tests are shown and discussed in Chapter 5, focusing on the pressure distribution along the artery.

Chapter 6 compares the results of the non-invasive method developed with real invasive FFR results.

Finally, in Chapter 7, the conclusions, limitations, and the future work on the subject are discussed.

The entire code implemented is displayed at Appendix A. 


\section{PROBLEM MODELLING}

This chapter describes the blood modelling with seven different viscosity models and the governing equations of a incompressible fluid flow.

\subsection{Blood Modelling}

In the Introduction (Chapter 1), an overall view about the blood and its constituents has been presented. In this section a more in-depth study is presented, focusing on the mechanical properties of the blood, and, in special, on its rheological properties.

As explained before, blood behaves as a non-Newtonian shear-thinning fluid, it has lower viscosity $(\nu$ or $\mu$ ) when submitted to higher shear rates $(\dot{\gamma})$. This is mainly caused by two erythrocytes' factors: their predisposition to form microstructures called rouleaux and their deformability.

The rouleaux structures are an agglutination of erythrocytes and proteins formed at low shear rate values, as a response of the coagulation process. The presence of these microstructures rises the blood viscosity (ROBERTSON; SEQUEIRA; OWENSE, 2009).

With the increment of the shear rate, these structures start to break up into smaller structures. At sufficient high shear rates the rouleaux is so small that their influence can be neglected. At high shear rates, the erythrocytes shape is modified from a biconcave disk to a flatten elongated ellipse, due to its elasticity, stops rotating in the flow and align itself with the flow direction causing a reduction in the viscosity.

Flows with high shear rates can be modelled as a Newtonian fluid, this includes computer simulations of large arteries such as healthy coronaries. However, the presence of the stenosis creates a recirculation zone (region of low shear rates) after the lesion, reason why this dissertation is going to study also how different blood models impact the FFR calculations in computer simulations.

For all blood models used in this dissertation, the blood is considered an incompressible fluid with constant density of $\rho=1056 \frac{\mathrm{kg}}{\mathrm{m}^{3}}$, and an isothermal fluid with constant body temperature of $37^{\circ} \mathrm{C}$.

\subsubsection{Newtonian and Non-Newtonian Models}

The most simple model consists in considering blood a Newtonian fluid, with constant viscosity $\mu=0.00345$ Pa.s (CHO; KENSEY, 1991). 
There are several constitutive models that can be used to account for the non-Newtonian characteristics of the blood. The present work is going to explore six of them: Power-Law, Casson, Carreau, Carreau-Yasuda, Cross and Modified Cross.

By considering the viscosity as a function of the shear rate $\mu(\dot{\gamma})$, using $\dot{\gamma}=\sqrt{2\|\boldsymbol{\epsilon}(\mathbf{u})\|_{F}}$, where $\|\cdot\|_{F}$ is the Fröbenius norm, the viscosity can be calculated by using one of the non-newtonian blood models.

The Power-Law is an exponential viscosity model dependent on two constant parameters $k$ and $n$ and can be calculate as follows:

$$
\mu(\dot{\gamma})=k \dot{\gamma}^{(n-1)}
$$

Walburn and Schneck (1976) improved the power-law model to take into account the hematocrit $(H t)$, the volume percentage of red blood cells (erythrocytes) in the blood:

$$
\begin{aligned}
& k=C_{1} e^{C_{2} H t} \\
& n=1-C_{3} H t
\end{aligned}
$$

where $C_{1}=0.00148, C_{2}=5.12$ and $C_{3}=0.499$ are fitted parameters from experimental data and $H t$ is equal to 0.4 . Hence, the values for $k$ and $n$ are, respectively, equal to 0.1147 and 0.8004 .

The Casson equation for the viscosity as function of the shear rate $\mu(\dot{\gamma})$ is given by:

$$
\mu(\dot{\gamma})=\mu_{\infty}+\frac{2 \sqrt{\mu_{\infty} \tau_{0}}}{\sqrt{\dot{\gamma}}}+\frac{\tau_{0}}{\dot{\gamma}}
$$

It can also be modified to account for other parameters such as hematocrit $(H t)$ (YEOW et al., 2002), cell rigidity $\left(T_{k}\right)$ (DINTENFASS, 1985), and blood plasma viscosity $\left(\eta_{0}\right)(B R U N$; ALOULOU; VARLET-MARIE, 2004):

$$
\begin{aligned}
\tau_{0} & =0.0287 H t^{3} \\
\mu_{\infty} & =\eta_{0} T_{k}(1-H t)^{-2.5}
\end{aligned}
$$

where $\eta_{0}=0.00145$ Pa.s is the blood plasma viscosity and $T_{k}=0.62$ is the erythrocyte rigidity.

The other four models (Carreau, Carreau-Yasuda, Cross and, Modified Cross) use asymptotic values for the minimum and maximum viscosities, where $\mu_{0}$ is the limit viscosity for $\dot{\gamma} \rightarrow 0$ and $\mu_{\infty}$ for $\dot{\gamma} \rightarrow \infty$, and $\lambda$ is a dimensional time constant. 
The equation for the Carreau-Yasuda model is given by:

$$
\frac{\mu-\mu_{\infty}}{\mu_{0}-\mu_{\infty}}=\left(1+(\lambda \dot{\gamma})^{a}\right)^{\frac{n-1}{a}}
$$

The Carreau model is a particular case of the Carreau-Yasuda, obtained by using $a=2$ in Eq. (2.3).

The shear dependent viscosity, in the Modified Cross model, is described by:

$$
\frac{\mu-\mu_{\infty}}{\mu_{0}-\mu_{\infty}}=\left(1+(\lambda \dot{\gamma})^{a}\right)^{-m}
$$

The Modified Cross with $m=1$ yields the Cross model. All viscosity models are summarized in Table 2.1.

Table 2.1 - Non-Newtonian models.

\begin{tabular}{lll}
\hline \multicolumn{1}{c}{ Model } & \multicolumn{1}{c}{ Equation } & Constants \\
\hline Power-Law & $\mu=k \dot{\gamma}^{(n-1)}$ & $k=0.1147$ \\
& $n=0.8004$ \\
Casson & $\mu=\frac{\tau_{y}}{\dot{\gamma}}+\frac{2 \sqrt{\mu_{\infty} \tau_{y}}}{\sqrt{\dot{\gamma}}}+\mu_{\infty}$ & $\begin{array}{l}\tau_{y}=0.001719 \\
\mu_{\infty}=0.026\end{array}$ \\
& & $\lambda=1.902$ \\
Carreau-Yasuda & $\frac{\mu-\mu_{\infty}}{\mu_{0}-\mu_{\infty}}=\left(1+(\lambda \dot{\gamma})^{a}\right)^{\frac{n-1}{a}}$ & $n=0.22$ \\
& & $a=1.5$ \\
Carreau & $\frac{\mu-\mu_{\infty}}{\mu_{0}-\mu_{\infty}}=\left(1+(\lambda \dot{\gamma})^{2}\right)^{\frac{n-1}{2}}$ & $\lambda=3.313$ \\
& & $n=0.3568$ \\
Modified Cross & $\frac{\mu-\mu_{\infty}}{\mu_{0}-\mu_{\infty}}=\left(1+(\lambda \dot{\gamma})^{a}\right)^{-m}$ & $\begin{array}{l}\lambda=3.736 \\
\end{array}$ \\
& & $m=0.254$ \\
Cross & $\frac{\mu-\mu_{\infty}}{\mu_{0}-\mu_{\infty}}=\left(1+(\lambda \dot{\gamma})^{a}\right)^{-1}$ & $\lambda=1.007$ \\
\end{tabular}

The maximum viscosity at low shear rates $\mu_{0}$ is equal to $0.056 \mathrm{~Pa} . \mathrm{s}$ and the minimum viscosity at high shear rates $\mu_{\infty}$ is equal to 0.00345 Pa.s.

All parameters are obtained from the work of Robertson, Sequeira and Owense (2009) and from Cho and Kensey (1991), where they have used experimental results of a viscometer to fit the parameters of the different blood models.

By using these values and the other parameters described in Table 2.1 a comparison of the viscosity models can be performed as shown in Figure 2.1. 
Figure 2.1 - Comparison of different viscosity models.

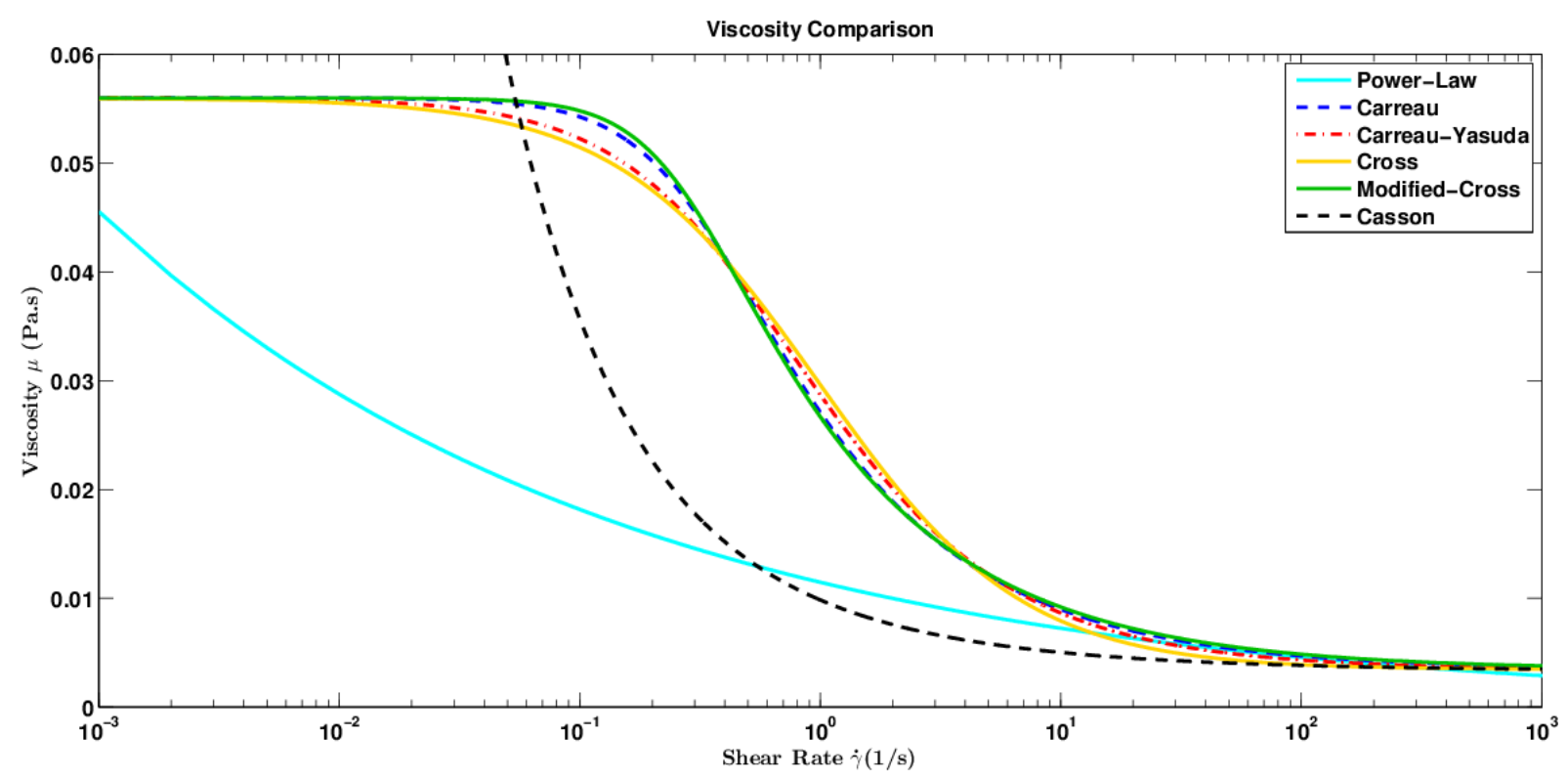

From Figure 2.1 we see a good correlation between the viscosity for the Cross, Modified Cross, Carreau and Carreau-Yasuda models. The Casson model exhibits higher values of viscosity and the Power-Law model lower values of viscosity, both at low shear rates values in comparison with the others. All models predicted a viscosity close to the Newtonian value for shear rates larger than $100 \mathrm{~s}^{-1}$. In the computer simulations, only the Carreau-Yasuda, Power-Law, and Casson models are adopted, because the other models have a relative close behavior among them.

\subsection{Governing Equations}

With the blood modelled, it is possible to express, with a mathematical formulation, the blood flow motion. Blood flow motion can be described by the Navier-Stokes equations, Partial Differential Equations (PDEs) that solves the velocity $(\mathbf{u})$ and pressure fields $(p)$ of a fluid, for a given viscosity ( $\mu$ or $\nu$ ), density $(\rho)$ and appropriated boundary conditions.

One possible way to derive the Navier-Stokes is to use the Reynolds Transport Theorem for the mass conservation principle and for the momentum conservation (REDDY, 2004).

The Navier-Stokes equations for an incompressible Newtonian fluid can be written as:

$$
\begin{aligned}
\rho\left(\frac{\partial \mathbf{u}}{\partial t}+\mathbf{u} \cdot \nabla \mathbf{u}\right) & =\nabla \cdot 2 \mu \boldsymbol{\epsilon}(\mathbf{u})-\nabla p \\
\nabla \cdot \mathbf{u} & =0
\end{aligned}
$$

where $\boldsymbol{\epsilon}(\mathbf{u})=\frac{\left(\nabla \mathbf{u}+\nabla \mathbf{u}^{T}\right)}{2}$ is the symmetric gradient. 
The same equation is used for the non-Newtonian case, by replacing the constant viscosity $\mu$ with the shear rate dependent viscosity $\mu(\dot{\gamma})$ :

$$
\begin{aligned}
\rho\left(\frac{\partial \mathbf{u}}{\partial t}+\mathbf{u} \cdot \nabla \mathbf{u}\right) & =\nabla \cdot 2 \mu(\dot{\gamma}) \boldsymbol{\epsilon}(\mathbf{u})-\nabla p \\
\nabla \cdot \mathbf{u} & =0
\end{aligned}
$$

Equation (2.6) have the same behavior of Equation (2.5), by considering the viscosity locally Newtonian, and therefore constant, in a sufficient small region. In order to solve Equation (2.6), it is necessary to define appropriated initial and boundary conditions.

The initial condition considered must be a feasible solution of the whole domain at a given time.

The boundary conditions used in this dissertation are the Dirichlet boundary condition, where the value of a primary variable (velocity and pressure) is specified, and the Neumann boundary condition, where the derivative of the primary variables is specified.

The boundaries of the problem are subdivided in inlet, wall and outlet. At the inlet and at the wall, is used a Dirichlet boundary condition for the velocity, and at the outlet is used a Dirichlet boundary condition for the pressure. An homogeneous Neumann boundary condition for both velocity and pressure is used in all boundaries. The values of the boundary conditions are addressed in Section 3.4. 


\section{NUMERICAL MODELLING}

For most of real world problems, the Navier-Stokes equations described in Equation 2.5 do not have an analytical solution. Therefore, one technique to solve the PDEs is to use a numerical method to approximate the solution with a satisfactory error.

Several numerical methods can be applied, such as Finite Difference Method (FDM), Finite Volume Method (FVM) or Finite Element Method (FEM), however this dissertation is going to focus in the "Incremental Pressure Correction Scheme" (IPCS) formulation solved by the Finite Element Method.

\subsection{Incremental Pressure Correction Scheme}

The Incremental Pressure Correction Scheme (IPCS) is an iterative numerical method that decouples the pressure and the velocity fields of the Navier-Stokes equations, where they are solved separately at each time-step of the transient flow.

It is essentially a projection method that uses the Helmholtz-Hodge decomposition to separate the flow field into a sum of a solenoidal part, representing the incompressibility in a divergence-free component (curl of the velocity vector) and a irrotational part, representing the curl-free component (gradient of the scalar pressure).

This method was first implemented by Goda (1979) and follows the same principle used by Chorin (1968). The main difference between these methods is that the former uses the previous values of the pressure, while the latter initially neglects the pressure terms.

Valen-Sendstad et al. (2012) compared different methods to solve the Navier-Stokes equations for different problems and showed that the IPCS is a good numerical method in regarding the memory computational cost and simulation time consumption.

We start by discretizing the time with the first order backward Euler difference scheme:

$$
\frac{\partial \mathbf{u}}{\partial t} \approx \frac{\mathbf{u}^{n}-\mathbf{u}^{n-1}}{\Delta t}
$$

where the index $n$ represents the variable at the actual time step, $n-1$ the variable at the previous time step, and $\Delta t$ is the time increment.

The non-linearity caused by the convection term $\mathbf{u} \cdot \nabla \mathbf{u}$ gives rise to numerical instabilities in the solution. This dissertation linearizes the convection term by using a semi-implicitly 
technique known as Picard iteration, in order to obtain better stability.

$$
\mathbf{u} \cdot \nabla \mathbf{u} \approx \mathbf{u}^{n-1} \cdot \nabla \mathbf{u}^{n}
$$

The viscosity is assumed locally Newtonian and evaluated at the previous time-step:

$$
\mu(\dot{\gamma}) \approx \mu\left(\mathbf{u}^{n-1}\right)
$$

By applying these hypothesis in the Navier-Stokes Equation (2.6) we are left with:

$$
\begin{aligned}
\rho\left(\frac{\mathbf{u}^{n}-\mathbf{u}^{n-1}}{\Delta t}\right)+\mathbf{u}^{n-1} \cdot \nabla \mathbf{u}^{n}-\nabla \cdot 2 \mu\left(\mathbf{u}^{n-1}\right) \boldsymbol{\epsilon}\left(\mathbf{u}^{n}\right)+\nabla p^{n} & =0 \\
\nabla \cdot \mathbf{u}^{n} & =0
\end{aligned}
$$

However, the pressure term $p^{n}$ is still unknown. By calculating a tentative velocity $\mathbf{u}_{t}^{n}$ using the previous pressure values $p^{n-1}$ in $p^{n}$, we can write:

$$
\rho\left(\frac{\mathbf{u}_{t}^{n}-\mathbf{u}^{n-1}}{\Delta t}\right)+\mathbf{u}^{n-1} \cdot \nabla \mathbf{u}_{t}^{n}-\nabla \cdot 2 \mu\left(\mathbf{u}^{n-1}\right) \boldsymbol{\epsilon}\left(\mathbf{u}_{t}^{n}\right)+\nabla p^{n-1}=0
$$

The correction velocity can be defined as:

$$
\mathbf{u}_{c}^{n}=\mathbf{u}^{n}-\mathbf{u}_{t}^{n}
$$

By writing the kinematic viscosity as $\nu=\frac{\mu}{\rho}$, and by subtracting Equation (3.5) from Equation (3.4), we have:

$$
\mathbf{u}_{c}^{n}+\Delta t\left[\mathbf{u}^{n-1} \cdot \nabla \mathbf{u}_{c}^{n}-\nabla \cdot 2 \nu\left(\mathbf{u}^{n-1}\right) \boldsymbol{\epsilon}\left(\mathbf{u}_{c}^{n}\right)\right]+\frac{\Delta t}{\rho} \nabla\left(p^{n}-p^{n-1}\right)=0
$$

By using $\Phi^{n}=p^{n}-p^{n-1}$ and neglecting the second term as explained in Guermond, Minev and Shen (2006), Equation (3.7) is simplified to:

$$
\mathbf{u}_{c}^{n}+\frac{\Delta t}{\rho} \nabla \Phi^{n}=0
$$

By multiplying Equation (3.8) by the operator $\nabla$. leads to:

$$
\nabla \cdot \mathbf{u}_{c}^{n}+\frac{\Delta t}{\rho} \nabla \cdot \nabla \Phi^{n}=0
$$

From Equation (3.6) and by using $\nabla \cdot \mathbf{u}^{n}=0$, we can write:

$$
\nabla \cdot \mathbf{u}_{c}^{n}=-\nabla \cdot \mathbf{u}_{t}^{n}
$$


Therefore, Equation (3.9) can be rearranged to:

$$
\nabla \cdot \nabla \Phi^{n}=\frac{\rho}{\Delta t} \nabla \cdot \mathbf{u}_{t}^{n}
$$

Now the pressure can be corrected by resolving the Poisson's equation resulting from Equation (3.11), by using the tentative velocity and the previous value of the pressure.

From Equation (3.6) and Equation (3.8), the velocity can be finally recalculated by:

$$
\mathbf{u}^{n}=\mathbf{u}_{t}^{n}-\frac{\Delta t}{\rho} \nabla \Phi^{n}
$$

The IPCS method can be summarized as follows:

1. A tentative velocity is calculated by Equation (3.5), with the previous values of the pressure and the velocities boundary conditions.

2. The pressure is then corrected by solving Equation (3.11) that includes the tentative velocity and the pressure boundary conditions.

3. The velocity is recalculated with Equation (3.12) by using the corrected pressure and the tentative velocity.

\subsection{Finite Element Method}

The Finite Element Method (FEM) is the method chosen to solve the IPCS equations in order to use the functionality of the open-source software FEniCS, that performs the discretization of the variational formulation automatically.

The FEM is a numerical method used to find an approximate solution of the PDEs, it essentially consists in subdividing the domain of interest $\Omega$ in several small parts called finite elements $\Omega_{e}$, and then, over each finite element, approximating the unknown variables by a linear combination of polynomial equations that can be solved numerically (REDDY, 2004).

From a general linear variational problem, the FEM can be defined in a canonical form as: find $u \in V$ such that

$$
a(u, v)=L(v), \quad \forall v \in \hat{V}
$$

where $a:=V \times \hat{V} \rightarrow \mathbb{R}$ is the bilinear form, $L:=\hat{V} \rightarrow \mathbb{R}$ is the linear form, $V$ is the trial function space and $\hat{V}$ is the test function space.

Now we discretize the variational problem and rewrite as: find $u_{h} \in V_{h} \subset V$ such that

$$
a\left(u_{h}, v\right)=L(v), \quad \forall v \in \hat{V}_{h} \subset V
$$


The unknown variables $u$ are approximated by $u_{h}$, at each element, as combination of polynomial equations:

$$
u(x) \approx u_{h}(x)=\sum_{i=1}^{N_{\text {dof }}} U_{i} \phi_{i}(x)
$$

where $U_{i}$ are the nodal values, $\phi_{i}(x)$ are the basis functions of the trial space and $N_{d o f}$ is the number of degrees of freedom.

In this dissertation the basis functions chosen to interpolate the variables at each element are the Lagrange functions, a nodal basis that ensure the continuity of the variables of interest in the elements (conforming elements). The linear and quadratic Lagrange basis functions (KARNIADAKIS; SHERWIN, 2005), defined for a standard element in one dimension $\left(\Omega_{s t} \in[-1 ; 1]\right)$ are:

$$
\begin{aligned}
\text { Linear: } h_{p}\left(\xi_{i}\right) & =\frac{-\left(\xi_{i}-1\right)}{2} U_{1}+\frac{\left(\xi_{i}+1\right)}{2} U_{2} \\
\text { Quadratic: } h_{p}\left(\xi_{i}\right) & =\frac{\xi_{i}\left(\xi_{i}-1\right)}{2} U_{1}-\left(\xi_{i}-1\right)\left(\xi_{i}+1\right) U_{2}+\frac{\xi_{i}\left(\xi_{i}+1\right)}{2} U_{3}
\end{aligned}
$$

where $\xi_{i}$ is the spatial variable in the direction $i$ of the standard element.

The three dimensional basis can be obtained by a combination of one dimensional basis such as $\phi_{i, j, k}=h_{p}\left(\xi_{i}\right) h_{p}\left(\xi_{j}\right) h_{p}\left(\xi_{k}\right)$.

The computer simulations use the tetrahedron elements and only the number of nodes per element used are different, depending on the variable of interest. The viscosity used a constant element (Figure 3.1a), the pressure a linear element (Figure 3.1b), and the velocity a quadratic element (Figure 3.1c).

Figure 3.1 - Tetrahedral Elements.

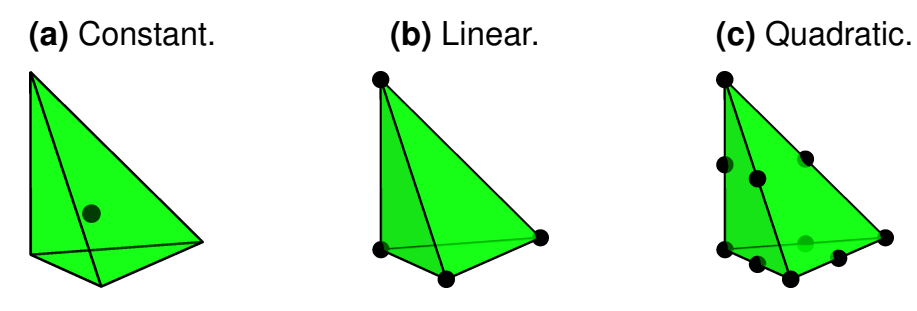

Adapted from Logg, Mardal and Wells (2012).

By using the approximated solution $u_{h}(x)$ in the governing equations, calculating the residual $R\left(x, U_{i}\right)$ and making the residual zero in a weight-integral sense we can write (REDDY, 2004):

$$
\int_{\Omega} W_{i}(x) R\left(x, U_{i}\right) d \Omega=0 \quad \text { for } i=1, \cdots, N_{d o f}
$$

where $W_{i}$ are weighted functions. 
The problem now is to seek of a solution of $u_{h}$ which ensure that the integration above is satisfied at the nodal points of the element. The use of the same basis functions $\phi_{i}(x)$ (trial functions) as the weight functions $W_{i}(x)$ (test functions) is known as the Galerkin's Method (REDDY, 2004).

\subsection{IPCS with FEM}

In order to construct the Galerkin's Method, the PDEs from the IPCS formulation shown in Section 3.1 are multiplied by a test function, the inner product is integrated over the domain and the result is equaled to zero. Then we perform the integration by parts when needed to remove the high order derivatives and get a variational problem (weak formulation), defined in terms of the bilinear and linear forms described in Section 3.2. This method is shown in details next.

First, the tentative velocity equation is rearranged to:

$$
\frac{1}{\Delta t} \mathbf{u}_{t}^{n}+\mathbf{u}^{n-1} \cdot \nabla \mathbf{u}_{t}^{n}-\nabla \cdot\left[2 \nu\left(\mathbf{u}^{n-1}\right) \boldsymbol{\epsilon}\left(\mathbf{u}_{t}^{n}\right)\right]=\frac{1}{\Delta t} \mathbf{u}^{n-1}-\frac{1}{\rho} \nabla p^{n-1}
$$

For the sake of simplicity, the Galerkin's Method is applied separately in the left hand side (LHS) and in the right hand side (RHS). Starting with the LHS, the equation is multiplied by the test function $\mathbf{v}$ and integrated over the domain:

$$
\begin{aligned}
& \int_{\Omega}\left\{\frac{1}{\Delta t} \mathbf{u}_{t}^{n}+\mathbf{u}^{n-1} \cdot \nabla \mathbf{u}_{t}^{n}-\nabla \cdot\left[2 \nu\left(\mathbf{u}^{n-1}\right) \boldsymbol{\epsilon}\left(\mathbf{u}_{t}^{n}\right)\right]\right\} \cdot \mathbf{v} d \mathbf{x}= \\
& \int_{\Omega} \frac{1}{\Delta t} \mathbf{u}_{t}^{n} \cdot \mathbf{v} d \mathbf{x}+\int_{\Omega}\left(\mathbf{u}^{n-1} \cdot \nabla \mathbf{u}_{t}^{n}\right) \cdot \mathbf{v} d \mathbf{x}-\int_{\Omega} 2 \nu \nabla \cdot \boldsymbol{\epsilon}\left(\mathbf{u}_{t}^{n}\right) \cdot \mathbf{v} d \mathbf{x}
\end{aligned}
$$

By reducing the order of the last term, we have:

$$
\begin{aligned}
& -\int_{\Omega} 2 \nu \nabla \cdot \boldsymbol{\epsilon}\left(\mathbf{u}_{t}^{n}\right) \cdot \mathbf{v} d \mathbf{x}= \\
& \int_{\Omega} 2 \nu \boldsymbol{\epsilon}\left(\mathbf{u}_{t}^{n}\right): \nabla \mathbf{v} d \mathbf{x}-\int_{\partial \Omega} \nu(\nabla \mathbf{u})^{T} \mathbf{n} \cdot \mathbf{v} d S-\int_{\partial \Omega} \nu \nabla \mathbf{u n} \cdot \mathbf{v} d S= \\
& \quad \int_{\Omega} 2 \nu \boldsymbol{\epsilon}\left(\mathbf{u}_{t}^{n}\right): \nabla \mathbf{v} d \mathbf{x}-\int_{\partial \Omega} \nu(\nabla \mathbf{u})^{T} \mathbf{n} \cdot \mathbf{v} d S
\end{aligned}
$$

where the operator : is the Fröbenius inner product that arises from the inner product of two matrices.

The term $\int_{\Omega} \nu \nabla \mathbf{u n} \cdot \mathbf{v} d S$ vanishes due to the homogeneous Neumann boundary condition, and the test function $\mathbf{v}$ is defined as zero where the Dirichlet boundary condition is imposed. 
The LHS can be written as:

$$
\frac{1}{\Delta t} \int_{\Omega} \mathbf{u}_{t}^{n} \cdot \mathbf{v} d \mathbf{x}+\int_{\Omega}\left(\mathbf{u}^{n-1} \cdot \nabla \mathbf{u}_{t}^{n}\right) \cdot \mathbf{v} d \mathbf{x}+\int_{\Omega} 2 \nu \boldsymbol{\epsilon}\left(\mathbf{u}_{t}^{n}\right): \nabla \mathbf{v} d \mathbf{x}-\int_{\partial \Omega} \nu(\nabla \mathbf{u})^{T} \mathbf{n} \cdot \mathbf{v} d S
$$

where $\int_{\Omega} \frac{1}{\Delta t} \mathbf{u}_{t}^{n} \cdot \mathbf{v} d \mathbf{x}$ is the transient term, $\int_{\Omega}\left(\mathbf{u}^{n-1} \cdot \nabla \mathbf{u}_{t}^{n}\right) \cdot \mathbf{v} d \mathbf{x}$ is the convective term, and $\int_{\Omega} 2 \nu \boldsymbol{\epsilon}\left(\mathbf{u}_{t}^{n}\right): \nabla \mathbf{v} d \mathbf{x}-\int_{\partial \Omega} \nu(\nabla \mathbf{u})^{T} \mathbf{n} \cdot \mathbf{v} d S$ are the terms relative to the viscosity.

By applying the same method to the RHS we have:

$$
\begin{aligned}
& \int_{\Omega}\left(\frac{1}{\Delta t} \mathbf{u}^{n-1}-\frac{1}{\rho} \nabla p^{n-1}\right) \cdot \mathbf{v} d \mathbf{x}= \\
& \frac{1}{\Delta t} \int_{\Omega} \mathbf{u}^{n-1} \cdot \mathbf{v} d \mathbf{x}-\frac{1}{\rho} \int_{\Omega} \nabla p^{n-1} \cdot \mathbf{v} d \mathbf{x}= \\
& \frac{1}{\Delta t} \int_{\Omega} \mathbf{u}^{n-1} \cdot \mathbf{v} d \mathbf{x}+\frac{1}{\rho} \int_{\Omega} p^{n-1} \cdot \nabla \mathbf{v} d \mathbf{x}-\frac{1}{\rho} \int_{\partial \Omega} p^{n-1} \mathbf{n} \cdot \mathbf{v} d S
\end{aligned}
$$

Therefore, the bilinear and linear forms of the tentative velocity are defined by:

$$
\begin{gathered}
a_{1}\left(\mathbf{u}_{t}^{n}, \mathbf{v}\right)=\frac{1}{\Delta t} \int_{\Omega} \mathbf{u}_{t}^{n} \cdot \mathbf{v} d \mathbf{x}+\int_{\Omega}\left(\mathbf{u}^{n-1} \cdot \nabla \mathbf{u}_{t}^{n}\right) \cdot \mathbf{v} d \mathbf{x} \\
+\int_{\Omega} 2 \nu \boldsymbol{\epsilon}\left(\mathbf{u}_{t}^{n}\right): \nabla \mathbf{v} d \mathbf{x}-\int_{\partial \Omega} \nu(\nabla \mathbf{u})^{T} \mathbf{n} \cdot \mathbf{v} d S \\
L_{1}(\mathbf{v})=\frac{1}{\Delta t} \int_{\Omega} \mathbf{u}^{n-1} \cdot \mathbf{v} d \mathbf{x}+\frac{1}{\rho} \int_{\Omega} p^{n-1} \cdot \nabla \mathbf{v} d \mathbf{x}-\frac{1}{\rho} \int_{\partial \Omega} p^{n-1} \mathbf{n} \cdot \mathbf{v} d S
\end{gathered}
$$

The weak formulation for the pressure correction by using the Galerkin's Method is presented next:

$$
\begin{aligned}
& \int_{\Omega} \nabla \cdot \nabla\left(p^{n}-p^{n-1}\right) q d \mathbf{x}=\int_{\Omega} \frac{\rho}{\Delta t} \nabla \cdot \mathbf{u}_{t}^{n} q d \mathbf{x} \\
& -\int_{\Omega} \nabla\left(p^{n}-p^{n-1}\right) \cdot \nabla q d \mathbf{x}+\int_{\partial \Omega} q \nabla\left(p^{n}-p^{n-1}\right) \cdot \mathbf{n} d S=\int_{\Omega} q \frac{\rho}{\Delta t} \nabla \cdot \mathbf{u}_{t}^{n} d \mathbf{x} \\
& \int_{\Omega} \nabla p^{n} \cdot \nabla q d \mathbf{x}=\int_{\Omega} \nabla p^{n-1} \cdot \nabla q d \mathbf{x}-\int_{\Omega} q \frac{\rho}{\Delta t} \nabla \cdot \mathbf{u}_{t}^{n} d \mathbf{x}
\end{aligned}
$$

where $q$ is the scalar test function used to approximate the pressure. Again, the boundary term $\int_{\partial \Omega} q \nabla\left(p^{n}-p^{n-1}\right) \cdot \mathbf{n} d S$ vanishes due to the homogeneous Neumann boundary condition and the test function.

The pressure correction, defined in terms of the bilinear and linear forms, is:

$$
\begin{gathered}
a_{2}\left(p^{n}, q\right)=\int_{\Omega} \nabla p^{n} \cdot \nabla q d \mathbf{x} \\
L_{2}(q)=\int_{\Omega} \nabla p^{n-1} \cdot \nabla q d \mathbf{x}-\int_{\Omega} q \frac{\rho}{\Delta t} \nabla \cdot \mathbf{u}_{t}^{n} d \mathbf{x}
\end{gathered}
$$


Finally, the velocity is corrected by using the tentative velocity and corrected pressure, where the bilinear and linear forms by using the Galerkin's Method are:

$$
\begin{gathered}
a_{3}\left(\mathbf{u}^{n}, \mathbf{v}\right)=\int_{\Omega} \mathbf{u}^{n} \cdot \mathbf{v} d \mathbf{x} \\
L_{3}(\mathbf{v})=\int_{\Omega} \mathbf{u}_{t}^{n} \cdot \mathbf{v} d \mathbf{x}-\frac{\Delta t}{\rho} \int_{\Omega} \nabla\left(p^{n}-p^{n-1}\right) \cdot \mathbf{v} d \mathbf{x}
\end{gathered}
$$

In the IPCS method, the boundary terms $\frac{\partial p}{\partial n}$ and $\frac{\partial \mathbf{u}}{\partial n}$ are considered zero (homogeneous Neumann boundary condition), which can lead to errors at the boundaries as pointed out by Guermond, Minev and Shen (2006). In order to minimize this issue, flow extensions are added to the geometry of the arteries at the inlet and outlets, and the solution are not analysed at the boundaries in the FFR analysis.

An advantage of this method is the possibility to work with just linear elements. The IPCS does not suffer from the Ladyzenskaya-Babuška-Brezzi (LBB) condition (BATHE, 2001), a known stability criteria for solving the Incompressible Navier-Stokes equations with the FEM. The LBB condition states that the polynomial degree of the basis functions used for the velocity should be at least one degree higher than the one used for the pressure filed. This dissertation is going to explore only two cases, the quadratic interpolation of the velocity with the linear interpolation of the pressure (P2P1) and a linear interpolation for both velocity and pressure (P1P1).

\subsection{Boundary and initial conditions}

In order to perform the computer simulations, suitable and feasible initial and boundary conditions need to be implemented.

\subsubsection{Initial condition}

The initial conditions for $t_{0}=0$ adopted are $\mathbf{u}\left(t_{0}\right)=0$ and $p\left(t_{0}\right)=0$. This assumption is discussed in the results section (Section 5.2.1).

\subsubsection{Inlet boundary condition}

At the inlet of the coronary arteries the velocity is prescribed with a Dirichlet boundary condition. A parabolic profile is used, and it is derived from the Hagen-Poiseuille Flow, the analytical solution of a flow inside a cylinder. The non-Newtonian effects alters the velocity profile, however it can be neglected in larger arteries, which is the case of the entrance of the coronaries (PERKTOLD et al., 1999). 
The parabolic profile is implemented as follows:

$$
u=u_{\max }\left[1-\left(\frac{d}{r_{\text {inlet }}}\right)^{2}\right]
$$

where $u_{\max }$ is velocity at the center of the inlet, $r_{\text {inlet }}$ is the inlet radius and $d$ is the distance to the inlet center calculated as $d=\sqrt{x^{2}+y^{2}+z^{2}}$.

The values of the average blood flow of the coronary arteries are different for the right coronary artery (RCA) and the left main coronary artery (LMCA). In this dissertation, an average blood flow of $125 \mathrm{~mL} / \mathrm{min}$ is used for the RCA and $187.5 \mathrm{~mL} / \mathrm{min}$ for the LMCA, in order to emulate the hyperemic state (WILSON et al., 1990).

The transient flow is implemented as a Fourier series function fitted from blood flow values obtained in Barrett et al. (2010):

$$
\begin{aligned}
u_{\max }(t) & =v_{\text {factor }} \frac{24.59}{\rho \pi r^{2}}[0.18-0.023 \cos (w t)+0.043 \sin (w t) \\
& -0.016 \cos (2 w t)+0.028 \sin (2 w t)-0.032 \cos (3 w t)-0.00019 \sin (3 w t) \\
& +0.0022 \cos (4 w t)-0.016 \sin (4 w t)]
\end{aligned}
$$

where $\rho$ is the blood density, $r$ is the inlet radius, $w$ is the frequency, $t$ is the time, and $v_{\text {factor }}$ is the velocity factor used to alter the flow for the RCA and the LMCA. The constant 24.59 is used to adequate the blood flow to $125 \mathrm{~mL} / \mathrm{min}$.

The transient flow profile of one cardiac cycle can be seen in Figure 3.2. It is assumed that the human heart rate is 60 beats per minute or 1 beat per second, this is equivalent to consider a frequency equal to $1 \mathrm{~Hz}$ or $6.28 \mathrm{rad} / \mathrm{s}$.

Figure 3.2 - Transient flow profile.

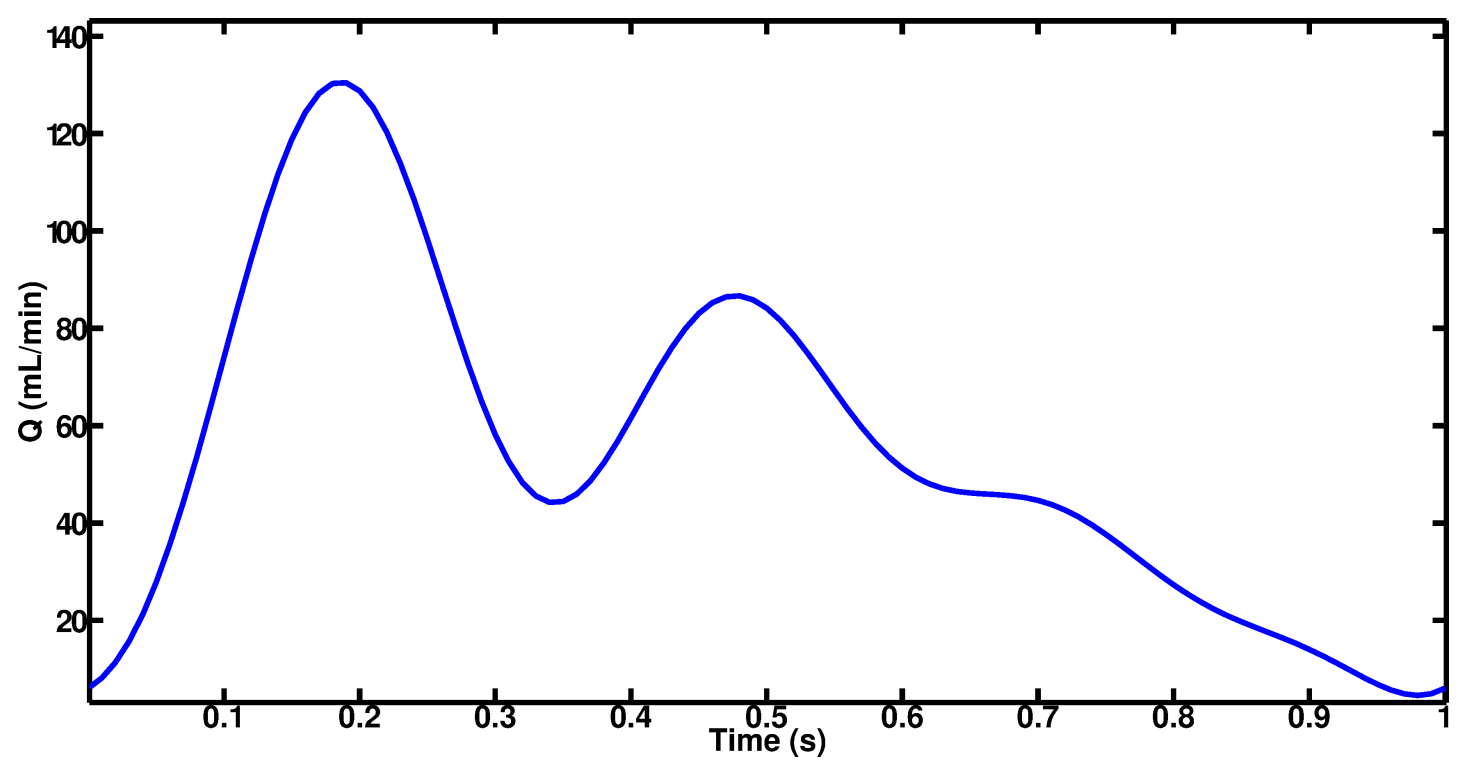




\subsubsection{Wall boundary condition}

At the interface of the blood flow with the artery wall the no-slip condition is chosen.

$$
\mathbf{u}=0 \text { at } \partial \Omega_{\text {wall }}
$$

Even though the arterial wall exhibits an intrinsic elastic behavior, the wall is modeled as rigid and static, in order to reduce computational cost in regarding simulation time, memory consumption, and numerical stability (REYMOND et al., 2013).

\subsubsection{Outlet boundary condition}

The Dirichlet pressure boundary condition is used at the coronary outlets. The pressure value applied at the outlet depends on the patient minimal blood pressure. The average minimal human blood pressure is $80 \mathrm{mmHg}$ or $10.66 \mathrm{kPa}$, and this is the value used in the computer simulations, unless stated otherwise.

$$
p=10.66 k P a \text { at } \partial \Omega_{\text {outlet }}
$$

The locations of the boundary conditions for a right coronary artery are shown in Figure 3.3a, and for a left coronary artery in Figure 3.3b.

Figure 3.3 - Boundary condition locations.

(a) Right coronary artery.

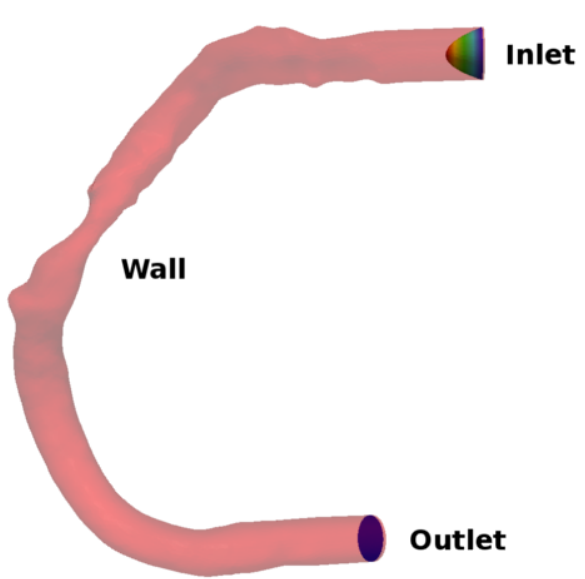

(b) Left coronary artery.

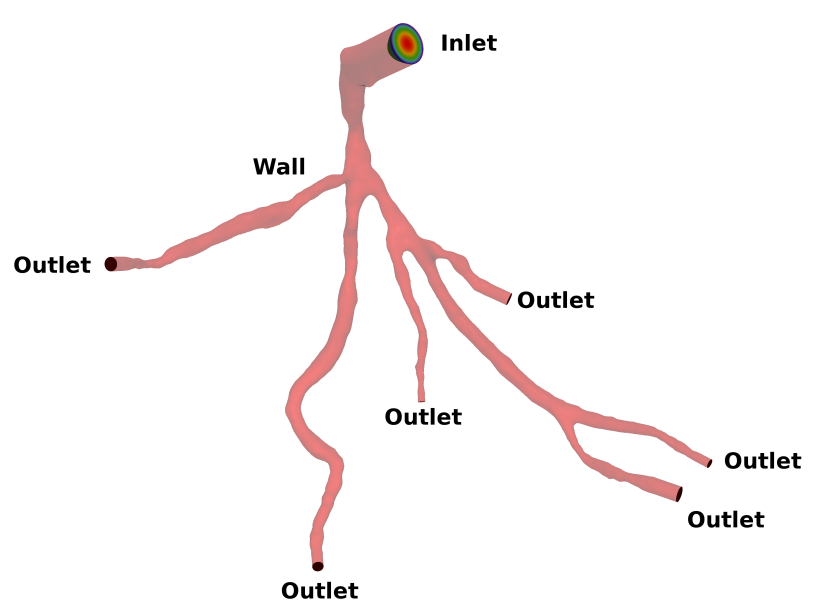




\section{METHOD IMPLEMENTATION}

The method implemented in this dissertation follows a well-defined sequence. It uses the patient medical exam obtained from a Computed Tomography Angiography (CTA) to generates a suitable computational geometrical model of the coronary arteries. Then the computer simulations are performed, with the appropriated boundary conditions, and the results are exported to a visualization program. The entire process, together with the file formats and programs used, can be visualized in Figure 4.1.

Figure 4.1 - Flowchart sequence of the method implemented.

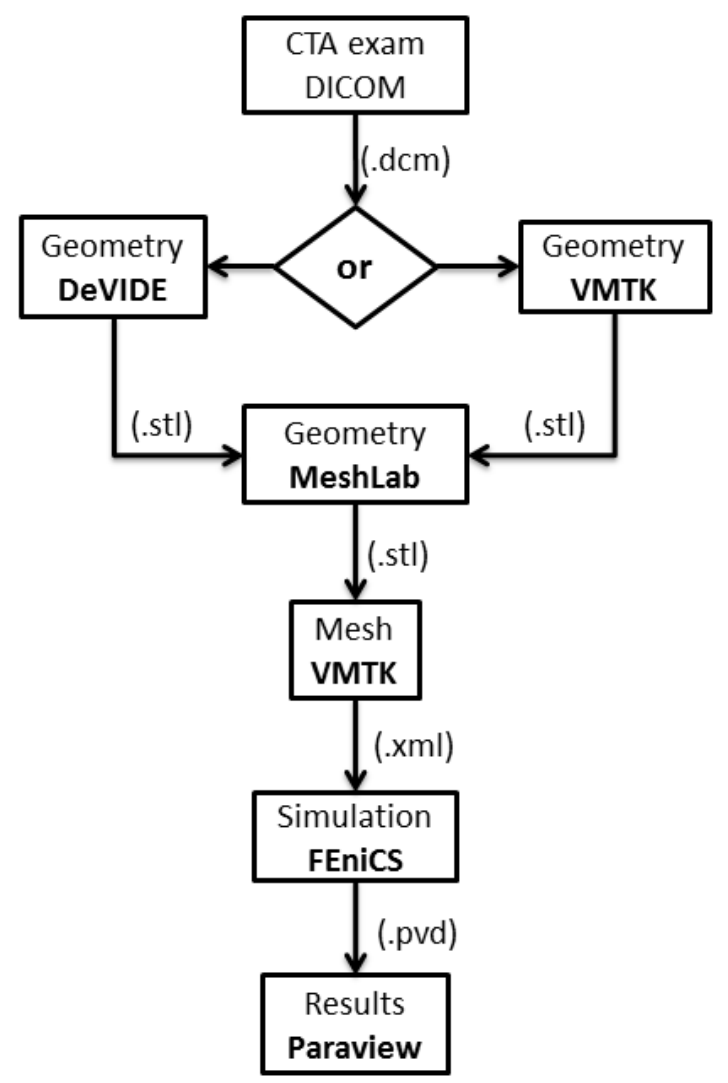

In order to validate the method implemented, the results obtained from the computer simulations are compared with the invasive FFR procedure, that occurred in the facilities of Institute Dante Pazzanese of Cardiology of São Paulo and is supervised by the cardiologist Tiago Senra Garcia dos Santos (CRM-SP 104417). The present work is a partnership among Institute Dante Pazzanese of Cardiology of São Paulo and the University of São Paulo, all medical images used in this dissertation are provided by the cardiology institute.

The programs used and the details of the implementation are explained in the next sections. 


\subsection{Medical Images}

The medical images obtained from the Computed Tomography Angiography exam are an aggregate of two dimensional $x$-ray images that represents cross-sectional slices of the region of interest, in this case, the heart.

Figure 4.2 - Sequence of CTA images.

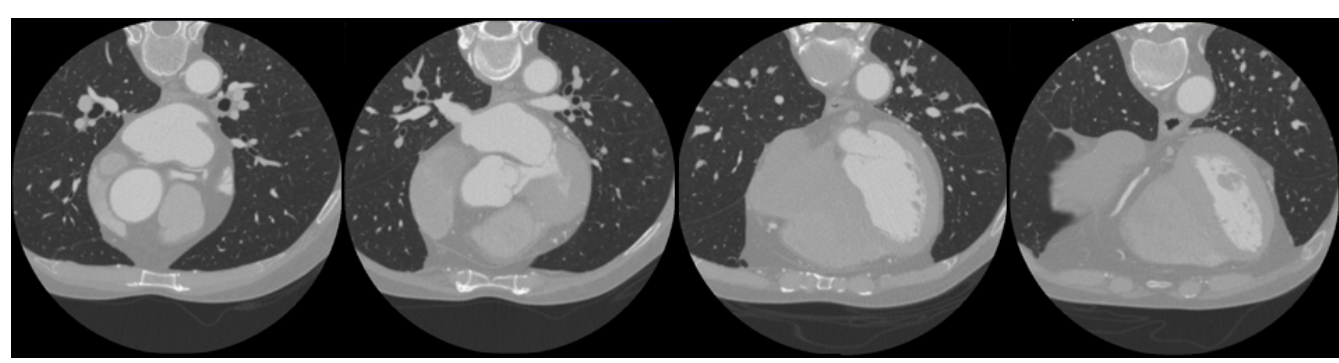

As can be seen in Figure 4.2, different tissues present different gray contrast in the images. During CTA, the patient is medicated with a vasodilator and a contrast material in order to enhance the image quality. The use of the contrast material makes regions filled with blood to appear brighter in the images, and therefore, it highlights the lumen ${ }^{1}$ of the arteries.

The CTA images are saved in file format named Digital Imaging and Communications in Medicine (DICOM). This format was created and developed by professionals from National Electrical Manufacturers Association (NEMA) to standardize the storage and the transmission of the medical images, in order to assure the quality of the images and to facilitate the communications among the medical community.

DICOM files carry all information about the exam and the patient, however in favor of preserving the patient privacy and not to violate any ethical standards, all information in the medical images about the patients was previously deleted before the image use.

\subsection{Acquisition of Geometrical Model}

In this dissertation, two programs are used to extract the geometrical models of the coronaries from the DICOM files: the Delft Visualization and Image processing Development Environment (DeVIDE) (BOTHA; POST, 2008) and the Vascular Modelling ToolKit (VMTK) (ANTIGA et al., 2008).

Both of them use the same concept to generate the geometrical models of the arteries: first, a contrast filter is used, then a surface contour is generated in the region delimited by the contrast, a surface treatment is performed (smooth), and finally, the model is saved.

\footnotetext{
1 inside space or passage of the artery where the blood flow occurs
} 


\subsubsection{Delft Visualization and Image processing Development Environment}

The DeVIDE ${ }^{2}$ is a open-source software developed for rapid prototyping of medical images. It works in a dataflow visual programming environment (Figure 4.3), with specific tools to read the DICOM images and to generate the geometry model.

Figure 4.3 - DeVIDE environment.

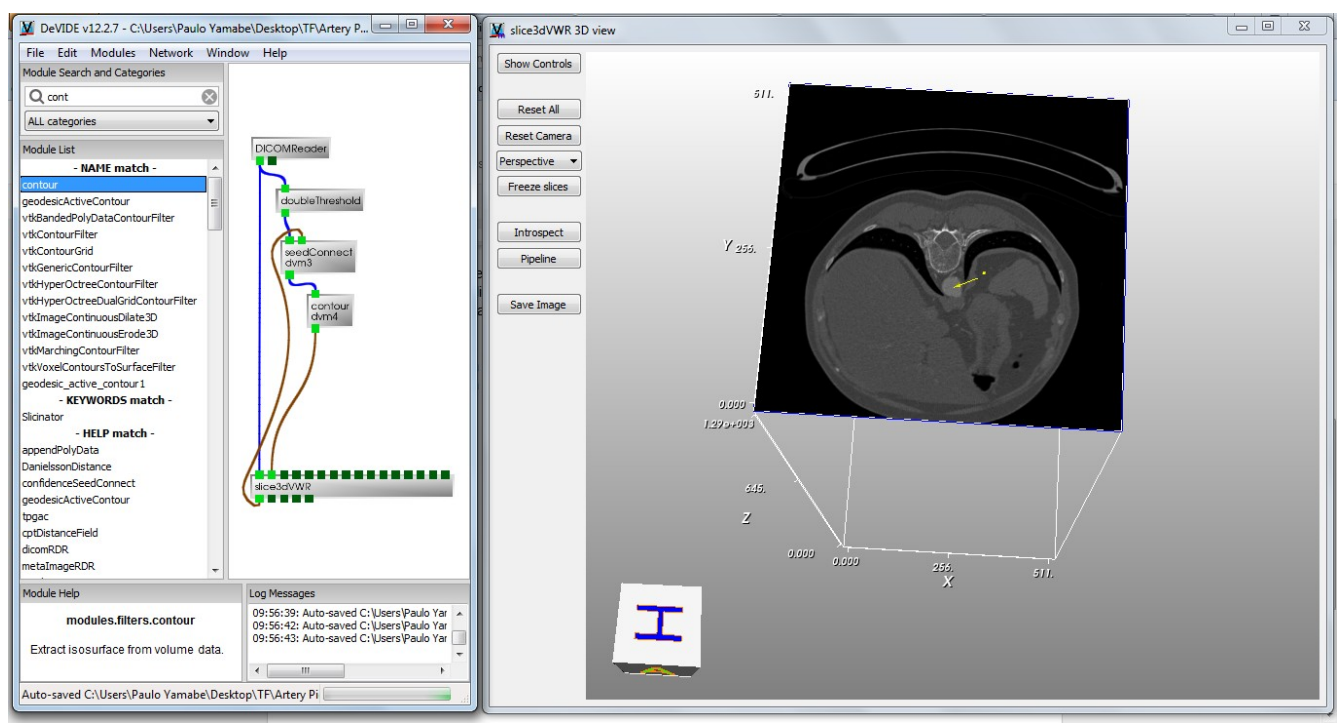

In order to implement the desired sequence of operations, the modules are linked together by the input and output. The sequence of modules used to extract the geometrical model can be visualized in Figure 4.4 and a brief explanation of each one is presented next:

Figure 4.4 - DeVIDE modules used to extract the geometrical model of the coronary artery.

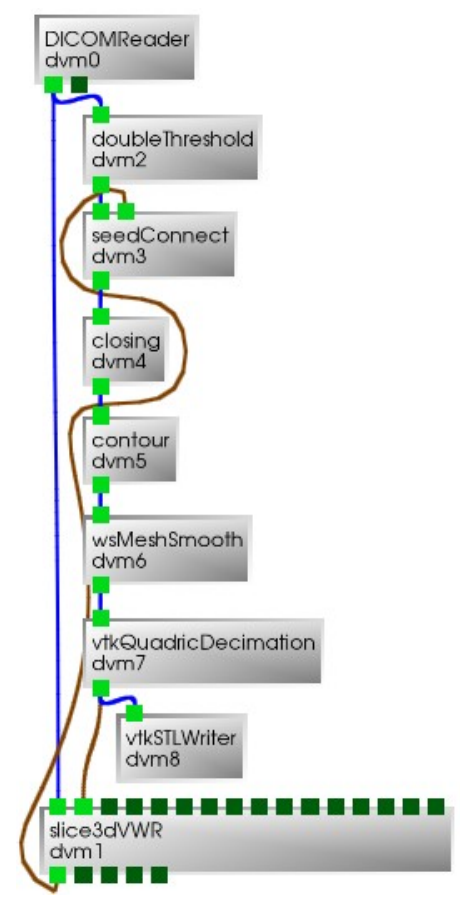

2 Available at <http://code.google.com/p/devide/> 
DICOMReader: Reads the DICOM file or folder

doubleTreshold: Implements a contrast filter based on minimum and maximum values defined by the user.

seedConnect: Choice of a starting point in the region of interest. Based on the contrast already defined, it performs a region growth of the model.

closing: Image enhancement of the region of interest.

contour: Creates the surface contour of the region.

wsMeshSmooth: Performs a surface treatment, based on a surface smooth.

stIWTR: writes the surface as a $\mathrm{STL}^{3}$ file.

slice3dVWR: Module used to visualize the model and the operations implemented.

The model extracted from the DICOM file using the modules described is showed in Figure 4.5.

Figure 4.5 - Rigth coronary model obtained using the DeVIDE.

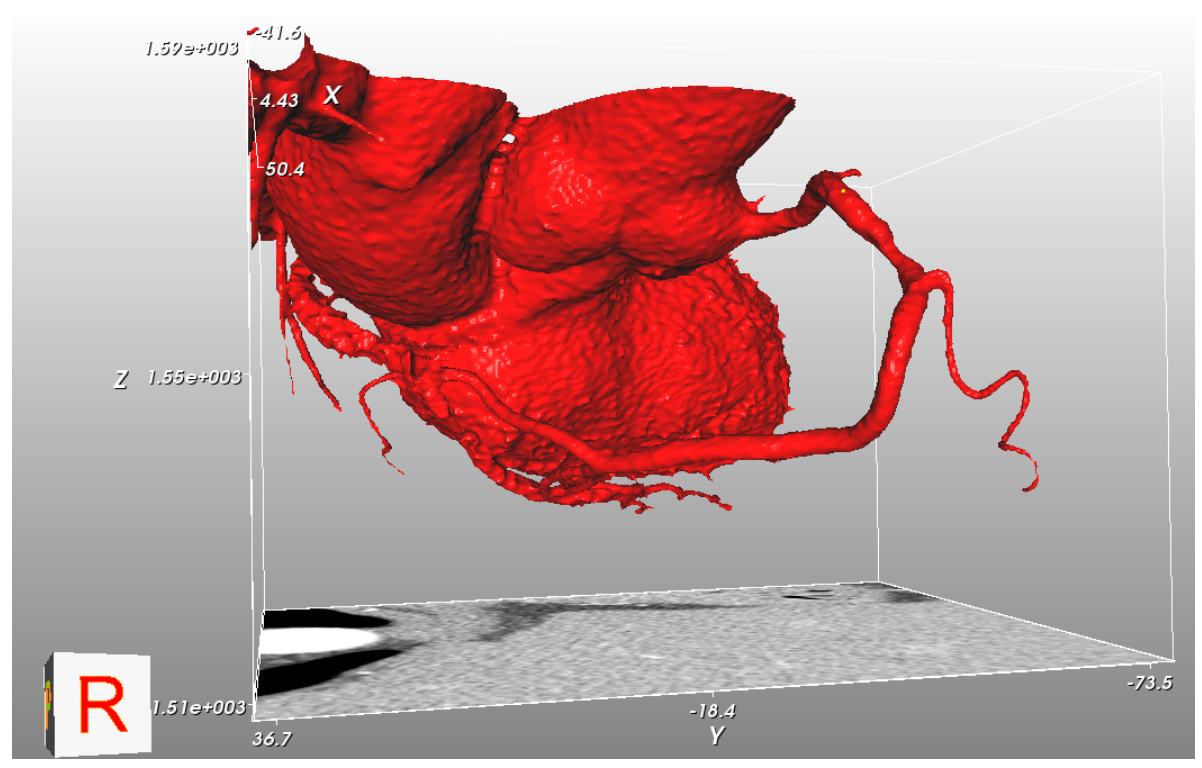

A disadvantage of this software is the inability to generate a geometrical model of only a part of the coronary, and it is still necessary to clean the model before using it in the computer simulation. The coronary segmentation and model cleaning can be performed by using a third party open-source software called MeshLab ${ }^{4}$. The geometrical model obtained after the segmentation is presented in Figure 4.6.

3 The STL file format stands for StereoLithography, the same format used by three dimensional printing machines, and is formed only by triangular elements.

4 Available at <http://meshlab.sourceforge.net/> 
Figure 4.6 - Right coronary model obtained using DeVIDE and MeshLab.

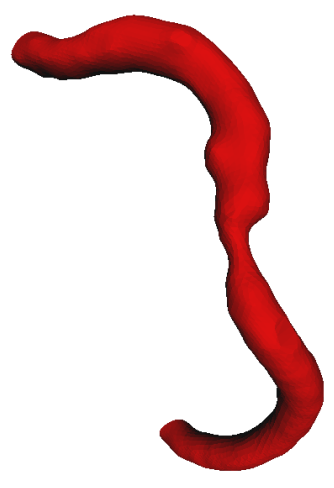

\subsubsection{Vascular Modelling ToolKit}

The VMTK ${ }^{5}$ is another open-source software consisting in a collection of libraries and tools for 3D reconstruction of patient-specific blood vessels. It is used through command line scripts that can be concatenated together to define a sequence of desired operations.

The scripts used to perform the extraction of the coronary artery were:

vmtkimagereader: Reads the DICOM file or folder.

vmtkimagewriter: Writes the image in a compatible file format (.vti) to process the other operations inside the program.

vmtklevelsetsegmentation: Defines the contrast threshold and the seed points to obtain the geometry.

vmtkmarchingcubes: Creates a polygonal surface based on the threshold.

vmtksurfacesmoothing: Performs the surface smoothing.

vmtksurfacewriter: Writes the surface in a STL file format.

vmtksurfaceviewer: To visualize the surface generated.

vmtksurfaceclipper: Performs the segmentation of the model.

vmtkcenterlines: Computes the centerlines of the artery, based on the maximal inscribed sphere radius.

vmtkflowextensions: Adds an extension at the inlets and outlets of the model.

vmtkmeshgenerator: Creates the tetrahedral mesh.

vmtkmeshwriter: Writes the generated mesh in a XML (.xml) file format. 
VMTK was developed specifically to model blood vessels and, therefore, has specialized functions to generate the geometrical model, such as artery centerlines, flow extensions at the boundaries, and mesh generation.

Near the artery wall, a refinement of the mesh is performed, due to the higher velocity gradients that occur inside the boundary layer. It can be visualized in Figure 4.7a.

A model obtained form the DICOM files using the VMTK is shown in Figure $4.7 \mathrm{~b}$

Figure 4.7 - Right coronary geometry model using the VMTK.

(a) Mesh refinement near wall.

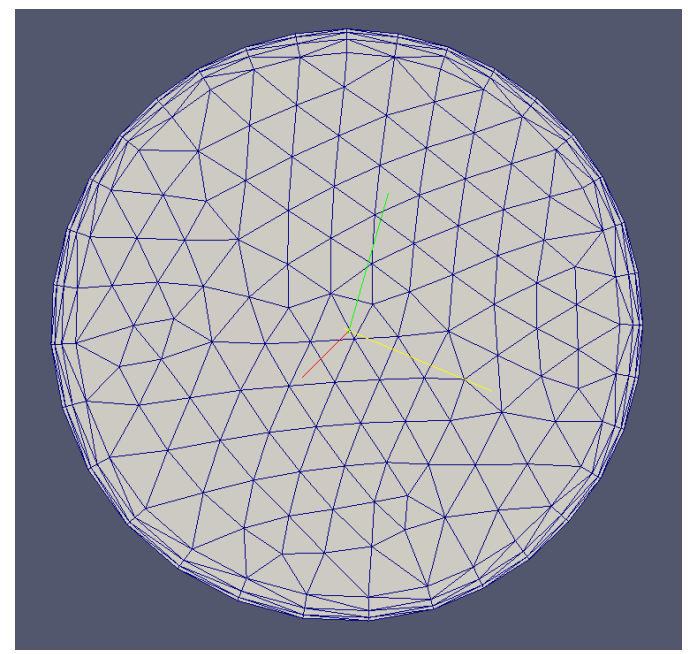

(b) Geometry model.

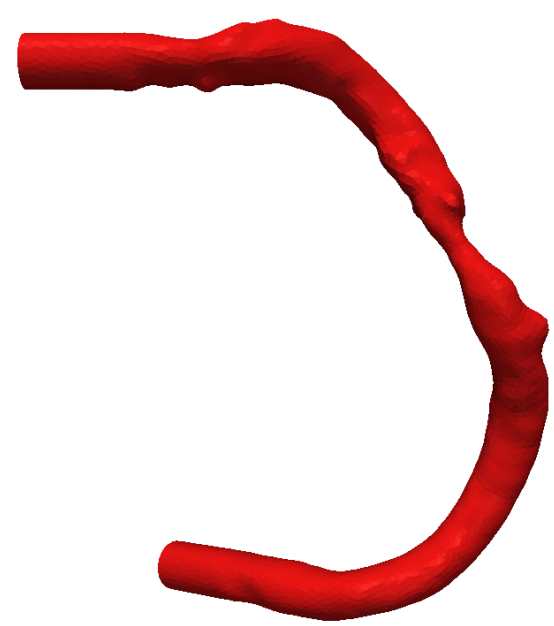

The VMTK is the program chosen to generate the coronaries models, because most of the models generated with it does not present geometrical problems, such as holes, and the time needed to generate the models are lower in comparison with the DeVIDE.

However, the DeVIDE is still used to visualize some medical images, which is the reason why the program features are explained in the later section (Section 4.2.1). The DeVIDE is easier to implement, if it is desired to just visualize the coronary arteries.

\subsection{Computer simulations implementation}

The computer simulations of the coronary arteries can be performed in several different programs, such as ANSYS, COMSOL, OpenFOAM, FEniCS etc. Among then, FEniCS showed to be a good alternative, because it is a free open-source and builds the FEM from the weak formulation.

FEniCS allows the user to focus on the implementation itself, by writing the governing equations in the weak formulation and by choosing the appropriated boundary conditions, instead of being concerned about the code assembling of the matrices or the system solver methods. 


\subsubsection{FEniCS}

FEniCS ${ }^{6}$ is an open-source software developed to automate the solution of mathematical models described by PDEs. It starts from the weak formulation to derive and solve the desired problem by using the FEM.

User applications in FEniCS can be programmed both in $C++$ and Python, where the latter is the language chosen to implement the computer simulation in the present work.

Essentially, the FEniCS software consists in core components named DOLFIN, FEniCS Form Compiler (FFC), Unified Form Language (UFL), Unified Form-assembly Code (UFC), FInite element Automatic Tabulator (FIAT) and Instant. The basic relationship of these components can be seen in Figure 4.8 and a brief explanation of each one is presented next.

Figure 4.8 - FEniCS components overview.

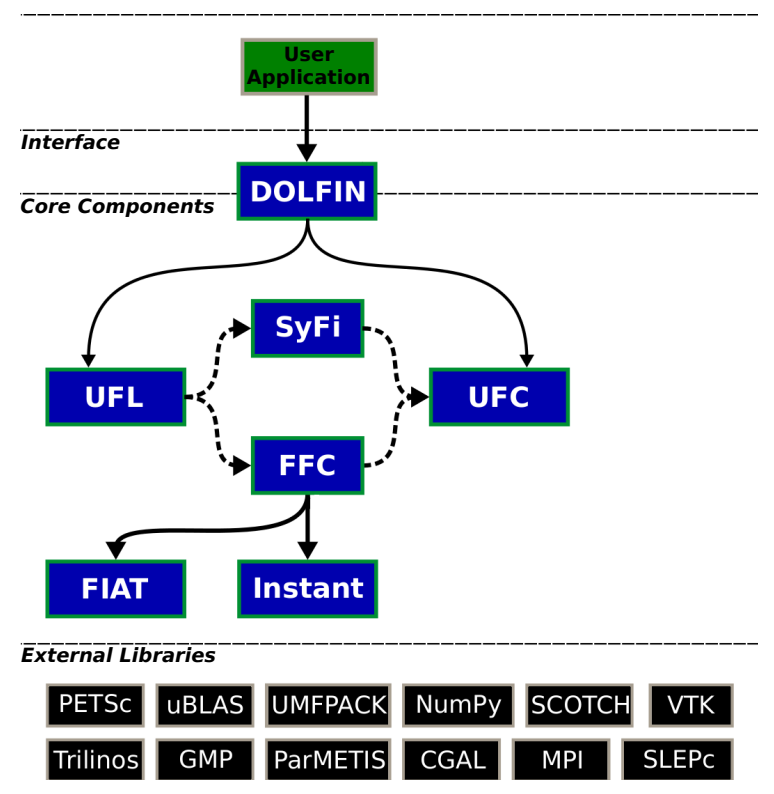

Adapted from Logg, Mardal and Wells (2012).

The user application is then implemented by using the DOLFIN package. It behaves as a user interface and a core component of FEniCS, because it performs all the communications between the user program and the other FEniCS components.

DOLFIN is a collection of libraries with efficient and convenient $C++$ classes developed for finite element computing. All its modules and features can be imported to a Python environment in a single command line (Listing 4.1).

Listing 4.1 - Importing the DOLFIN package.

from dolfin import *

$6 \quad$ Available at <http://fenicsproject.org/> 
The "dolfin" is a Python package providing access to the all DOLFIN libraries, features and functions. DOLFIN also uses external libraries for the linear algebra computations, such as PETSc, Trilinos and UBLAS, and for the mesh partitioning, such as ParMETIS and SCOTCH.

The mesh must be stored in a specific file format called DOLFIN XML. The reading of a mesh file is performed by the DOLFIN Mesh class and can be visualized in Listing 4.2.

Listing 4.2 - Importing the mesh file.

mesh $=$ Mesh ("mesh.xml")

The VMTK software (Section 4.2.2) exports the mesh in the DOLFIN XML format, reason why all meshes used in the computer simulations are generated by using the VMTK.

The weak formulation of the governing equations must be expressed in a suitable form language called Unified Form Language (UFL). It has as high point a very close correspondence between the Python syntax and the mathematical expressions.

For example, a weak formulation for the Poisson problem is given by:

$$
\int_{\Omega} \nabla u \cdot \nabla v d x=\int_{\Omega} f v d x
$$

where $u$ is the trial function, $v$ is the test function and $f$ is the source function, can be written in the UFL Python code as shown in Listing 4.3

Listing 4.3 - Poisson's problem.

$\mathrm{a}=\operatorname{inner}(\operatorname{grad}(\mathrm{u}), \operatorname{grad}(\mathrm{v})) * \mathrm{dx}$

$\mathrm{L}=\mathrm{f} * \mathrm{v} * \mathrm{dx}$

where $a$ is the bilinear form and $L$ is the linear form of the weak formulation explained in Section 3.2.

The weak formulation in the UFL format is passed to the FEniCS Form Compiler (FFC), which is responsible for generating a $\mathrm{C}++$ code, in order to facilitate and automate the assembly of sparse matrices from the finite element bilinear forms for the user-specific weak formulation. The FFC depends on the FInite element Automatic Tabulator (FIAT), that contains a library of pre-defined elements, and on the just-in-time compiler Instant.

The FIAT is an extensive list of pre-defined elements for lines (1D), triangles (2D) and tetrahedra (3D). The computer simulations use the tetrahedron elements and only the number of nodes per element used are different, depending on the variable of interest. The viscosity uses a constant element, the pressure uses a linear element, and the velocity uses a quadratic element. 
The code generated in the FFC is in the Unified Form-assembly Code (UFC) format, to facilitate the assemble of the matrices of the FEM and the solution of the resulting system by the linear algebra package.

Finally, the code generated by the FFC in the UFC format, can be used by DOLFIN to assemble the linear systems using a linear algebra package. In the default installation, FEniCS uses the linear algebra package denominated PETSc (BALAY et al., 1997), to handle the vectors, matrices and linear system solver methods, such as direct or iterative methods and also eigenvalue solvers. Other linear algebra packages are available, however they are not used in the implementation of the computer simulations.

A generic linear system of the kind $A x=b$ can be solved by the solve function as can be visualized in Listing 4.4 .

Listing 4.4 - Solving linear systems.

$\operatorname{solve}(A, x, b)$

It is also possible to select the solver method and the preconditioner in the calling of the function. The solver method used in this dissertation is the Generalized Minimal Residual Method (GMRES) (SAAD; SCHULTZ, 1986), an iterative method for solving linear systems by minimizing the norm of the residual vector over a Krylov subspace.

The preconditioners can be described as a set of algebraic operators used for improving the convergence of the solution. The standard $A x=b$ linear system is transformed into $M^{-1} A x=M^{-1} b$, where the fundamental tradeoff is to choose $\mathrm{M}$ to reduce the convergence rate without increasing the computational cost of solving systems with $M$.

The two preconditioners chosen to solve the linear systems of this dissertation are the Geometric Algebraic Multigrid (AMG) (STÜBEN, 1999) and an Incomplete Lower Upper Factorization (ILU) (CHAN; VORST, 2001), a modified Gaussian Elimination Method. The former has better properties to deal with Poisson's like equations and it is used in the pressure correction step, and the latter is more robust, demanding more computational effort, and it is used for the tentative velocities calculations and final velocity correction. Listing 4.5 displays the implementation of the solver and the preconditioners.

Listing 4.5 - Solver.

solver1 = KrylovSolver("gmres", "ilu")

solver2 = KrylovSolver("gmres", "amg")

The GMRES solver using the ILU and AMG preconditioners can be set with specific parameters for the relative and absolute tolerance, and the maximum number of iterations allowed to reach the convergence of the solution. This improves the control over the final solution and can be implemented as shown in Listing 4.6. 
Listing 4.6 - Solver and preconditioner parameters.

prm $=$ parameters ['krylov_solver']

prm ['absolute_tolerance'] $=1 \mathrm{E}-6$

prm ['relative_tolerance'] $=1 \mathrm{E}-8$

prm ['maximum_iterations'] $=2000$

Further explanation of the software FEniCS and all its components can be found in the FEniCS Book (LOGG; MARDAL; WELLS, 2012).

\subsubsection{IPCS Implementation}

This section shows the implementation of IPCS method with the FEM formulation presented in Section 3.3 with Python code examples. The entire code used in the computer simulations is presented in Appendix A.

The creation of the Lagrange function spaces are shown in Listing 4.7.

Listing 4.7 - Definition of the function spaces.

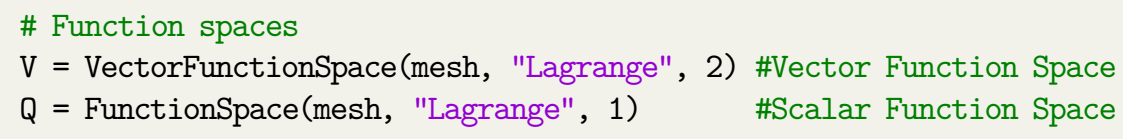

The trial and test function of the Galerkin formulation, explained in Section 3.2, are defined in Listing 4.8.

Listing 4.8 - Definition of the trial and test functions.

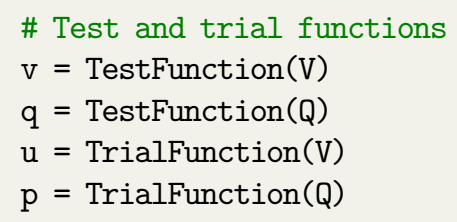

The Dirichlet boundary conditions for the parabolic velocity at the inlet, the pressure at outlet and the no-slip condition at the wall, described in Section 3.4, are implemented as shown in Listing 4.9.

Listing 4.9 - Definition of the boundary conditions.

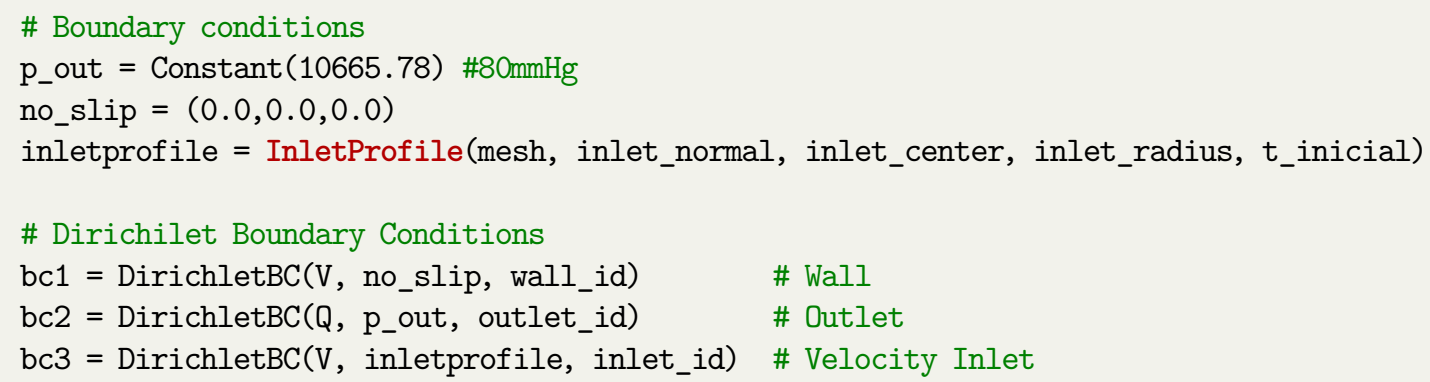


The initial conditions are defined as shown in Listing 4.10.

Listing 4.10 - Definition of the initial conditions.

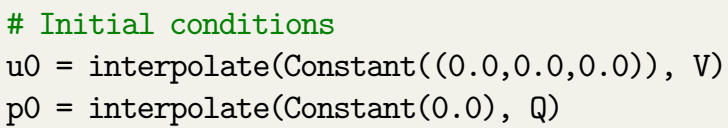

The code implementation of the IPCS with FEM formulation for the tentative velocity, pressure correction, and velocity correction shown in Section 3.3, can be visualized in Listing 4.11

Listing 4.11 - IPCS implementation.

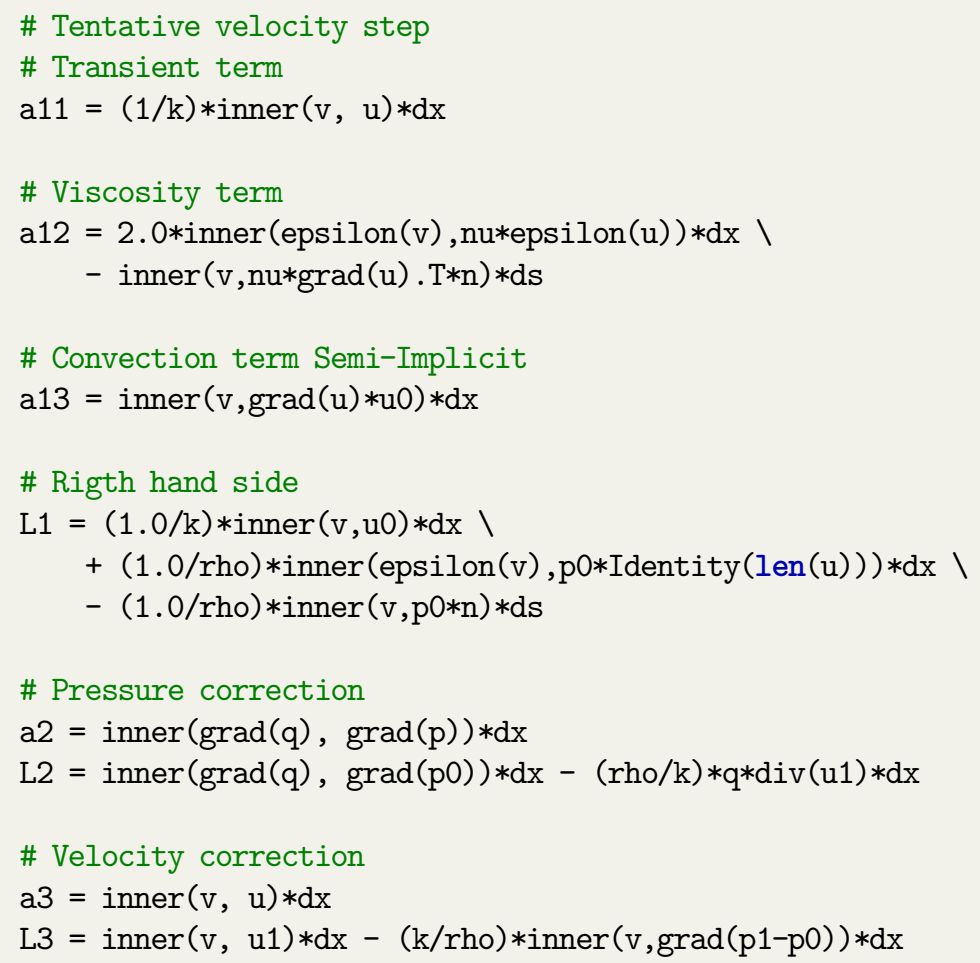

The assemble of the global matrices is performed as displayed in Listing 4.12.

Listing 4.12 - Assembling the matrices.

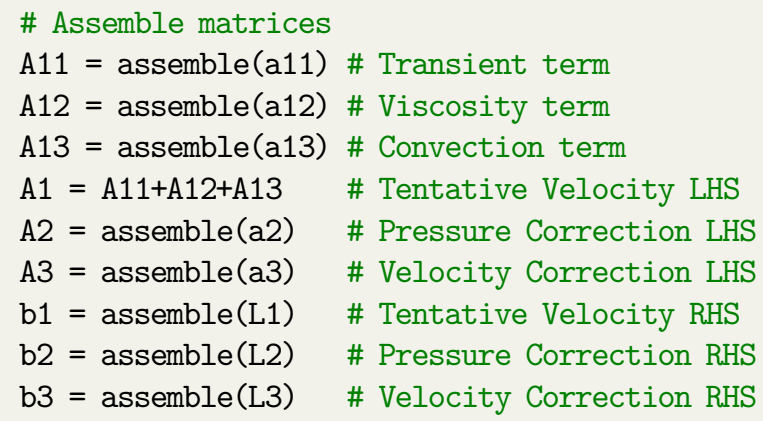


The solution of the transient problem is performed in a time-loop, where for each time-step the IPCS formulation is implemented and solved, and the Python code can be visualized in Listing 4.13.

Listing 4.13 - Time loop for the transient solution.

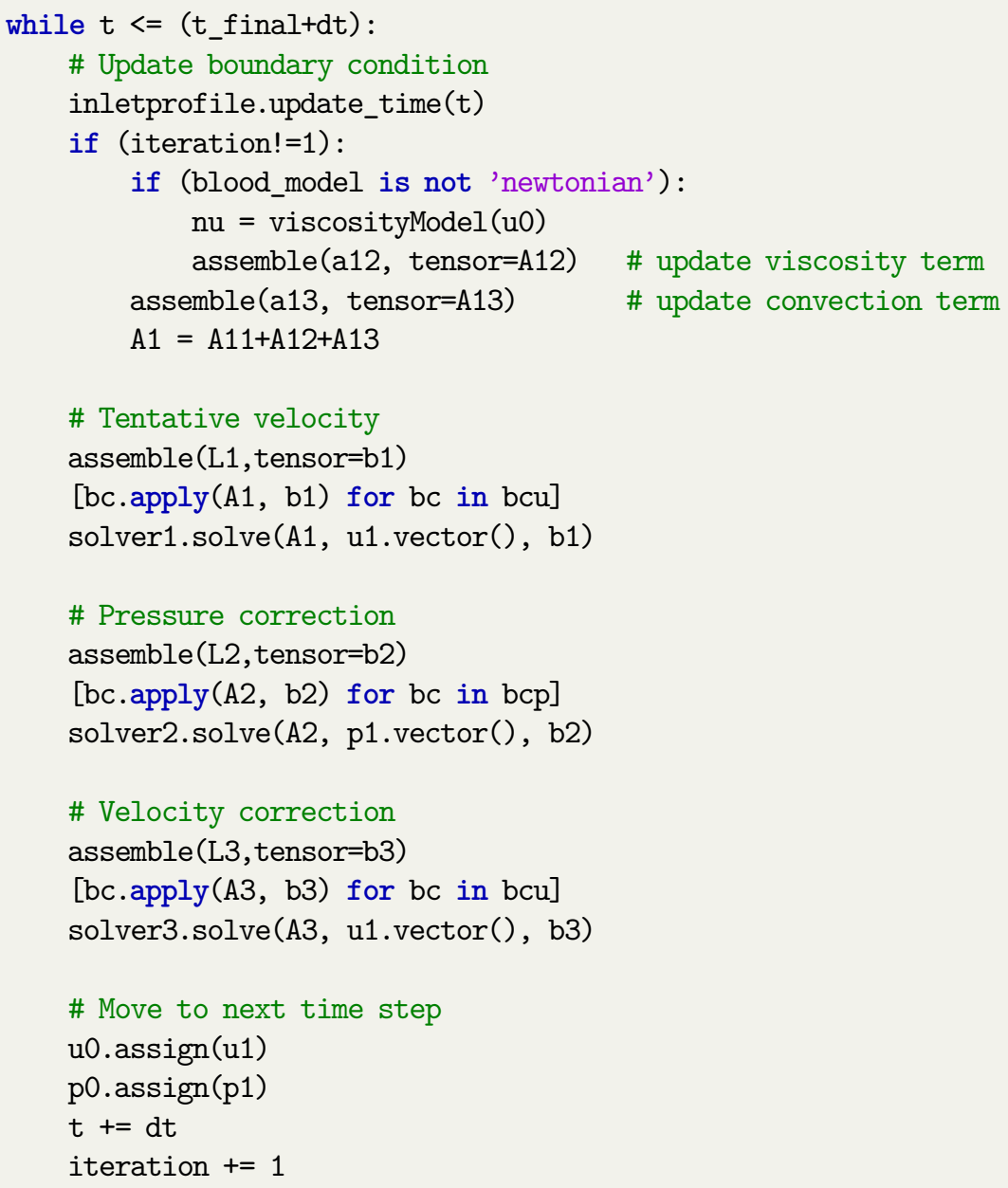

Note that, for the case of the Newtonian blood model, the viscosity term is assembled only once and outside the time-loop. The non-Newtonian models demand the viscosity term to be assembled every time step.

\subsection{Paraview}

The pressure results of the computer simulations are then exported to the Paraview ${ }^{7}$, an open-source software specialized in data analysis and data visualization. ParaView was developed to analyze large data, which is the case of the results from the computer simulations used in this dissertation.

7 Available at <http://http://www.paraview.org/> 


\subsection{Non-invasive FFR}

From the pressure results obtained in the computer simulations, the non-invasive FFR is calculated as follows:

First, the average pressure of the $j$ time-step is calculated as the integral of the pressure over the cross section area of the region analysed:

$$
P_{a v g, j}=\frac{1}{A} \int p d S
$$

Then, the average pressure is integrated over one cardiac cycle:

$$
P_{i}=\int_{0}^{T} P_{a v g} d t
$$

where $T$ is the period of the cardiac cycle considered.

Because of the time discretization, the time integral is approximated by:

$$
P_{i}=\int_{0}^{T} P_{a v g} d t \approx \frac{1}{N_{t}} \sum_{j=0}^{N_{t}} P_{a v g, j}
$$

where $N_{t}$ is the number of the time-steps of one cardiac cycle and $P_{a v g, j}$ is the average pressure in the $j$ time-step

Finally, the non-invasive FFR is calculated by:

$$
\text { non-invasive FFR }=\frac{P_{\text {distal }}}{P_{\text {proximal }}}=\frac{P_{i}}{P_{\text {inlet }}}
$$

where $P_{\text {inlet }}$ is the time average pressure at the inlet region and $P_{i}$ is the time average pressure of the region analysed. For the sake of simplicity, the non-invasive FFR evaluated by using the computer simulations is called ni-FFR in this dissertation.

\subsection{Invasive FFR}

As explained in the Introduction (Chapter 1), the FFR is the present gold standard used in the clinical practice to evaluate the functional impact of a stenosed artery.

First, the patient is submitted to a CTA, where the radiation dosage used in the contrast agent is approximately three to six milisievert $(\mathrm{mSv})^{8}$. The CTA is performed on the GE Discovery CT750 HD CT Scanner, which produces high definition images at up to 230 micron resolution according to the manufacturer web site ${ }^{9}$.

8 The Sievert (Sv) represents the equivalent biological effect of the deposit of a joule of radiation energy in a kilogram of human tissue.

9 <http://www.ctmedicalscanners.com/ge-ct-scanners/ge-discovery-ct750-hd-ct-scanner/> 
Next, after at least three days from the CTA, the patients are submitted to the invasive FFR measurement. This procedure can be summarized as follows:

- A specialized disposable pressure guide wire is introduced through a guiding catheter into the coronary artery;

- Then, the pressure guide wire is calibrated and moved to the distal tip of the catheter;

- Next, the guide wire is advanced into the coronary artery with the pressure sensor placed after the stenosed part;

- Afterward, the distal and proximal pressures are measured at the maximal hyperemia condition (achieved by drug administration);

- Finally, the mean pressure values and the FFR are displayed at a pressure monitor.

Figure 4.9 shows the result of the FFR displayed in the pressure monitor.

Figure 4.9 - Pressure monitor.

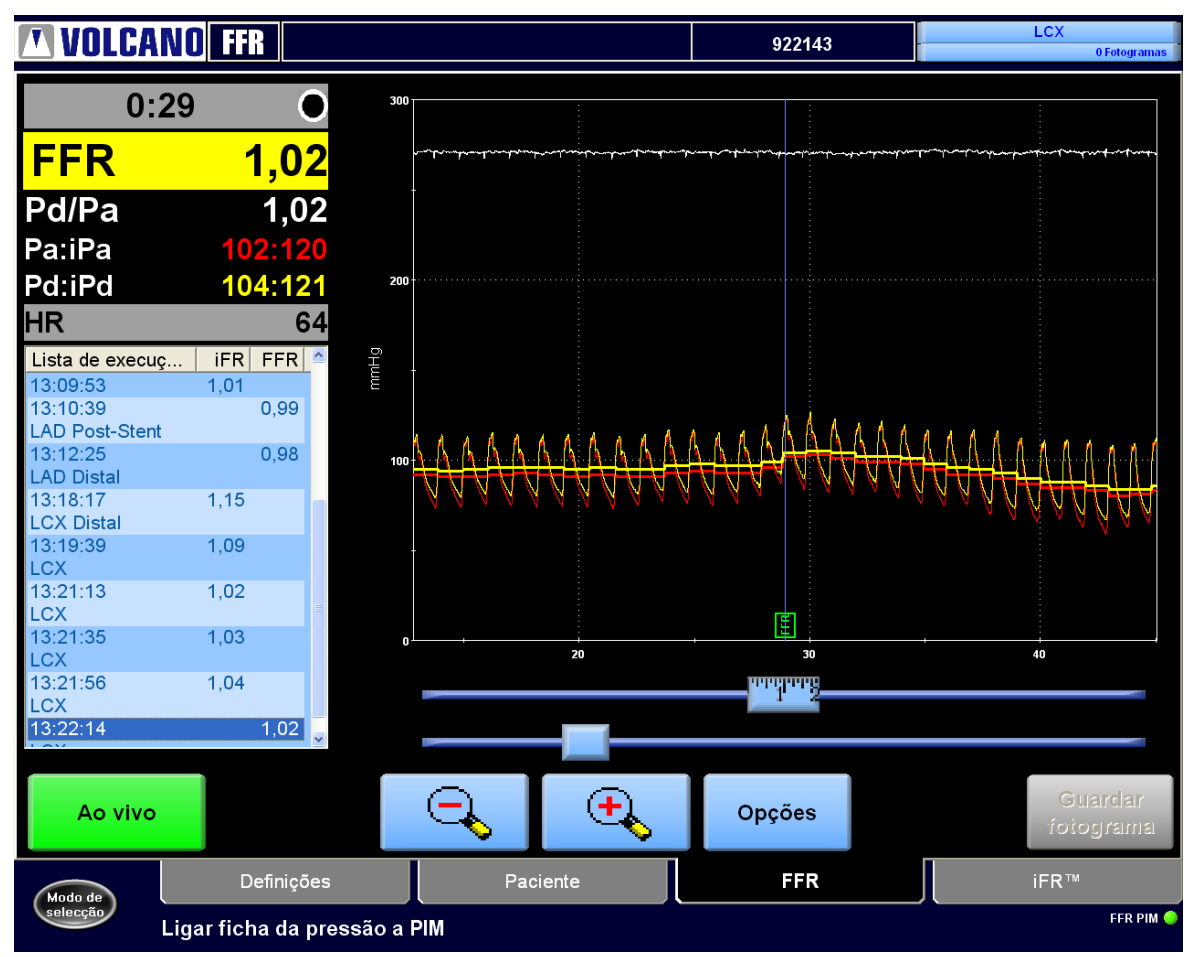

The pressure catheter has $0.3556 \mathrm{~mm}(0.014$ ") of diameter and acquires the pressure inside the coronary at a rate of $5 \mathrm{~ms}$ by using a piezo-resistive sensor.

The presence of the catheter can alter the flow and, therefore, the pressure inside the artery measured, however, as stated by De Bruyne et al. (1993), this error is only significant for very severe stenosis (more than $90 \%$ of obstruction) where the FFR is well below 0.80 and the FFR still predict ischemia. 
The procedure usually takes twenty to thirty minutes to be fully executed and has a minimum risk chance to cause myocardium infarction, cerebral vascular accident (stroke) or coronary vasospasm.

The method developed is compared with the invasive FFR, by considering that the medical procedure is well established and is the gold standard used in the clinical practice. 


\section{EVALUATION OF THE METHOD IMPLEMENTED}

This chapter contains the results of all computer simulations for the solver validation, the evaluation of the number of cycles, the mesh independence test, the analysis of different blood models, and the sensibility analysis of the boundary conditions.

\subsection{Evaluation of the solver}

\subsubsection{Convergence analysis}

In order to validate the solver implemented, computer simulations of a three dimensional flow inside a cylinder is performed and the results are compared with the analytical solution of the problem.

The schematic representation of the cylinder can be visualized in Figure 5.1. The cylinder simulated has $L=10 \mathrm{~mm}$ and $R=1 \mathrm{~mm}$.

Figure 5.1 - Schematic representation of flow inside cylinder.

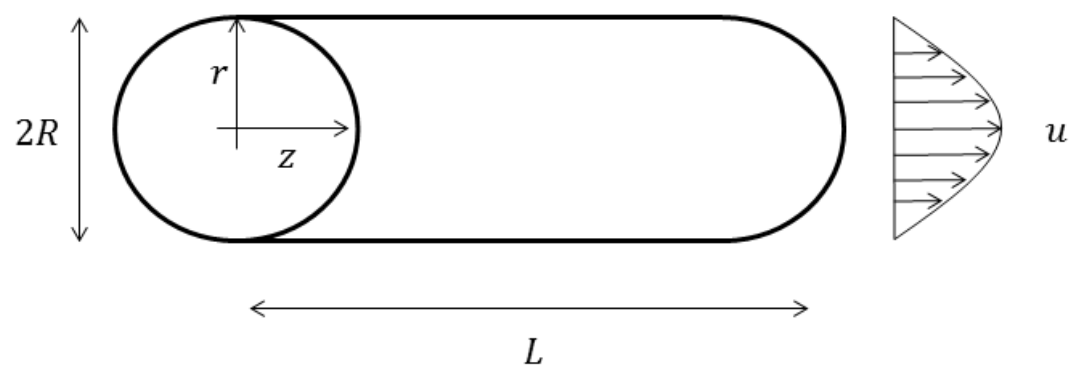

The boundary conditions used are: parabolic velocity profile at the inlet, zero pressure at the outlet, and no-slip condition at the cylinder wall. The peak velocity at the inlet was $u_{\max }=1 \mathrm{~m} / \mathrm{s}$ and the viscosity is considered constant with the value of $\mu=0.00345$ Pa.s.

In order to test the convergence of solution, only the refinement level $(N)$ of the meshes is varied. To achieve the steady-state condition, the computer simulations considered a constant parabolic velocity at the inlet. The flow is simulated for 1.0 second, with the time step being equal to 0.01 seconds.

Because of the space discretization at the circular boundary of the cylinder, some geometrical errors are present, as can be seen in Figure 5.2 where the error is highlighted in red. 
Figure 5.2 - Schematic representation of the area error.

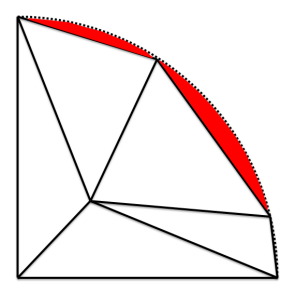

The reference value of the area used in the calculation of the error is $A=\pi R^{2}=3.14$. The number of elements and the geometrical error of each mesh are displayed in Table 5.1.

Table 5.1 - Number of elements and geometrical error for different meshes.

\begin{tabular}{cccc}
\hline Refinement level N & Elements & Area $\left(\mathbf{m m}^{2}\right)$ & Area Error $(\%)$ \\
\hline 2 & 1163 & 3.02 & 3.85 \\
3 & 3405 & 3.08 & 1.82 \\
4 & 7863 & 3.11 & 0.97 \\
5 & 17723 & 3.12 & 0.59 \\
6 & 30397 & 3.13 & 0.41 \\
7 & 47612 & 3.13 & 0.30 \\
8 & 70911 & 3.13 & 0.24 \\
9 & 100553 & 3.14 & 0.18 \\
10 & 136853 & 3.14 & 0.14 \\
15 & 455404 & 3.14 & 0.11 \\
\hline
\end{tabular}

Figure 5.3 displays three different meshes (refinement level 2, 5, and 15), for better visualization of the element density of each mesh.

Figure 5.3 - Different refinement level of the meshes.
(a) $\mathrm{N}=2$.
(b) $\mathrm{N}=5$.
(c) $\mathrm{N}=15$.
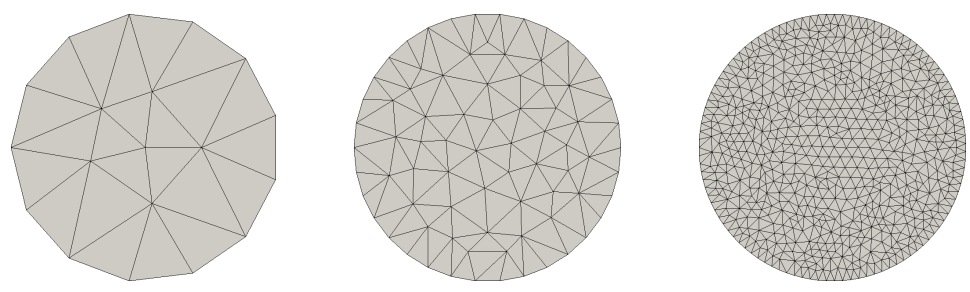

Because of the known boundary errors explained in Section 3.3, the results are taken at the middle of the cylinder. The analytical pressure at $L=5 \mathrm{~mm}$ is $P_{\text {analytical }}=69 \mathrm{~Pa}$.

The error is analysed with the $\mathrm{L} 2$ norm of the pressure, calculated as:

$$
P_{\text {norm }}=\sqrt[2]{\sum_{i=1}^{N_{e l}}\left(P_{i}-P_{\text {analytical }}\right)^{2}}
$$

where $N_{e l}$ is the number of elements and $P_{i}$ is the pressure of each element $i$ at $L=5 \mathrm{~mm}$. 
The average pressure is calculated as the integral of the pressure over the cross section area:

$$
\frac{1}{A} \int P_{i} d S
$$

The results for the pressure are displayed in Table 5.2 and in Figure 5.4.

Table 5.2 - Comparison of the numerical solution with the analytical solution.

\begin{tabular}{ccc}
\hline $\mathbf{N}$ & Average Pressure (Pa) & Norm L2 Error \\
\hline 2 & 75.25 & 10.95 \\
3 & 72.04 & 6.07 \\
4 & 70.15 & 2.97 \\
5 & 70.03 & 2.13 \\
6 & 69.74 & 1.59 \\
7 & 69.57 & 1.21 \\
8 & 69.51 & 1.03 \\
9 & 69.38 & 0.77 \\
10 & 69.29 & 0.61 \\
15 & 69.23 & 0.46 \\
\hline
\end{tabular}

From Table 5.2 we can see that the solver implemented converges to the analytical solution when the refinement of the mesh is improved, the norm diminishes with the increase of the number of elements.

Theoretically, the relationship between the error and the number of degrees of freedom (represented as the number of elements of the mesh) in a log-log graphic is linear. However because of the inherent numerical errors of the methods used, this linearity was not fully accomplished, although the results presented an almost linear relationship as can be visualized in Figure 5.4.

Figure 5.4 - Graphic of the norm pressure error against the mesh size.

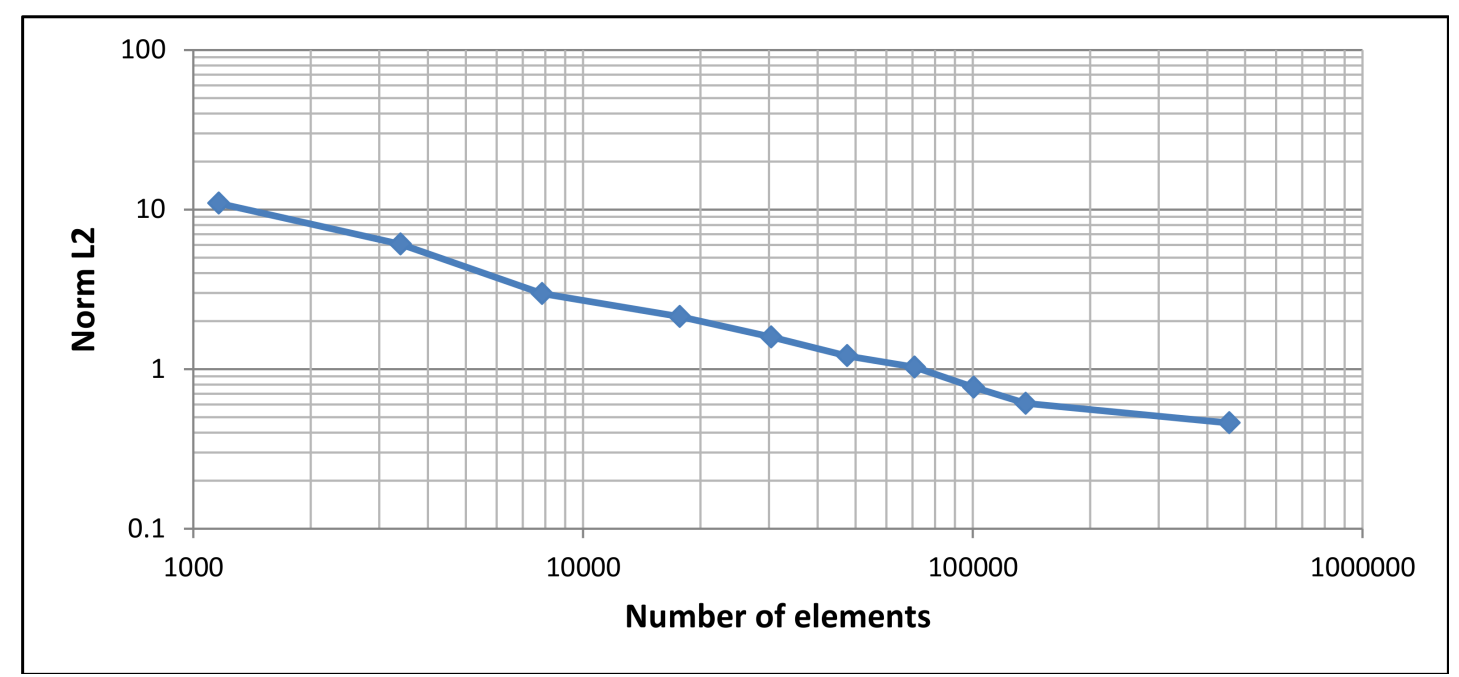


The error of the velocity is evaluated by the value of the volumetric flow rate at the inlet and the outlet, and by the difference between them, in order to exam the numerical error in the conservation laws.

The analytical volumetric flow rate is calculated as follows:

$$
Q_{\text {analytical }}=\frac{1}{2} u_{\max } A=1570.80 \mathrm{~mm}^{3} / \mathrm{s}
$$

where $u_{\max }=1000 \mathrm{~mm} / \mathrm{s}$ and $A=\pi r^{2}=3.14$.

The volumetric flow rate is calculated by:

$$
Q=\int_{A} \mathbf{u} \cdot \mathbf{n} d S
$$

where $A$ is the area of the region considered and $\mathbf{n}$ is the unitary vector normal to the considered area.

The loss percentage is evaluated by:

$$
Q_{\text {loss }}=\frac{Q_{\text {inlet }}-Q_{\text {outlet }}}{Q_{\text {inlet }}}
$$

The results for the volumetric flow rate evaluation can be seen in Table 5.3.

Table 5.3 - Error evaluation of the volumetric flow rate.

\begin{tabular}{ccccc}
\hline $\mathbf{N}$ & $\mathbf{Q}_{\text {inlet }}\left(\mathbf{m m}^{3} / \mathbf{s}\right)$ & $\mathbf{Q}_{\text {outlet }}\left(\mathbf{m m}^{3} / \mathbf{s}\right)$ & Loss (\%) & Error (\%) \\
\hline 2 & 1568.01 & 1559.73 & 0.53 & 3.27 \\
3 & 1570.18 & 1568.49 & 0.11 & 1.70 \\
4 & 1570.62 & 1569.57 & 0.07 & 0.91 \\
5 & 1570.73 & 1570.16 & 0.04 & 0.55 \\
6 & 1570.76 & 1570.35 & 0.03 & 0.38 \\
7 & 1570.78 & 1570.57 & 0.01 & 0.29 \\
8 & 1570.79 & 1570.63 & 0.01 & 0.23 \\
9 & 1570.79 & 1570.69 & 0.01 & 0.17 \\
10 & 1570.79 & 1570.70 & 0.01 & 0.14 \\
15 & 1570.79 & 1570.77 & 0.00 & 0.11 \\
\hline
\end{tabular}

As expected, both, the volumetric flow rate error and the volumetric flow rate loss, diminish with the mesh refinement.

The simulations performed used a quadratic interpolation for the velocity and a linear interpolation for the pressure P2P1. This was first chosen because of the LBB condition described in Section 3.3. However, the IPCS decouples the pressure and velocity fields, and the linear interpolation of both velocity and pressure P1P1 do not affect the numerical stability of the solver implemented. 


\subsubsection{Polynomial order of the base functions}

Computer simulations are performed for the cylinder case, where only the degree of the interpolation of the velocity is varied, in order to evaluate the differences between the P2P1 and P1P1 models. All other assumptions and boundary conditions are kept the same.

The comparison between the computer simulations for the P2P1 and the P1P1 in the pressure error analysis can be visualized in Figure 5.5. The volumetric flow rate error comparison can be visualized in Figure 5.6, and the time expended at each simulation can be visualized in Figure 5.7.

Figure 5.5 - Comparison of the pressure error for P2P1 and P1P1.

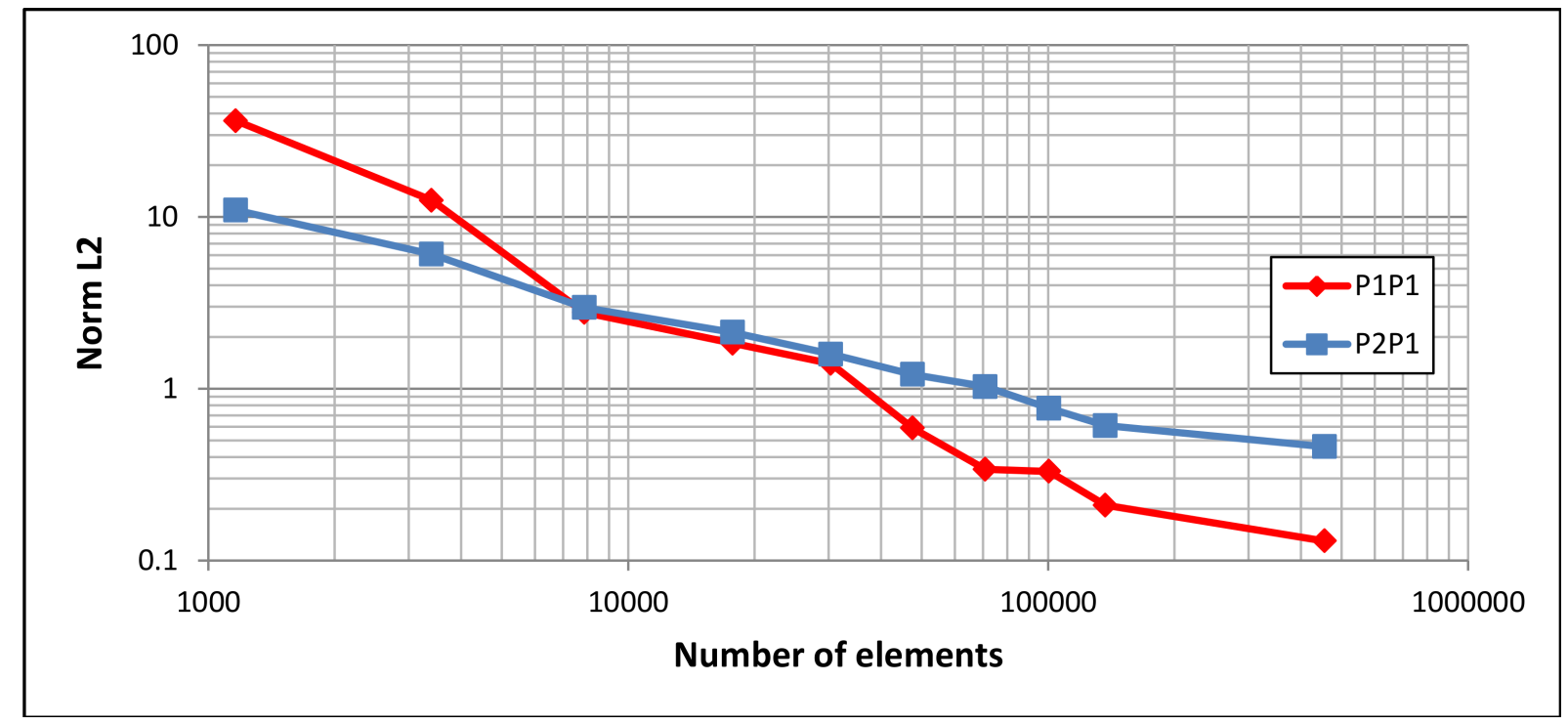

Figure 5.6 - Comparison of the volumetric flow rate error for P2P1 and P1P1.

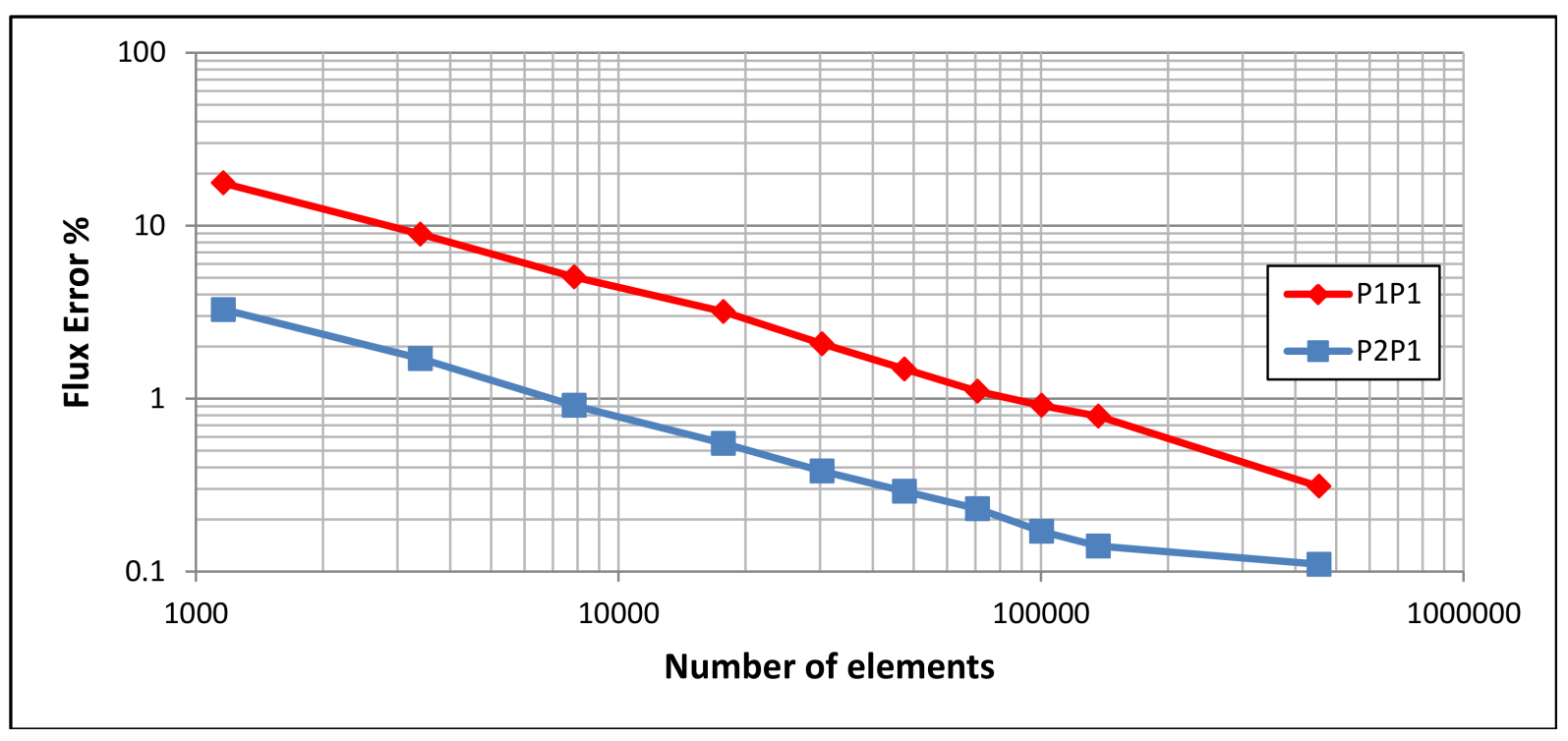


Figure 5.7 - Comparison of the simulation time for P2P1 and P1P1.

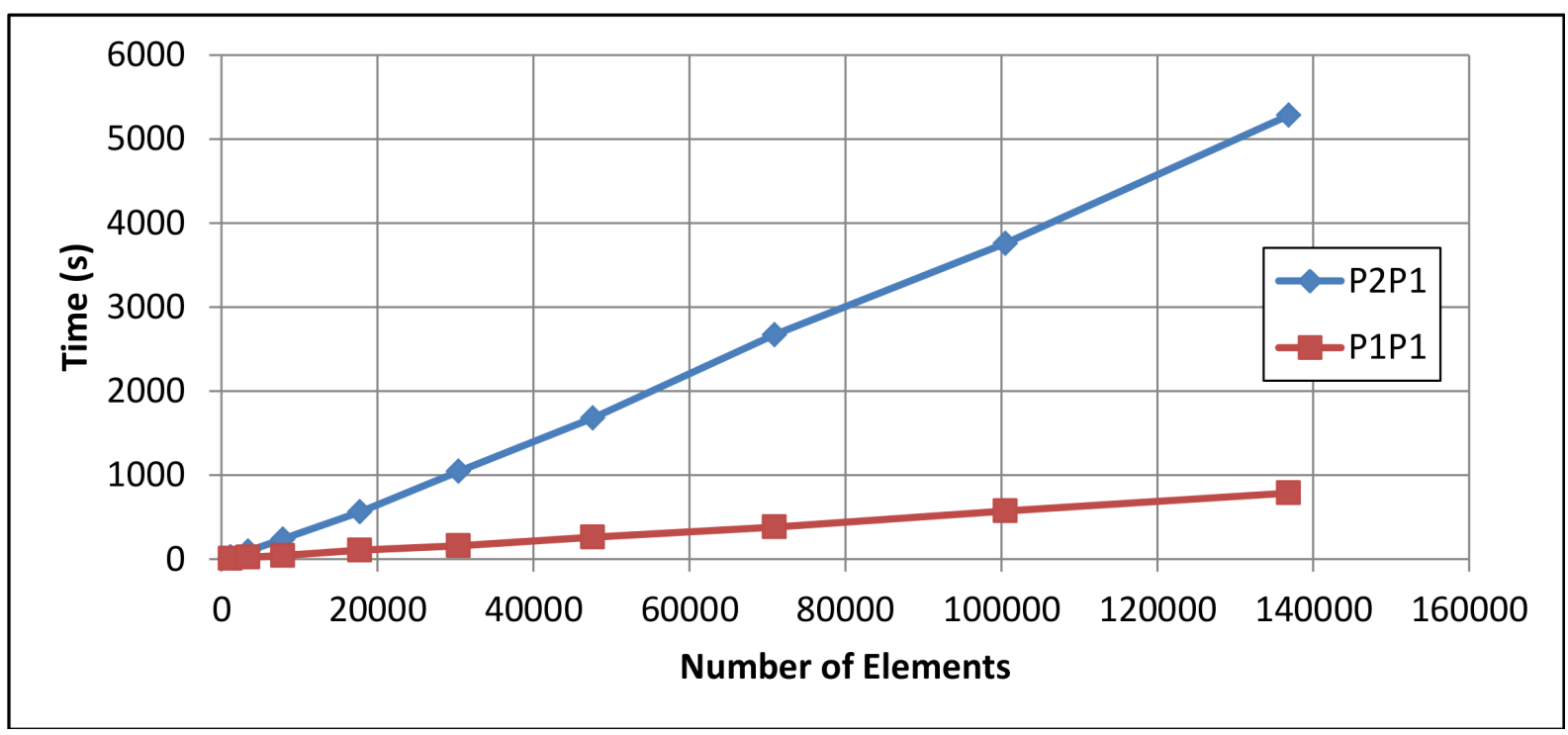

The results of the $\mathrm{P} 1 \mathrm{P} 1$ simulations for $\mathrm{N}=15$ and the $\mathrm{P} 2 \mathrm{P} 1$ for $\mathrm{N}=7$ are displayed in Table 5.4, in order to compare two cases that expended almost the same time to complete.

Table 5.4 - Comparison of P2P1 for $\mathrm{N}=7$ and $\mathrm{P} 1 \mathrm{P} 1$ for $\mathrm{N}=15$.

\begin{tabular}{ccc}
\hline Case & P2P1 & P1P1 \\
\hline $\mathrm{N}$ & 7 & 15 \\
Elements & 47612 & 455404 \\
Area error $(\%)$ & 0.3043 & 0.1077 \\
Pressure Norm & 1.21 & 0.13 \\
$Q_{\text {inlet }}\left(\mathrm{mm}^{3} / \mathrm{s}\right)$ & 1570.78 & 1564.97 \\
$Q_{\text {outlet }}\left(\mathrm{mm}^{3} / \mathrm{s}\right)$ & 1570.57 & 1564.21 \\
$Q_{\text {loss }}(\%)$ & 0.014 & 0.049 \\
$Q_{\text {error }}(\%)$ & 0.29 & 0.31 \\
Time $(\mathrm{s})$ & 1682 & 1339 \\
\hline
\end{tabular}

Both simulations presented roughly the same volumetric flow rate error. However, the $\mathrm{P} 1 \mathrm{P} 1$ displayed lower error for the pressure. This indicates that is preferable to use a finer mesh with more elements and the P1P1 interpolation instead of a coarser mesh and the P2P1 interpolation.

The P1P1 simulations presented lower pressure error, higher velocity error, and took less time to complete than the $\mathrm{P} 2 \mathrm{P} 1$ simulations. This dissertation focus on the pressure gradient in the evaluation of the ni-FFR, and, therefore, the P1P1 assumption is the one used in the ni-FFR analysis. 


\subsection{Computer simulation tests}

With the solver validated for a simpler model, the solver is tested for larger models of coronary arteries. These models are obtained from medical exams (CTA) by using the methodology explained in Chapter 4.

The first computer simulations tests are implemented in a coronary model of a patient with a stenosed right coronary (RCA). The model generated can be seen in Figure 5.8.

Figure 5.8 - Stenosed right coronary geometry model.

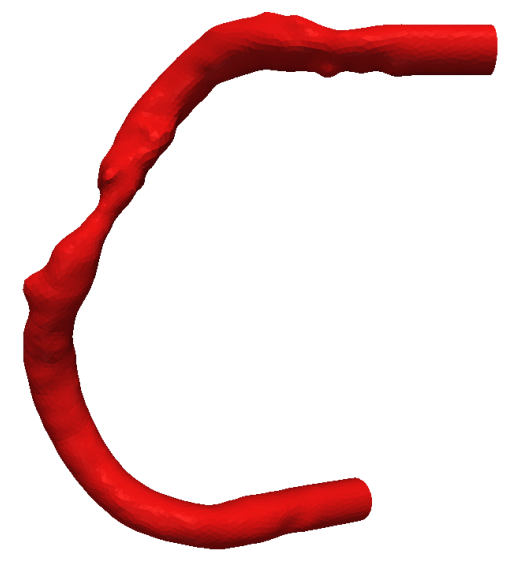

The computer simulations tests have the intend to evaluate, not only the performance of the solver in real coronary models, but also the assumptions considered in this dissertation. The tests performed are: the evaluation of the number of cycles considered, the mesh convergence test, and a sensitivity analysis of the boundary conditions implemented.

\subsubsection{Evaluating the number of cycles}

In order to study the viability of using zero initial conditions for both pressure and velocity, and the effects of this assumption, four cardiac cycles are simulated (Figure 5.9).

Figure 5.9 - Blood flow transient profile of four cardiac cycles.

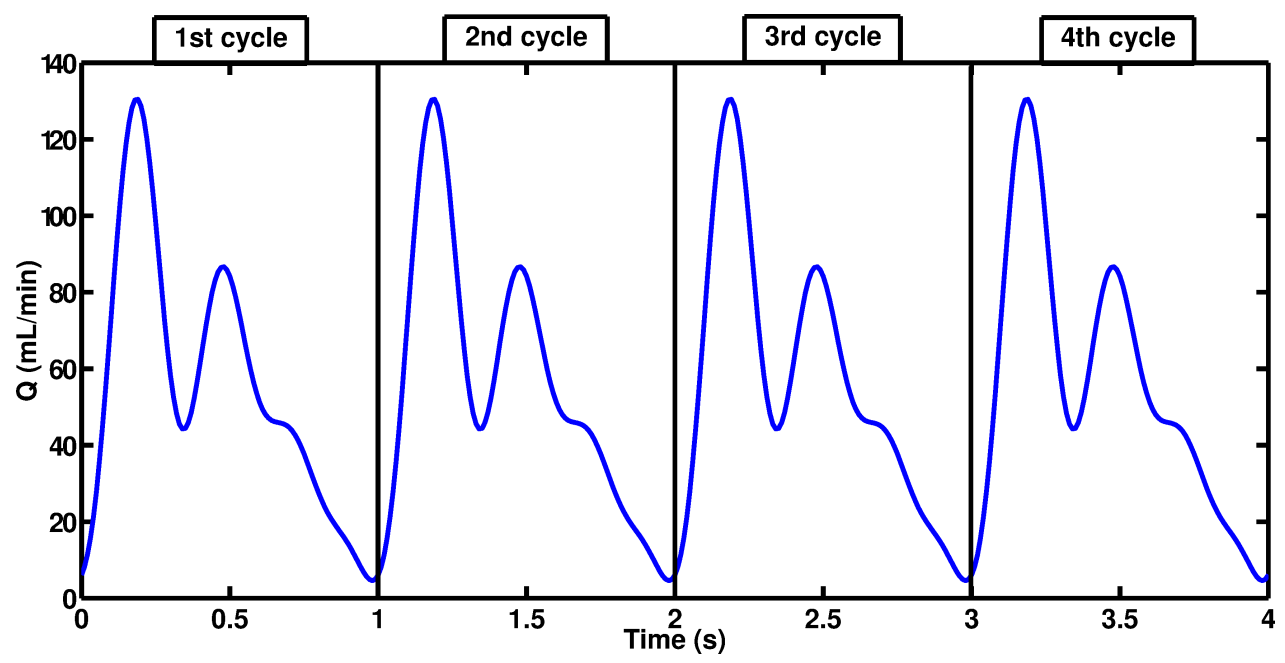


The location where the pressure is analysed is shown in Figure 5.10.

Figure $\mathbf{5 . 1 0}$ - Location where the pressure is analysed.

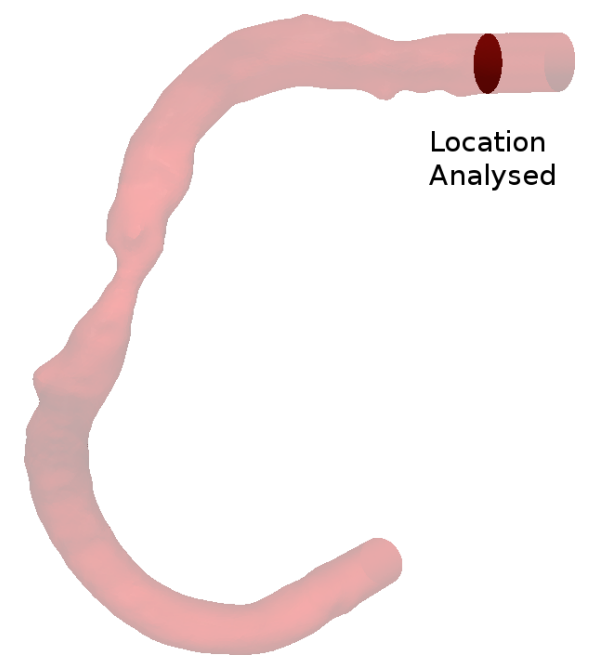

The results are displayed in Table 5.5, where the pressure is compared at the beginning $\left(t_{i}\right)$ and at the end $\left(t_{f}\right)$ of each cycle.

Table 5.5 - Pressure comparison for each cycle.

\begin{tabular}{cccc}
\hline Cycle & \multicolumn{2}{c}{ Pressure (kPa) } & Relative \\
& $\mathbf{t}_{i}$ & $\mathbf{t}_{f}$ & error \% \\
\hline 1 & 0.00 & 11.00 & 100.00 \\
2 & 11.00 & 10.99 & 0.03 \\
3 & 10.99 & 10.99 & 0.00 \\
4 & 10.99 & 10.99 & 0.00 \\
\hline
\end{tabular}

The results show that, the use of only two cycles and the zero initial conditions, explained in Section 3.4, do not affect significantly the results of the pressure field, and therefore the transient effects of this assumption can be neglected.

Thus, in all subsequently computer simulations, just two cycles are considered and only the last cycle is recorded and analysed.

\subsubsection{Mesh convergence test}

To test the mesh convergence, six meshes are created, where only the refinement level of each one is varied. This is performed to evaluate the needed mesh element size, to the computer simulation achieve convergence.

The mesh name used in this dissertation is related to minimal mesh element size, where the most refined is the mesh 015 and the coarser is the mesh 040 . The number of mesh elements are summarized in Table 5.6. 
Table 5.6 - Number of elements of each mesh.

\begin{tabular}{cc}
\hline Mesh Name & Number of Elements \\
\hline 040 & 112820 \\
035 & 159201 \\
030 & 237269 \\
025 & 382867 \\
020 & 684524 \\
015 & 1455693 \\
\hline
\end{tabular}

Figure 5.11 shows the element density of all meshes at the inlet of the coronary.

Figure 5.11 - Different refinement level of the meshes.

(a) 040 .

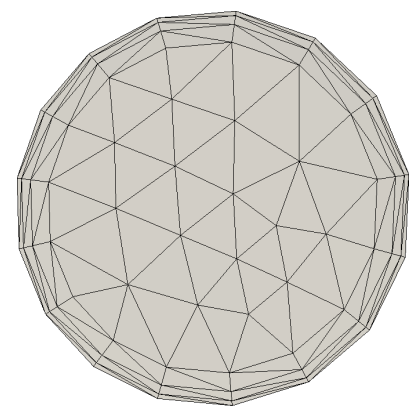

(d) 025 .

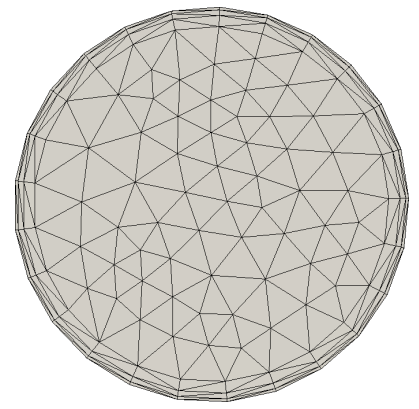

(b) 035 .

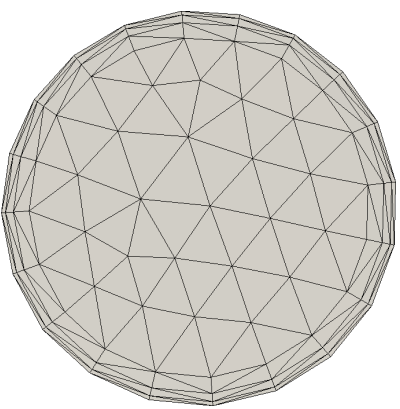

(e) 020 .

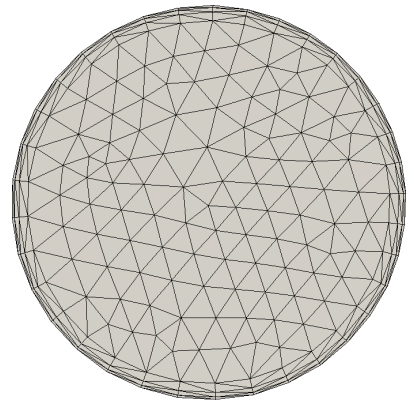

(c) 030 .

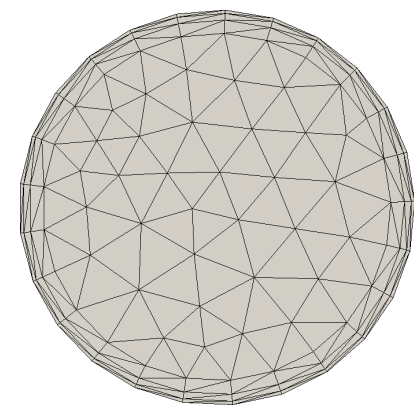

(f) 015 .

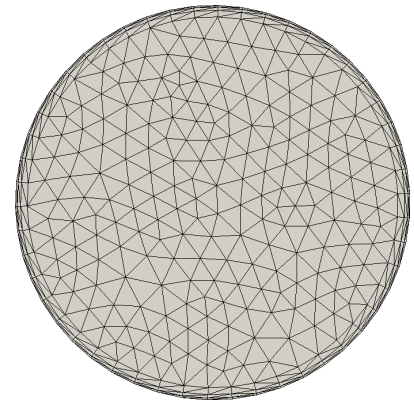

The computer simulations performed in this section considered the non-Newtonian effects of the blood by using the Carreau-Yasuda viscosity model described in Section 2.1, the linear interpolation for the both velocity and pressure (P1P1), and the boundary and initial conditions described in Section 3.4. The ni-FFR is calculated as explained in Section 4.5.

The analysis is performed in the same location shown in Figure 5.10. The results for the pressure and the ni-FFR can be seen in Table 5.7. 
Table 5.7 - Average Pressure for the different meshes.

\begin{tabular}{ccc}
\hline Mesh Name & Pressure (kPa) & ni-FFR \\
\hline mesh040 & $\mathrm{x}$ & $\mathrm{x}$ \\
mesh035 & $\mathrm{x}$ & $\mathrm{x}$ \\
mesh030 & $\mathrm{x}$ & $\mathrm{x}$ \\
mesh025 & $\mathrm{x}$ & $\mathrm{x}$ \\
mesh020 & 11.42 & 0.93 \\
mesh015 & 11.57 & 0.92 \\
\hline
\end{tabular}

$\mathrm{x}=$ did not achieve convergence

The coarser meshes did not achieved convergence, because of the high velocity gradients that occurs after the stenosis. The convergence is only possible for lower flow values at the inlet.

All coronary models generated subsequently used the same mesh element size of the models that achieved convergence.

\subsubsection{Different blood models}

The computer simulations so far used only the non-Newtonian Carreau-Yasuda model for blood. This section shows the results with the other models described in Section 2.1 (Newtonian, Casson and Power-Law). The mesh tested in this section is the mesh name 015 with 1455693 elements. The results can be visualized in Table 5.8.

Table 5.8 - Pressure and ni-FFR results for different blood models.

\begin{tabular}{ccccc}
\hline Model & Carreau-Yasuda & Newtonian & Casson & Power-Law \\
\hline Avg Pressure $(\mathrm{kPa})$ & 11.57 & 11.56 & 11.55 & $\mathrm{x}$ \\
ni-FFR & 0.92 & 0.92 & 0.92 & $\mathrm{x}$ \\
Time $(\mathrm{s})$ & 11764 & 9034 & 11714 & $\mathrm{x}$ \\
\hline \multicolumn{5}{c}{$\mathrm{x}=$ did not achieve convergence }
\end{tabular}

The Power-Law model is the only that has not achieved convergence. All models that converged presented similar results for the pressure and the same result for the ni-FFR. However, in regard the simulation time, the Newtonian model is the fastest as a result of the matrix assemble of the viscosity that only needs to be performed once and outside the time loop, while the non-Newtonian models reassemble the viscosity at each time step.

For the sake of completeness, all blood models are compared by using a lower value of blood flow $(62.5 \mathrm{~mL} / \mathrm{min})$, even though it is not a physiological value. The comparison of all blood models are displayed in Table 5.9. 
Table 5.9 - Pressure and ni-FFR results for different blood models with lower blood flow.

\begin{tabular}{ccccc}
\hline Model & Carreau-Yasuda & Newtonian & Casson & Power-Law \\
\hline Avg Pressure $(\mathrm{kPa})$ & 10.95 & 10.94 & 10.94 & 10.93 \\
ni-FFR & 0.97 & 0.97 & 0.97 & 0.97 \\
Time (s) & 11300 & 8139 & 11263 & 11287 \\
\hline
\end{tabular}

Again, all computer simulations present similar results for the pressure, same result for the ni-FFR, and the Newtonian model presents the lower computational time.

The velocity profile also has not changed significantly among the blood models, however if the velocity is a variable of interest, a more in-depth study should be performed.

Due to the results obtained in this section, the Newtonian model is the model used in the ni-FFR evaluation.

\subsubsection{Sensitivity analyses of the boundary conditions}

To evaluate the behavior of the solver implemented, different boundary conditions are applied at the inlet (velocity) and the outlet (pressure) of the model.

\section{Inlet analysis}

At the inlet, the simulations started with half of the blood flow rate value at hyperemia $\left(\frac{1}{2} 125 \mathrm{~mL} / \mathrm{min}=62.5 \mathrm{~mL} / \mathrm{min}\right)$ and are raised until the solver presented divergence issues. The pressure is kept constant and equal to $10.66 \mathrm{kPa}(80 \mathrm{~mm} \mathrm{Hg})$.

The location analysed is the same of the other simulations (Figure 5.10), the blood model used is the Newtonian. The pressure and ni-FFR results, for different inlet blood flow, are presented in Table 5.10.

Table 5.10 - Pressure and ni-FFR results considering different blood flow at the inlet.

\begin{tabular}{cccc}
\hline $\mathbf{v}_{\text {factor }}$ & Flow (mL/min) & Pressure (kPa) & ni-FFR \\
\hline 0.50 & 62.50 & 10.95 & 0.97 \\
0.75 & 93.75 & 11.21 & 0.95 \\
1.00 & 125.00 & 11.57 & 0.92 \\
1.10 & 137.50 & 11.72 & 0.91 \\
1.20 & 150.00 & 11.89 & 0.90 \\
1.25 & 156.25 & $\mathrm{x}$ & $\mathrm{x}$ \\
\hline \multicolumn{5}{c}{$\mathrm{x}=$ did not achieve convergence }
\end{tabular}

The relationship between the blood flow rate and the ni-FFR is practically linear in the range considered. This statement is also found in Pijls (2013) and in Govindaraju et al. (2013), showing that the simulations performed are in agreement with the FFR concepts. 
In the computer simulations using different blood models the ni-FFR results are the same, nevertheless only the Newtonian and the Carreau-Yasuda models achieve convergence for the blood flow of $150 \mathrm{~mL} / \mathrm{min}$ ( $v_{\text {factor }}=1.2$ ), showing that the Carreau-Yasuda model is more stable than the other non-Newtonian models. The Newtonian model is still the one that took less time to finish the simulation.

\section{Outlet analysis}

This model only has one inlet and one outlet. The variation of the pressure at the outlet boundary condition only produced different inlet pressure and kept the gradient between the inlet and the outlet the same. However, that affected the calculation of the ni-FFR, because it changed the values of the pressure at the inlet, even though it is not significant. The results can be seen in Table 5.11, where the mean blood flow rate is kept equal to $125.00 \mathrm{~mL} / \mathrm{min}$ for all simulations and only the pressure at the outlet is varied.

Table 5.11 - Pressure and ni-FFR for different outlet boundary condition.

\begin{tabular}{|c|c|c|c|}
\hline \multicolumn{2}{|c|}{ Outlet Pressure } & $\begin{array}{c}\text { Pressure } \\
\text { kPa }\end{array}$ & ni-FFR \\
\hline 70 & 9.33 & 10.23 & 0.91 \\
\hline 75 & 10.00 & 10.90 & 0.92 \\
\hline 80 & 10.66 & 11.56 & 0.92 \\
\hline 85 & 11.33 & 12.23 & 0.93 \\
\hline 90 & 12.00 & 12.90 & 0.93 \\
\hline
\end{tabular}

\subsubsection{Sensitivity analyses of the boundary conditions for multiple outlets}

In order to study a model with multiple outlets, a left coronary model is generated from medical images as can be visualized in Figure 5.12.

Figure 5.12 - Left coronary model.

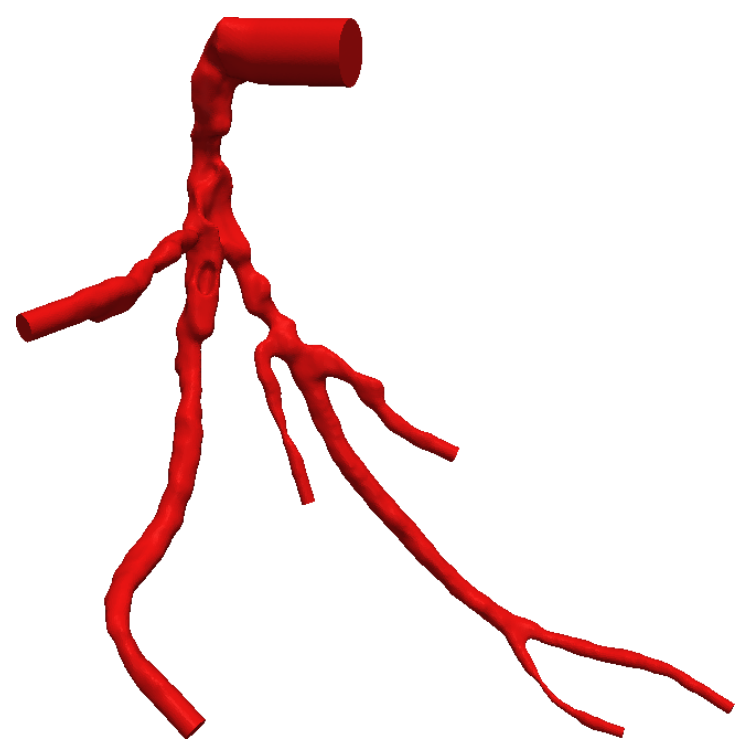


This model has 1620483 tetrahedral elements, and the regions where the pressure is analysed are shown in Figure 5.13.

Figure 5.13 - Locations analysed in the left coronary model.

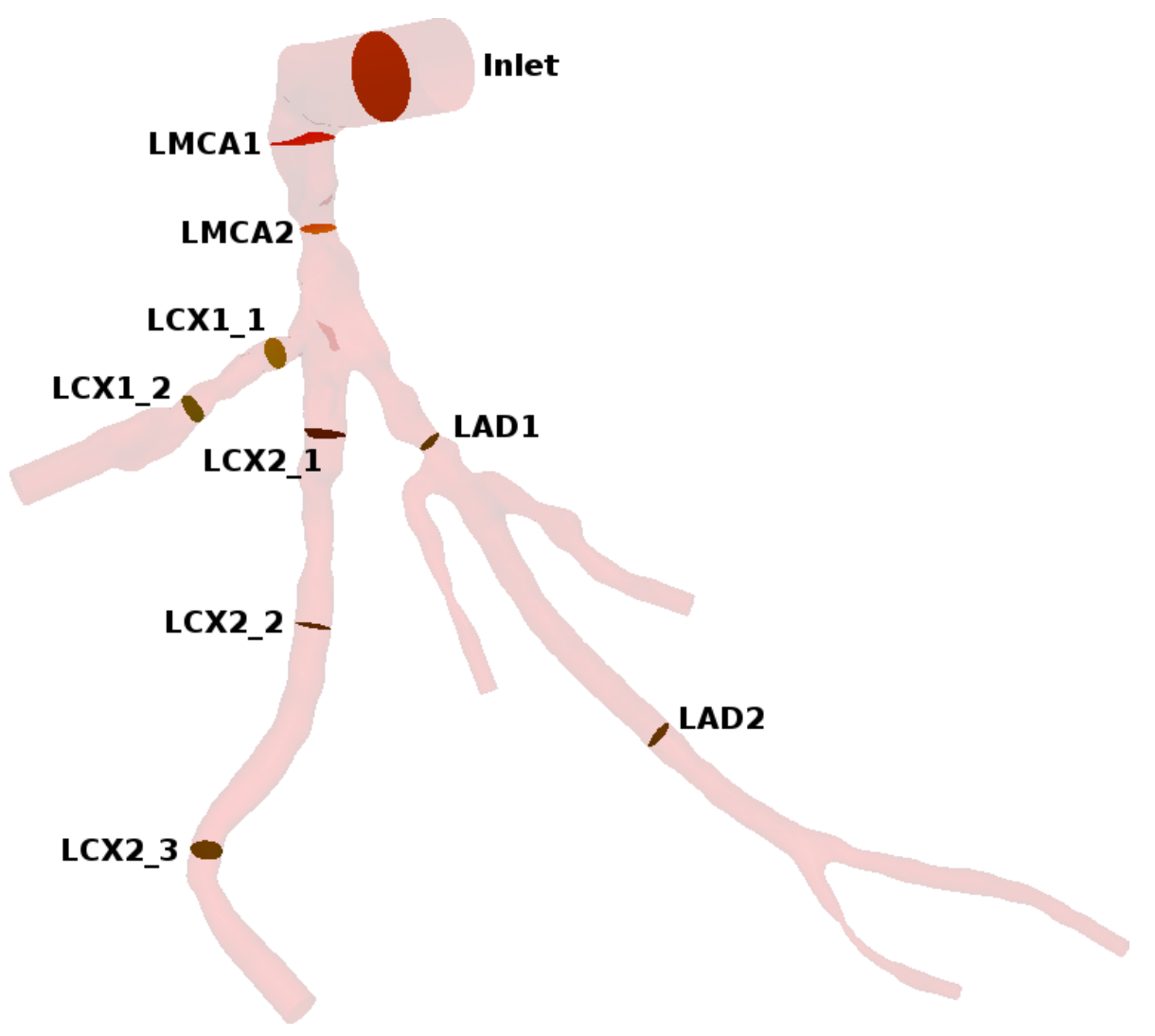

The names of the regions are derived from the location of the coronary tree, where LMCA is the Left Main Coronary Artery, LCX the Left Circumflex artery, and LAD the Left Anterior Descending artery.

The hypotheses used in the computer simulations are summarized below:

- Newtonian model of the blood.

- Linear interpolation of velocity and pressure (P1P1).

- Heart rate of $1 \mathrm{~Hz}$.

- Transient parabolic inlet profile (Equation 3.21) with mean blood flow of $187.5 \mathrm{~mL} / \mathrm{min}$.

- Constant value of $10.66 \mathrm{kPa}(80 \mathrm{~mm} \mathrm{Hg})$ for the pressure at the outlets.

- No-slip condition at the wall.

- Two cardiac cycles are simulated and only the last one is analysed.

The pressure and the ni-FFR results, at each region, can be visualized in Table 5.12. 
Table 5.12 - Pressure and ni-FFR results for the LMCA.

\begin{tabular}{ccc}
\hline Location & Pressure (kPa) & ni-FFR \\
\hline Inlet & 12.18 & 1.00 \\
LMCA1 & 12.04 & 0.99 \\
LMCA2 & 11.56 & 0.95 \\
LAD1 & 11.23 & 0.92 \\
LAD2 & 11.26 & 0.92 \\
LCX1_1 & 10.98 & 0.90 \\
LCX1_2 & 10.68 & 0.88 \\
LCX2_1 & 11.65 & 0.96 \\
LCX2_2 & 11.34 & 0.93 \\
LCX2_3 & 11.13 & 0.91 \\
\hline
\end{tabular}

The lower value of the ni-FFR happened at the LCX1_2 and is equal to 0.88 , however this value was still higher than the critical ischemic value of 0.80 .

\section{Inlet analysis}

Once more the mean blood flow at the inlet is varied until the solver presented divergence issues, the ni-FFR results at each location are displayed in Table 5.13.

Table 5.13 - ni-FFR results considering different blood flow at the inlet for the multiple outlets case.

\begin{tabular}{|c|c|c|c|c|c|c|c|c|c|c|}
\hline \multirow{2}{*}{$\mathbf{v}_{\text {factor }}$} & \multirow{2}{*}{$\begin{array}{c}\text { Blood } \\
\text { Flow } \\
\left(\mathrm{mm}^{3} / \mathrm{s}\right)\end{array}$} & \multicolumn{2}{|c|}{ LMCA } & \multicolumn{2}{|c|}{ LAD } & \multicolumn{2}{|c|}{ LCX1 } & \multicolumn{3}{|c|}{ LCX2 } \\
\hline & & 1 & 2 & 1 & 2 & 1 & 2 & 1 & 2 & 3 \\
\hline 1.40 & 175.00 & 0.99 & 0.95 & 0.93 & 0.93 & 0.91 & 0.89 & 0.96 & 0.94 & 0.92 \\
\hline 1.50 & 187.50 & 0.99 & 0.95 & 0.92 & 0.92 & 0.90 & 0.88 & 0.96 & 0.93 & 0.91 \\
\hline 1.60 & 200.00 & 0.99 & 0.94 & 0.91 & 0.92 & 0.89 & 0.86 & 0.95 & 0.92 & 0.91 \\
\hline 1.70 & 212.50 & 0.99 & 0.94 & 0.91 & 0.91 & 0.88 & 0.86 & 0.95 & 0.92 & 0.90 \\
\hline 1.80 & 225.00 & 0.98 & 0.93 & 0.90 & 0.90 & 0.87 & 0.84 & 0.94 & 0.91 & 0.89 \\
\hline 1.85 & 231.25 & 0.98 & 0.93 & 0.89 & 0.90 & 0.86 & 0.84 & 0.94 & 0.91 & 0.88 \\
\hline 1.90 & 237.50 & $x$ & $x$ & $x$ & $x$ & $x$ & $x$ & $x$ & $x$ & $x$ \\
\hline
\end{tabular}

The relationship between the ni-FFR and the blood flow is almost linear, the same behavior presented by the right coronary model with one inlet and one outlet.

In the left coronary tests, the velocity factor could be raised to higher values than the right coronary tests, because the different inlet radius of the models. The left coronary model used in the computer simulation tests has $r_{\text {left }}=2.69 \mathrm{~mm}$ and the right coronary model $r_{\text {right }}=1.80 \mathrm{~mm}$. The model with the higher radius decrease the maximum velocity at the inlet to achieve the same mean blood flow and allows higher velocity factors in the computer simulations, before the solver presents divergence problems. 


\section{Outlet analysis}

The pressure boundary condition are kept constant an equal to $10.66 \mathrm{kPa}$ or $80 \mathrm{~mm} \mathrm{Hg}$ for all outlets in the blood flow variation study. For the sensitivity analysis of the pressure boundary condition, first it is considered the same value of pressure for all outlets and then different values for each outlet. Table 5.14 shows the ni-FFR results using different pressure values for all outlets.

Table 5.14 - ni-FFR results considering the same pressure at the outlets.

\begin{tabular}{ccccccccccc}
\hline $\begin{array}{c}\text { Pressure } \\
(\mathbf{m m H g})\end{array}$ & $\begin{array}{c}\text { Pressure } \\
(\mathbf{k P a})\end{array}$ & \multicolumn{1}{c}{ LMCA } & \multicolumn{1}{c}{ LAD } & \multicolumn{2}{c}{ LCX1 } & \multicolumn{3}{c}{ LCX2 } \\
& $\mathbf{2}$ & $\mathbf{1}$ & $\mathbf{2}$ & $\mathbf{1}$ & $\mathbf{2}$ & $\mathbf{1}$ & $\mathbf{2}$ & $\mathbf{3}$ \\
\hline 70 & 9.33 & 0.99 & 0.94 & 0.91 & 0.92 & 0.89 & 0.86 & 0.95 & 0.92 & 0.90 \\
75 & 10.00 & 0.99 & 0.95 & 0.92 & 0.92 & 0.90 & 0.87 & 0.95 & 0.93 & 0.91 \\
80 & 10.67 & 0.99 & 0.95 & 0.92 & 0.92 & 0.90 & 0.88 & 0.96 & 0.93 & 0.91 \\
85 & 11.33 & 0.99 & 0.95 & 0.93 & 0.93 & 0.91 & 0.88 & 0.96 & 0.93 & 0.92 \\
90 & 12.00 & 0.99 & 0.95 & 0.93 & 0.93 & 0.91 & 0.89 & 0.96 & 0.94 & 0.92 \\
\hline
\end{tabular}

In order to use different pressure values for each boundary, the outlets are numbered as shown in Figure 5.14.

Figure 5.14 - Outlets numbers.

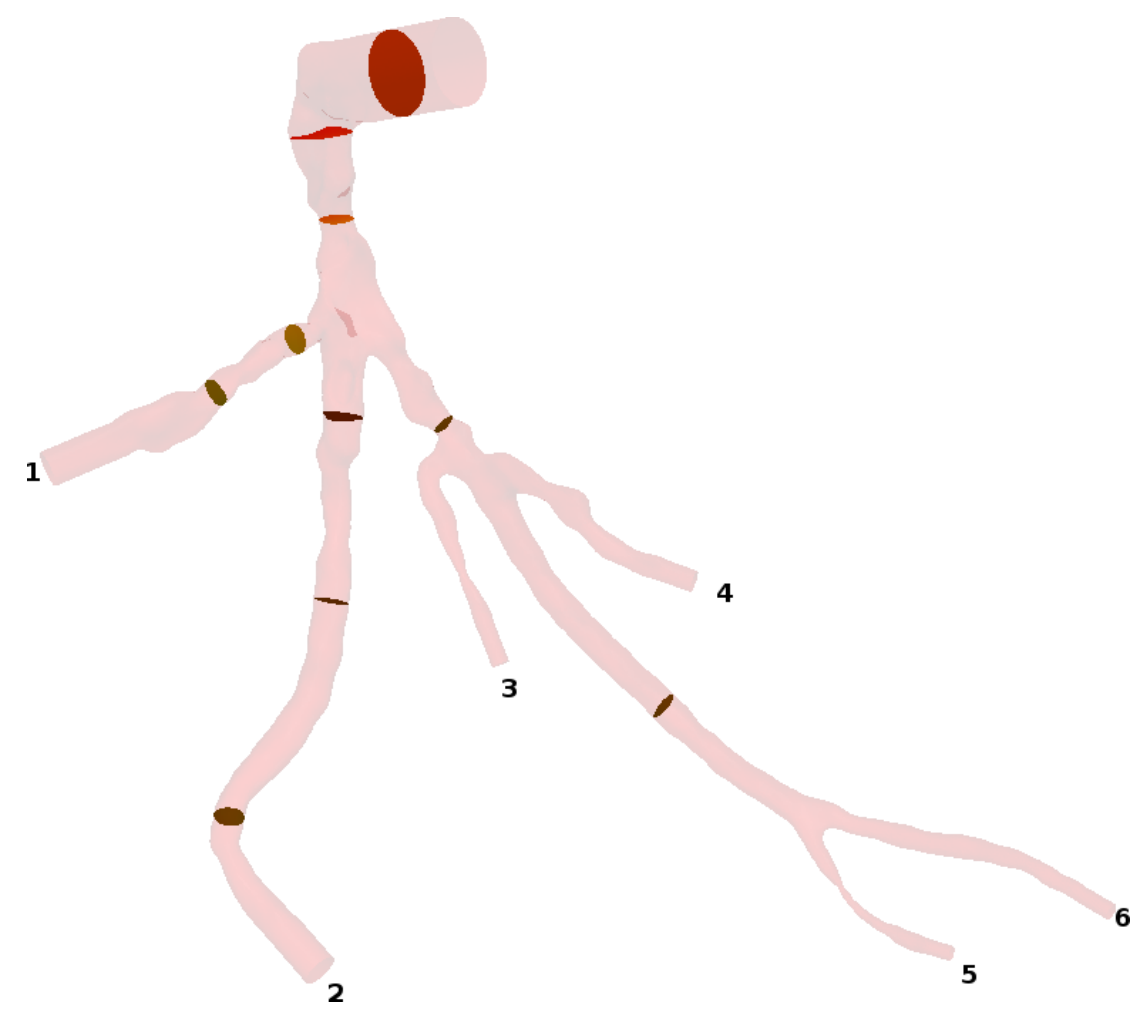

It is assumed that outlets with radius minor than $1 \mathrm{~mm}$ are already at the minimum pressure, therefore, only outlets 1 and 2 are varied, all others are considered equal to $10.67 \mathrm{kPa}$ or $80 \mathrm{~mm} \mathrm{Hg}$. 
The ni-FFR results can be visualized in Table 5.15.

Table 5.15 - ni-FFR results for different pressure in outlets 1 and 2 .

\begin{tabular}{|c|c|c|c|c|c|c|c|c|c|c|}
\hline \multirow{2}{*}{$\begin{array}{l}\text { Outlet } 1 \\
(\mathrm{kPa})\end{array}$} & \multirow{2}{*}{$\begin{array}{c}\text { Outlet } 2 \\
(\mathrm{kPa})\end{array}$} & \multicolumn{2}{|c|}{ LMCA } & \multicolumn{2}{|c|}{ LAD } & \multicolumn{2}{|c|}{ LCX1 } & \multicolumn{3}{|c|}{ LCX2 } \\
\hline & & 1 & 2 & 1 & 2 & 1 & 2 & 1 & 2 & 3 \\
\hline 10.67 & 11.33 & 0.99 & 0.95 & 0.91 & 0.92 & 0.89 & 0.86 & 0.96 & 0.95 & 0.94 \\
\hline 11.33 & 10.67 & 0.99 & 0.95 & 0.91 & 0.92 & 0.92 & 0.91 & 0.95 & 0.92 & 0.90 \\
\hline 11.33 & 11.33 & 0.99 & 0.95 & 0.91 & 0.91 & 0.92 & 0.90 & 0.96 & 0.94 & 0.93 \\
\hline 10.67 & 10.00 & 0.99 & 0.95 & 0.93 & 0.93 & 0.91 & 0.89 & 0.95 & 0.91 & 0.89 \\
\hline 10.00 & 10.67 & 0.99 & 0.95 & 0.93 & 0.93 & 0.87 & 0.84 & 0.96 & 0.94 & 0.92 \\
\hline 10.00 & 10.00 & 0.99 & 0.95 & 0.93 & 0.93 & 0.88 & 0.85 & 0.95 & 0.92 & 0.90 \\
\hline
\end{tabular}

The pressure variation of the outlets 1 and 2 has not affected the ni-FFR results in the LMCA and barely influenced the LAD ni-FFR results. The major influence in the ni-FFR happened in the LCX branches, this is expected because outlets 1 and 2 are associated with outlets of LCX1 and LCX2, respectively. The lower ni-FFR value obtained is 0.84 at the LCX1_2 for the case considering the pressure of $10.00 \mathrm{kPa}(75 \mathrm{~mm} \mathrm{Hg})$ at outlet 1 and pressure of $10.67 \mathrm{kPa}(80 \mathrm{~mm} \mathrm{Hg})$ for outlet 2 .

The pressure at the outlets is a parameter highly variable for each patient and it influences the ni-FFR values. However, this dissertation uses the value of $10.67 \mathrm{kPa}(80 \mathrm{~mm} \mathrm{Hg})$ for all outlets boundary condition in the non-invasive FFR computer simulations, due to the difficult to establish a correlation between the pressure value and the patient. In order to minimize the effect of this assumption, models considering almost the entire coronary tree can be used in the ni-FFR evaluation (WELLNHOFER et al., 2010). 


\section{RESULTS}

In this chapter the results of the ni-FFR are presented and compared with the invasive FFR medical procedure.

In order to validate the method implemented, the results obtained from the computer simulations are compared with the invasive FFR procedure, that occurred in the facilities of Institute Dante Pazzanese of Cardiology of São Paulo and is supervised by the cardiologist Dr. Tiago Senra.

\subsection{Comparison of the ni-FFR with the invasive FFR}

Given the results obtained in the last chapter, the computer simulations performed in the calculation of the ni-FFR consider the hypotheses summarized below:

- Newtonian model of the blood.

- Linear interpolation of velocity and pressure (P1P1).

- Heart rate of $1 \mathrm{~Hz}$.

- Transient parabolic inlet profile (Equation 3.21) with mean blood flow of $187.5 \mathrm{~mL} / \mathrm{min}$.

- Constant value of $10.66 \mathrm{kPa}(80 \mathrm{~mm} \mathrm{Hg})$ for the pressure at the outlets.

- No-slip condition at the wall.

- Two cardiac cycles are simulated and only the last one is analysed.

Three coronary models are generated to perform the computer simulations, however only one of the FFR values is actually acquired by the Institute Dante Pazzanese. Dr. Tiago Senra provided two medical images of patients that had previously been submitted to the invasive exam, where only the FFR values are available and the exact locations analysed are unknown. For these two patients, the comparison is going to consider the lowest FFR value in the ramification analysed.

\subsubsection{First patient}

The left coronary model used in the non-invasive FFR evaluation has 2234685 elements and can be visualized in Figure 6.1. 
Figure 6.1 - First model used in the non-invasive FFR evaluation.

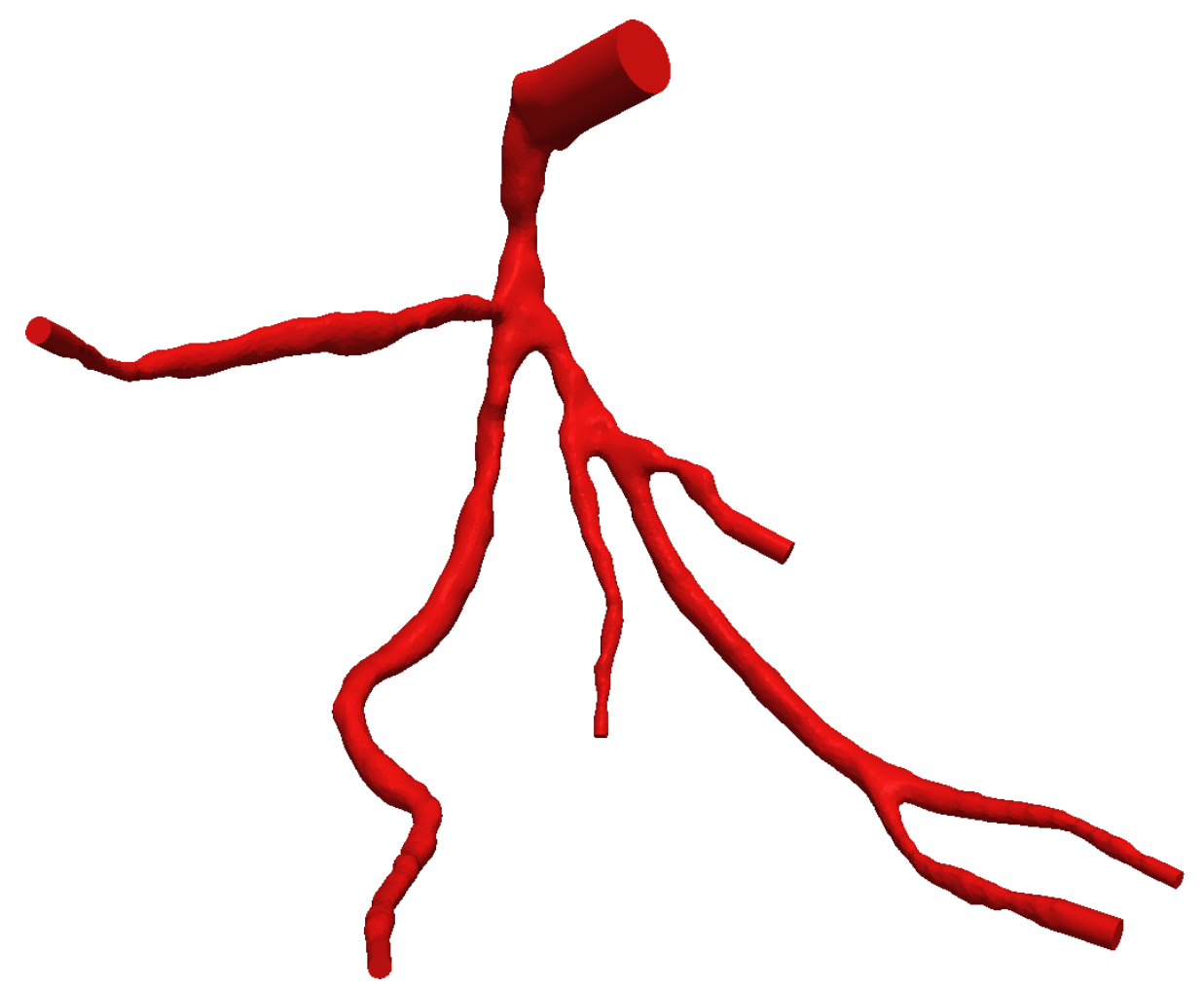

This model is obtained from the same medical images used in the simulation tests, however, has longer ramifications of the LCX.

This patient has calcifications inside the arterial wall, near the inlet region. Figure 6.2 shows the calcifications highlighted in blue.

Figure 6.2 - Calcifications present in the first model.

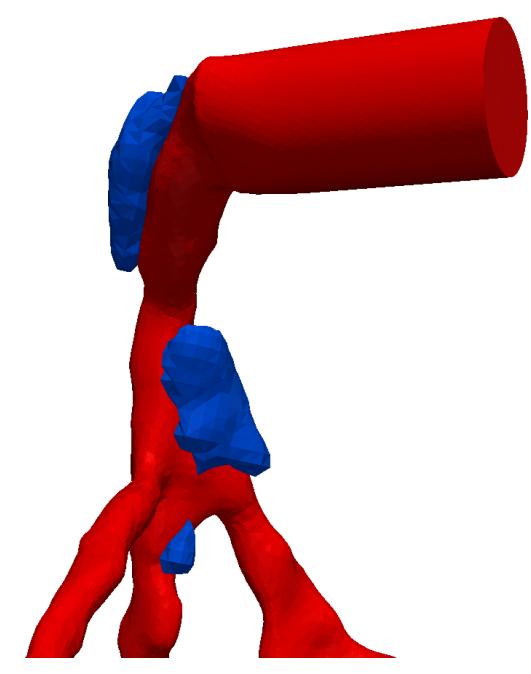

The calcifications are not part of the model used, they are shown just for better visualization of how the coronaries are affected by the atherosclerosis. The model used in the computer simulations consider only the fluid part. 
The locations where the results are analysed are shown in Figure 6.3.

Figure 6.3 - First model locations used in the ni-FFR evaluation.

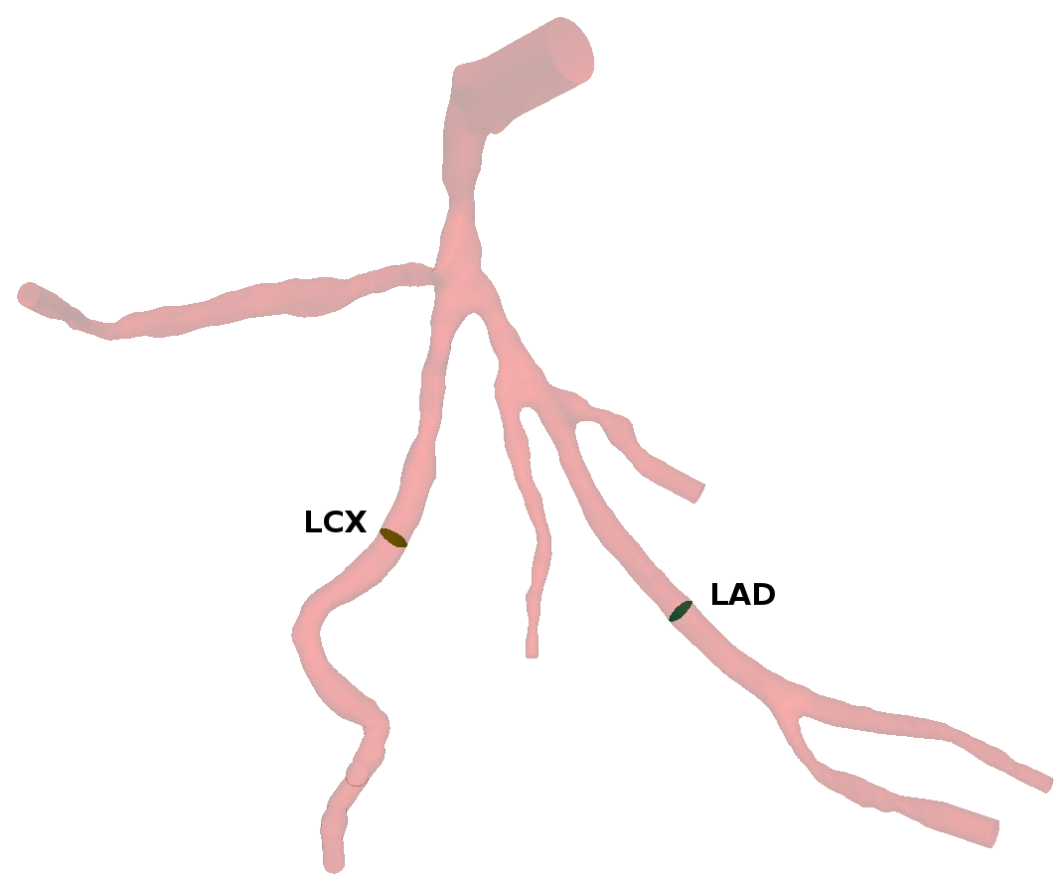

These locations are an estimation of where the FFR is calculated, they are showed by the cardiologist in the model and the exact location could not be precised. The use of an approximated location does not change significantly the non-invasive FFR results, because the regions analysed do not have ramifications or stenosis in the vicinities.

The pressure monitor results of the invasive FFR, in the left coronary ramification of the first patient, are displayed in Figures 6.4 and 6.5.

Figure 6.4 - Invasive FFR results measured in the LAD.

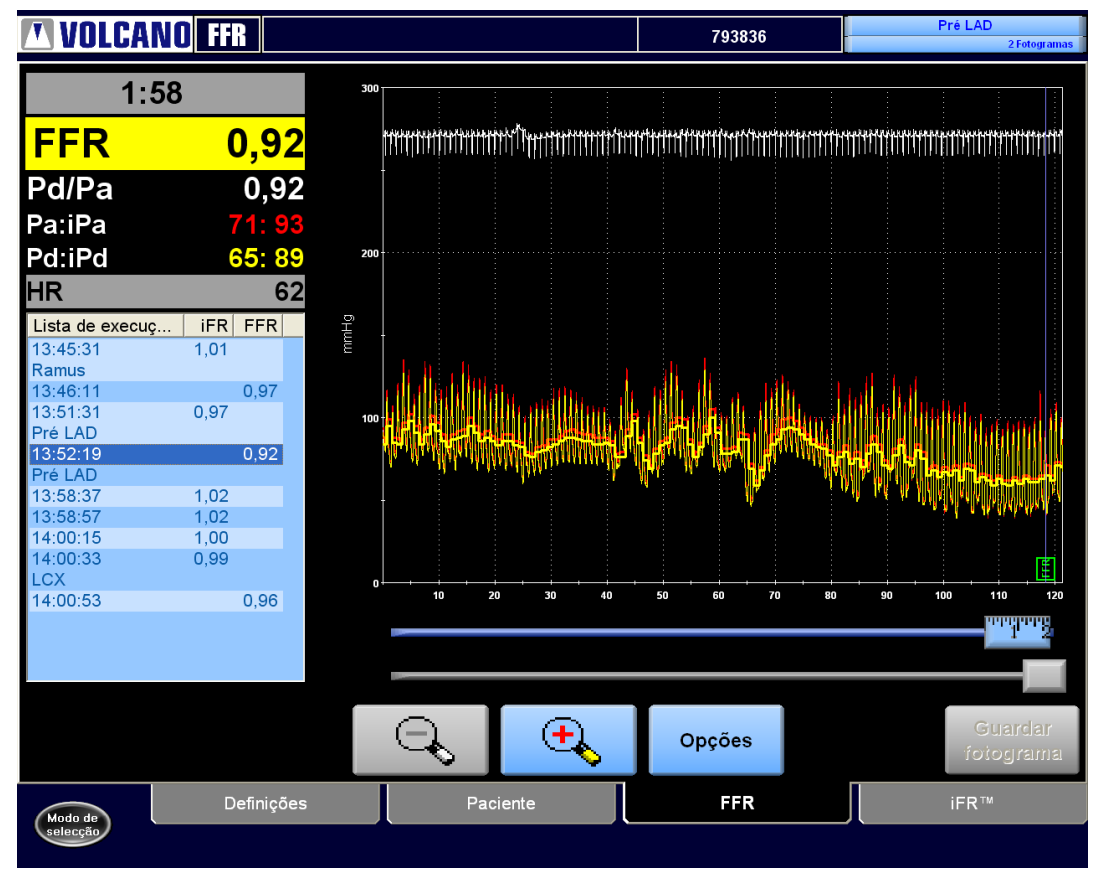


Figure 6.5 - Invasive FFR results measured in the LCX.

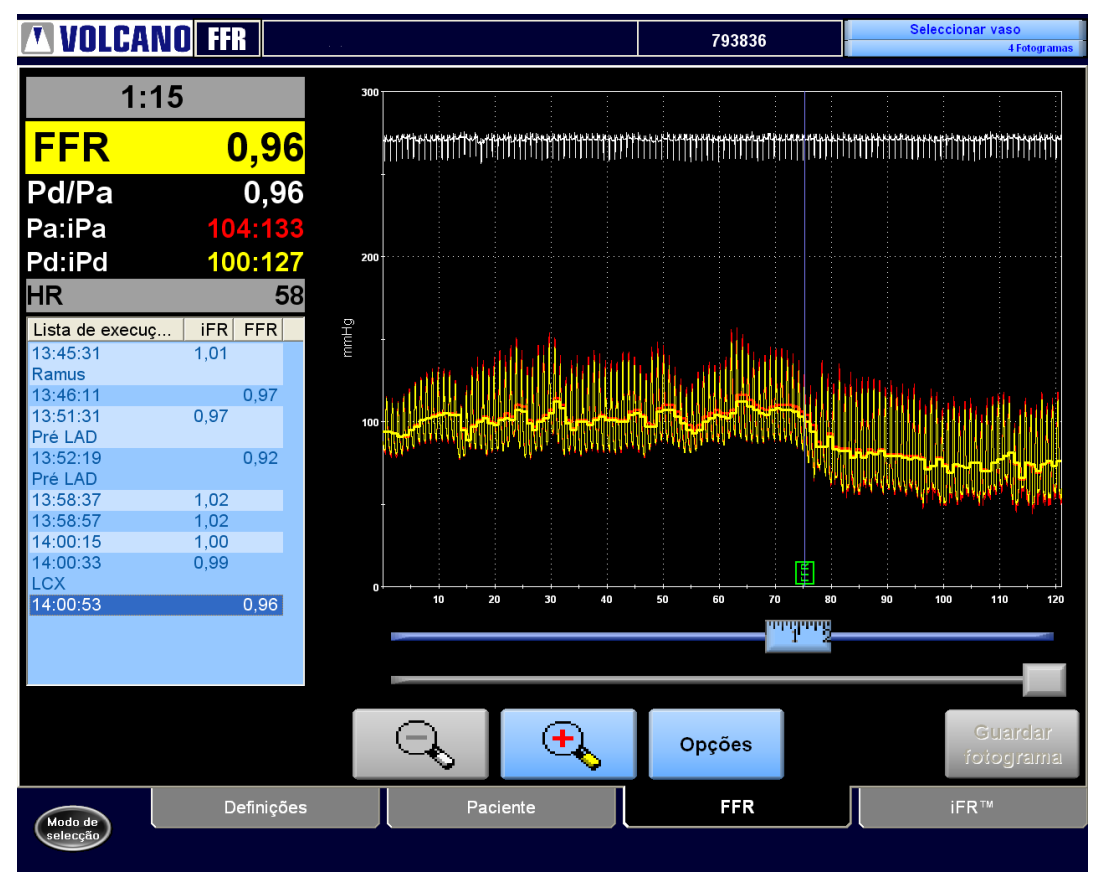

The results of the comparison of the ni-FFR with the invasive medical procedure are displayed in Table 6.1.

Table 6.1 - ni-FFR comparison of the first model.

\begin{tabular}{cccc}
\hline & ni-FFR & Invasive FFR & Error (\%) \\
\hline LAD & 0.91 & 0.92 & 1.09 \\
LCX & 0.96 & 0.96 & 0.43 \\
\hline
\end{tabular}

The ni-FFR evaluation shows to be a good estimation of the FFR, where the major relative error presented is approximately $1 \%$. The error associated to the LCX ramification is related to the decimal approximation used, the computer simulation produced a ni-FFR value of 0.9559 . The difference between the results of this simulation and the one performed at Section 5.2.5, model with shorter ramifications, shows that the method is dependent on the geometry considered. More specifically, is dependent of the size of the ramifications considered.

By performing the computer simulation with a lower blood flow of $175 \mathrm{~mL} / \mathrm{min}$, instead of $187.5 \mathrm{~mL} / \mathrm{min}$ improved the outcome of the computer simulations and produced ni-FFR results of 0.92 and 0.96 for the LAD and LCX, respectively. Probably this patient has a lower blood flow than the average human being or a different value pressure condition should be applied, nevertheless the ni-FFR evaluation by considering the blood flow $187.5 \mathrm{~mL} / \mathrm{min}$ produced good results. 


\subsubsection{Second Patient}

The second model generated has 3714915 elements and can be seen in Figure 6.6.

Figure 6.6 - Second model used in the ni-FFR evaluation.

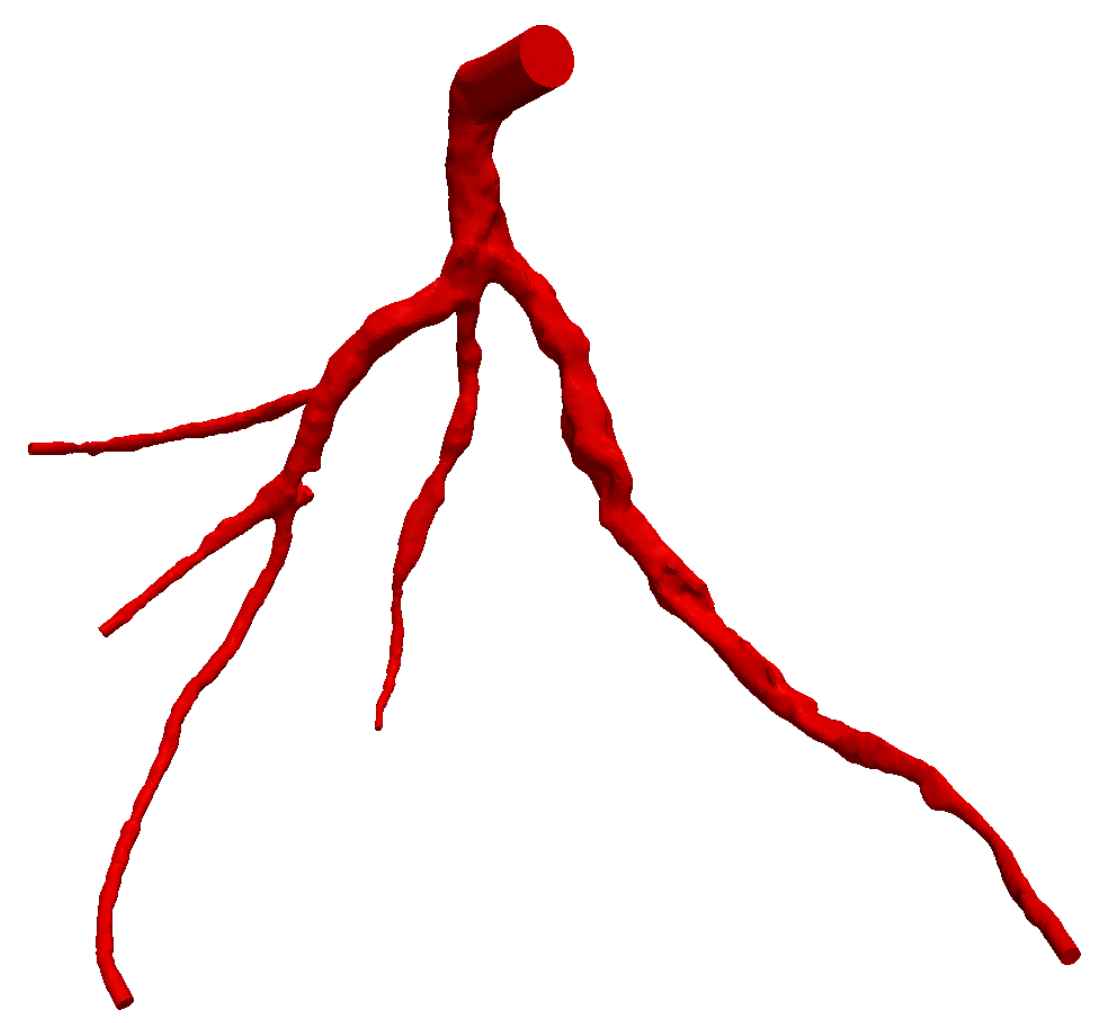

This model presented some geometry irregularities, shown in detail in Figure 6.7, due to the presence of large calcifications.

Figure 6.7 - Detail of the geometry irregularities of the second model.

(a) LCX.

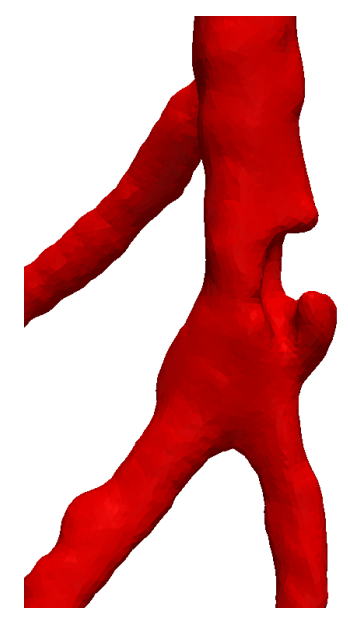

(b) LAD.

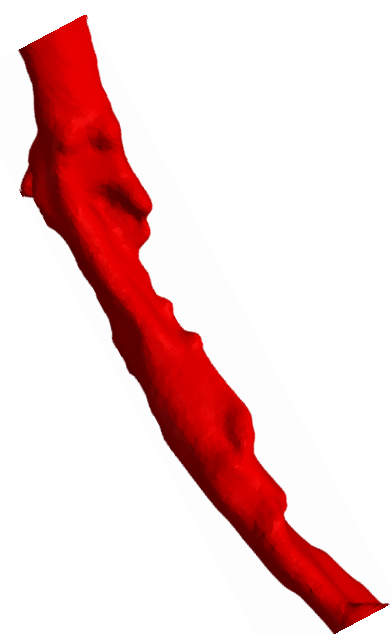

Because of these irregularities, the acquisition of the model is more difficult, and more time is needed to prepare the model to perform the computer simulations. 
For the sake of clarity, Figure 6.8 shows the calcification regions highlighted in blue.

Figure 6.8 - Second model with the calcifications.

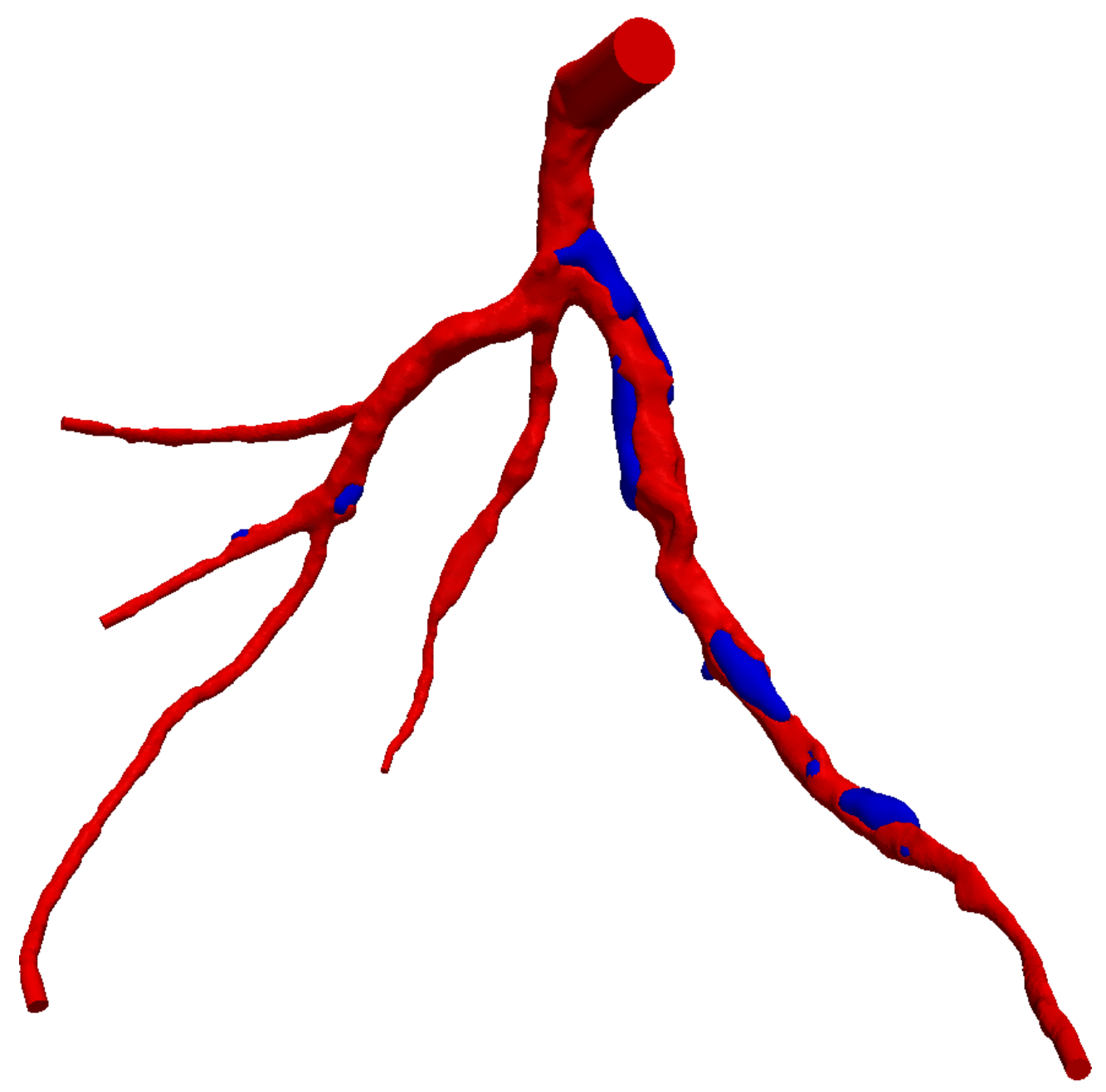

The result of the ni-FFR comparison of the second model is presented in Table 6.2.

Table 6.2 - ni-FFR comparison of the second model.

\begin{tabular}{cccc}
\hline & ni-FFR & Invasive FFR & Error (\%) \\
\hline LAD & 0.75 & 0.71 & 5.63 \\
\hline
\end{tabular}

The second model presented an error of approximately $5 \%$. However, the computer simulation still predicts a value lower than the critical ischemic value of 0.80 , the cut off value of the FFR used in the decision making process at the clinical practice.

This patient left coronary artery is severely compromised by the atherosclerosis in different regions of the coronary tree. Probably this patient went through a revascularization procedure, such as stent placement or by-pass surgery, in view of the invasive FFR being lower than 0.8. 


\subsubsection{Third Patient}

Figure 6.9 shows the third model that has been generated, it has 3176767 tetrahedra elements.

Figure 6.9 - Third model used in the ni-FFR evaluation.

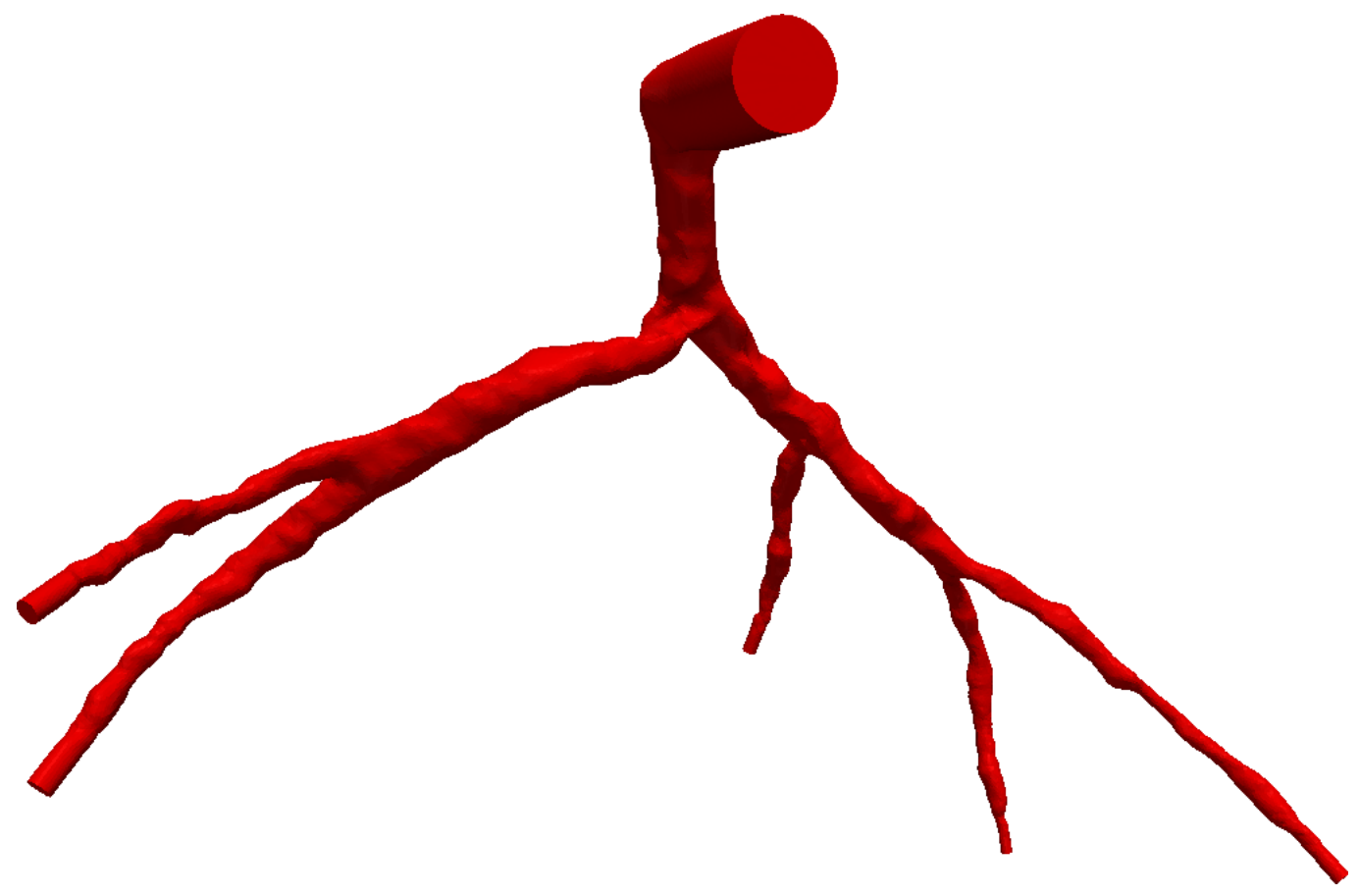

This patient calcifications are localized near the main bifurcation of the left coronary artery as shown in Figure 6.10.

Figure 6.10 - Third model with calcifications.

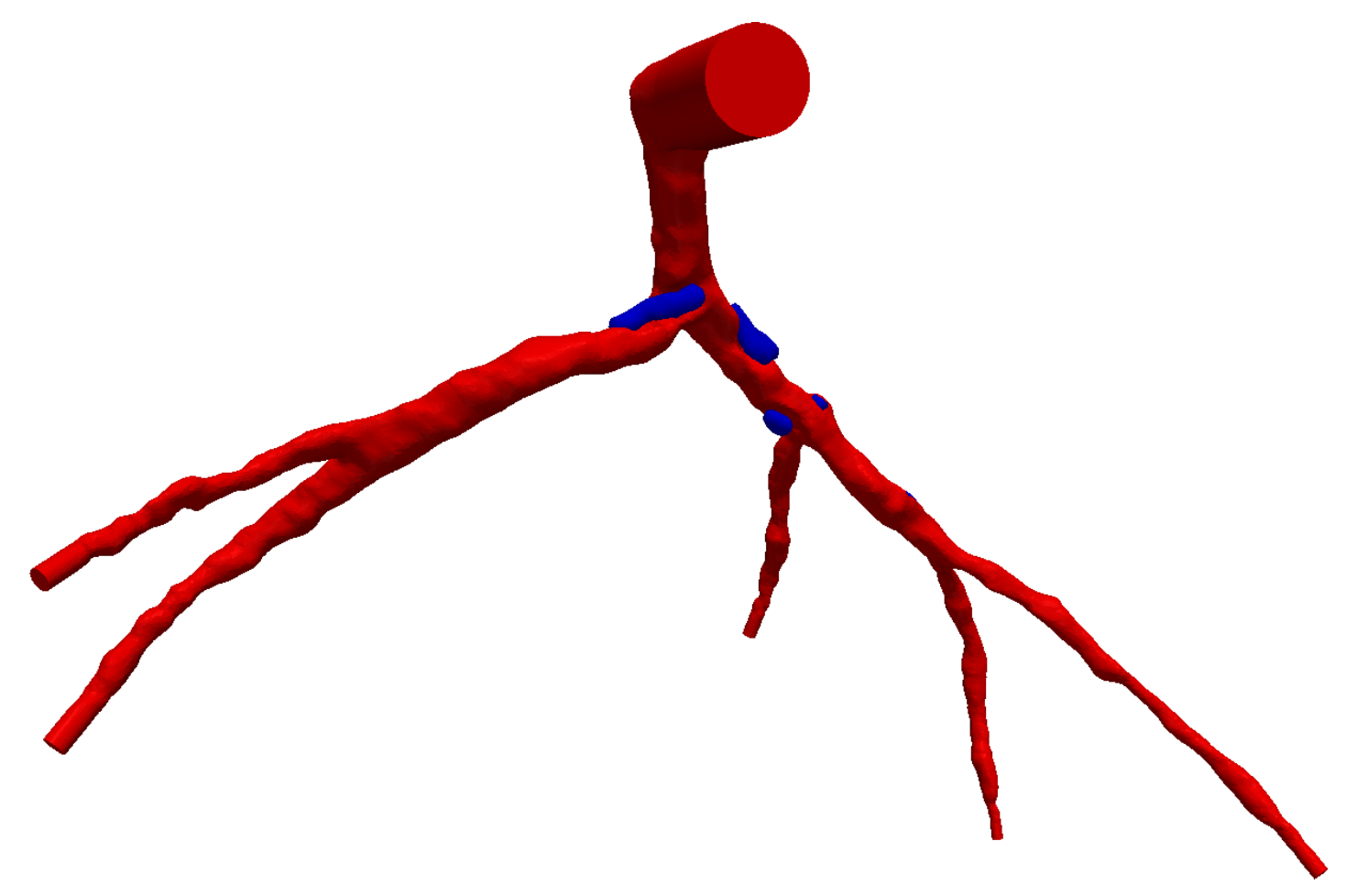


The results of the ni-FFR comparison of the third model are displayed in Table 6.3.

Table 6.3 - ni-FFR comparison of the third model.

\begin{tabular}{cccc}
\hline & ni-FFR & Invasive FFR & Error (\%) \\
\hline LAD & 0.88 & 0.85 & 3.53 \\
LCX & 0.95 & 0.94 & 1.06 \\
\hline
\end{tabular}

The third patient presented a higher error of the ni-FFR in the LAD than in the LCX. One possible cause for this can be the higher number of ramifications in the LAD.

\subsection{Discussion}

The method used in the non-invasive evaluation of the FFR with the aid of computer simulation (ni-FFR) presented differences when compared with the invasive FFR. This can be explained by the hypotheses and assumptions used, such as, the linear interpolation of the pressure and the velocity, the constant pressure boundary condition of $80 \mathrm{~mm} \mathrm{Hg}$, and the mean blood flow of $187.5 \mathrm{~mL} / \mathrm{min}$ at the inlet, the ni-FFR hypotheses used are summarized below:

- Newtonian model of the blood.

- Linear interpolation of velocity and pressure (P1P1).

- Heart rate of $1 \mathrm{~Hz}$ (60 beats per minute).

- Transient parabolic inlet profile (Equation 3.21) with mean blood flow of $187.5 \mathrm{~mL} / \mathrm{min}$.

- Constant value of $10.66 \mathrm{kPa}(80 \mathrm{~mm} \mathrm{Hg})$ for the pressure at the outlets.

- No-slip condition at the wall.

- Two cardiac cycles are simulated and only the last one is analysed.

Table 6.4 summarizes all ni-FFR results performed.

Table $6.4-$ ni-FFR results of all patients.

\begin{tabular}{ccccc}
\hline Patient & Coronary & ni-FFR & Invasive FFR & Error \\
\hline \multirow{2}{*}{ First } & LAD & 0.91 & 0.92 & 1.09 \\
& LCX & 0.96 & 0.96 & 0.43 \\
Second & LAD & 0.75 & 0.71 & 5.63 \\
& & & & \\
\multirow{2}{*}{ Third } & LAD & 0.88 & 0.85 & 3.53 \\
& LCX & 0.95 & 0.94 & 1.06 \\
\hline
\end{tabular}


The method used in this dissertation presented a higher error of $5.63 \%$ in the second patient, the case with the more obstructed coronary and large calcifications. However, the method could predict a ni-FFR value lower than the critical ischemic value of 0.80 .

The lower error $(0.43 \%)$ occurred in the LCX of the first patient, the case the invasive FFR being measured by the Institute Dante Pazzanese of Cardiology of São Paulo and where the locations analysed could be approximated with the doctor information.

The method discussed and analysed in this dissertation shows to be feasible in the analysis of the severity of obstructed coronary arteries, at least for the three cases studied. It could predict, with a maximum error of approximately $6 \%$, the FFR of patients in a non-invasive fashion by using computer simulations. 


\section{CONCLUSIONS}

The method used in this dissertation showed to be a good approach to perform patient-specific computer blood flow simulations in stenosed coronary arteries.

The coronary models, obtained from the CTA medical images, successfully seized the patient-specific characteristics of the lesions studied. The models acquired by using the VMTK software showed to be preferable in comparison with the DeVIDE, although the later is still a good alternative.

The geometry model of the coronary tree acquired from the CTA images needs to consider almost the entire coronary tree in order to improve the ni-FFR results. This is accomplished by considering longer ramifications in the model.

The Incompressible Navier-Stokes equations are solved by using the IPCS formulation with the FEM. The decoupling of the velocity and pressure fields is a good method when dealing with large tri-dimensional fluid flow computer simulations, specially when the linear approximation is used.

The computer simulations with the linear interpolation for both velocity and pressure (P1P1) and a refined mesh showed to be superior when compared to the quadratic interpolation for the the velocity and linear interpolation for the pressure (P2P1). The former presented lower pressure error and lower simulation time.

The IPCS with P1P1 is an adequate scheme for simulating large transient models. It produced relative light computer simulations, considering that three millions of elements used an average of 10GB RAM and that simulations took approximately six hours.

The solver is implemented in Python with the aid of the open source software FEniCS. This software showed to be a good and stable tool for solving PDEs with the FEM, in particular for solving transient blood flow problems inside arteries.

In relation to the pressure distribution, the Newtonian model for the blood showed to be a good hypothesis. The non-Newtonian models should be used in the study when the variable of interest is the velocity or the WSS distribution.

This dissertation compared three cases with the invasive FFR values, however only one was performed at the Institute Dante Pazzanese of Cardiology of São Paulo and could be supervised closely.

The method still needs to be compared with several cases to achieve a statistical measurement of the errors involved. However, the results showed that the method developed is a reasonable predictor for the FFR, at least for the cases studied. 
The differences among the models, assumptions, and hypotheses used in the method developed in this dissertation, and the HeartFlow approach need to be studied in more detail. Table 7.1 shows the main differences among the methods.

Table 7.1 - Comparison of the Models.

\begin{tabular}{ccc}
\hline Model & This dissertation & HeartFlow \\
\hline Geometry & CTA & CTA \\
Blood & Newtonian & Newtonian \\
Equation & Decoupled (IPCS) & Coupled \\
Wall & Rigid & FSI \\
Boundary Condition & Dirichlet & Multi-scale \\
\hline
\end{tabular}

\subsection{Future Work}

The method described in this dissertation is an attempt to introduce the concept of the non-invasive FFR to the Brazilian medical industry. It can be improved by using other hypotheses or models, such as the elastic behavior of the artery wall (FSI) or the use of a multi-scale coupled model.

Another point that can enhance the method developed in this dissertation are the boundary conditions implemented. The boundary conditions can be set specifically for each patient:

- Instead of considering the average human blood flow, the boundary condition at the inlet could be based on the volume of the heart or on the volume of the heart chamber.

- The pressure boundary condition can be dependent on the outlet radius of each artery.

In regarding decreasing simulation time, the use of parallel or distributed cores is a possibility.

Finally, the method used in this dissertation can be compared with the results of the HeartFlow company,in order to evaluate the differences among the hypotheses and models considered. 


\section{REFERENCES}

ANTIGA, L.; PICCINELLI, M.; BOTTI, L.; ENE-IORDACHE, B.; REMUZZI, A.; STEINMAN, D. a. An image-based modeling framework for patient-specific computational hemodynamics. Medical and Biological Engineering and Computing, v. 46, n. 11, p. 1097-1112, 2008. ISSN 01400118. Cited in page 43.

AURICCHIO, F.; CONTI, M.; FERRAZZANO, C.; SGUEGLIA, G. A. A simple framework to generate $3 \mathrm{D}$ patient-specific model of coronary artery bifurcation from single-plane angiographic images. Computers in Biology and Medicine, Elsevier, v. 44, n. 1, p. 97-109, 2014. ISSN 00104825. Cited in page 24.

BALAY, S.; GROPP, W.; MCINNES, L.; SMITH, B. Efficient Management of Parallelism in Object Oriented Numerical Software Libraries. In: BRUASET, A.; ARGE, E.; LANGTANGEN, H. P. (Ed.). Modern software tools in scientific computing. 1. ed. [S.I.]: Birkhauser Press, 1997. Chap. 8, p. 163-202. ISBN 978-1-4612-7368-4. Cited in page 50.

BARRETT, K.; BROOKS, H.; BOITANO, S.; BARMAN, S. Ganong's Review of Medical Physiology. 23rd. ed. [S.I.]: The McGraw-Hill Companies, Inc., 2010. 726 p. ISBN 978-0-07-160568-7. Cited 4 times in pages 15, 18, 19, and 40.

BATHE, K. J. The inf-sup condition and its evaluation for mixed finite element methods. Computers and Structures, v. 79, n. 2, p. 243-252, jan 2001. ISSN 00457949. Cited in page 39.

BERNSDORF, J.; WANG, D. Non-Newtonian blood flow simulation in cerebral aneurysms. Computers and Mathematics with Applications, Elsevier Ltd, v. 58, n. 5, p. 1024-1029, 2009. ISSN 08981221. Cited in page 23.

BLANCO, P.; FEIJÓO, R. A dimensionally-heterogeneous closed-loop model for the cardiovascular system and its applications. Medical Engineering and Physics, v. 35, n. 5, p. 652-667, 2013. ISSN 13504533. Cited in page 21.

BOTHA, C. P.; POST, F. H. Hybrid Scheduling in the DeVIDE Dataflow Visualisation Environment. Proceedings of Simulation and Visualization, v. 1, p. 309-322, 2008. Cited in page 43.

BRUN, J.-F.; ALOULOU, I.; VARLET-MARIE, E. Hemorheological aspects of the metabolic syndrome: markers of insulin resistance, obesity or hyperinsulinemia? Clinical hemorheology and microcirculation, v. 30, n. 3-4, p. 203-209, 2004. ISSN 1386-0291. Cited in page 29.

CHAICHANA, T.; SUN, Z.; JEWKES, J. Computation of hemodynamics in the left coronary artery with variable angulations. Journal of Biomechanics, Elsevier, v. 44, n. 10, p. 1869-1878, 2011. ISSN 00219290. Cited in page 25.

CHAN, T. F.; VORST, H. A. van der. Approximate and Incomplete Factorizations. Parallel Numerical Algorithms, ICASE/LaRC Interdisciplinary Series in Science and Engeneering, v. 4, p. 167-202, 2001. ISSN 1381-1339. Cited in page 50. 
CHO, Y. I.; KENSEY, K. R. Effects of the non-Newtonian viscosity of blood on flows in a diseased arterial vessel. Part 1: Steady flows. Biorheology, v. 28, n. 3-4, p. 241-262, 1991. ISSN 0006355X. Cited 2 times in pages 28 and 30.

CHORIN, A. J. Numerical solution of the Navier-Stokes equations. Mathematics of Computation, v. 22, n. 104, p. 745-762, 1968. ISSN 00255718. Cited in page 33.

De Bruyne, B.; PAULUS, W. J.; VANTRIMPONT, P. J.; SYS, S. U.; HEYNDRICKX, G. R.; PIJLS, N. H. Transstenotic coronary pressure gradient measurement in humans: In vitro and in vivo evaluation of a new pressure monitoring angioplasty guide wire. Journal of the American College of Cardiology, v. 22, n. 1, p. 119-126, jul 1993. ISSN 07351097. Available from Internet: <http://linkinghub.elsevier.com/retrieve/pii/073510979390825L>. Cited in page 55.

DINTENFASS, L. Red cell rigidity, 'Tk', and filtration. Clinical Hemorheology, v. 5, n. 3, p. 214-244, 1985. Cited in page 29.

EVJU, Ø.; VALEN-SENDSTAD, K.; MARDAL, K. A. A study of wall shear stress in 12 aneurysms with respect to different viscosity models and flow conditions. Journal of Biomechanics, Elsevier, v. 46, n. 16, p. 2802-2808, 2013. ISSN 00219290. Cited in page 23.

FORMAGGIA, L.; LAMPONI, D.; QUARTERONI, A. One-dimensional models for blood flow in arteries. Journal of Engineering Mathematics, v. 47, n. 3-4, p. 251-276, 2003. ISSN 00220833. Cited in page 20.

FU, W.; GU, Z.; MENG, X.; CHU, B.; QIAO, A. Numerical simulation of hemodynamics in stented internal carotid aneurysm based on patient-specific model. Journal of Biomechanics, Elsevier, v. 43, n. 7, p. 1337-1342, 2010. ISSN 00219290. Cited in page 21.

GEERS, A. J.; LARRABIDE, I.; MORALES, H. G.; FRANGI, A. F. Approximating hemodynamics of cerebral aneurysms with steady flow simulations. Journal of Biomechanics, Elsevier, v. 47, n. 1, p. 178-185, 2014. ISSN 00219290. Cited in page 21.

GODA, K. A multistep technique with implicit difference schemes for calculating two- or three-dimensional cavity flows. Journal of Computational Physics, v. 30, n. 1, p. 76-95, 1979. ISSN 00219991. Cited in page 33.

GOVINDARAJU, K.; BADRUDDIN, I. A.; VISWANATHAN, G. N.; RAMESH, S. V.; BADARUDIN, a. Evaluation of functional severity of coronary artery disease and fluid dynamics' influence on hemodynamic parameters: A review. Physica Medica, Elsevier Ltd, v. 29, n. 3, p. 225-232, 2013. ISSN 11201797. Cited in page 67.

GUERMOND, J. L.; MINEV, P.; SHEN, J. An overview of projection methods for incompressible flows. Computer Methods in Applied Mechanics and Engineering, v. 195, n. 44-47, p. 6011-6045, 2006. ISSN 00457825. Cited 2 times in pages 34 and 39.

HALL, J. E.; GUYTON, A. C. Textbook of Medical Physiology. 11th. ed. [S.I.]: Elsevier Inc., 2006. 1152 p. ISSN 1465-7333. ISBN 978-0-7216-0240-0. Cited 6 times in pages 15, 16, 17, 19, 22, and 23. 
JOHNSON, N. P.; TOTH, G. G.; LAI, D.; ZHU, H.; ACAR, G.; AGOSTONI, P.; APPELMAN, Y.; ARSLAN, F.; BARBATO, E.; CHEN, S. L.; Di Serafino, L.; DOMINGUEZ-FRANCO, A. J.; DUPOUY, P.; ESEN, A. M.; ESEN, O. B.; HAMILOS, M.; IWASAKI, K.; JENSEN, L. O.; JIMENEZ-NAVARRO, M. F.; KATRITSIS, D. G.; KOCAMAN, S. A.; KOO, B. K.; LOPEZ-PALOP, R.; LORIN, J. D.; MILLER, L. H.; MULLER, O.; NAM, C. W.; OUD, N.; PUYMIRAT, E.; RIEBER, J.; RIOUFOL, G.; RODES-CABAU, J.; SEDLIS, S. P.; TAKEISHI, Y.; TONINO, P. A.; Van Belle, E.; VERNA, E.; WERNER, G. S.; FEARON, W. F.; PIJLS, N. H.; De Bruyne, B.; GOULD, K. L. Prognostic value of fractional flow reserve: linking physiologic severity to clinical outcomes. Journal of the American College of Cardiology, v. 64 , n. 16, p. 1641-1654, 2014. ISSN 1558-3597. Cited in page 17.

JOHNSTON, B. M.; JOHNSTON, P. R.; CORNEY, S.; KILPATRICK, D. Non-Newtonian blood flow in human right coronary arteries: Steady state simulations. Journal of Biomechanics, v. 37, n. 5, p. 709-720, 2004. ISSN 00219290. Cited in page 25.

JOHNSTON, B. M.; JOHNSTON, P. R.; CORNEY, S.; KILPATRICK, D. Non-Newtonian blood flow in human right coronary arteries: Transient simulations. Journal of Biomechanics, v. 39, n. 6, p. 1116-1128, 2006. ISSN 00219290. Cited in page 25.

KANG, X. Assessment of the pulsatile wall shear stress in the stenosed and recanalized carotid bifurcations by the lattice Boltzmann method. Computers and Fluids, Elsevier Ltd, v. 97 , p. 156-163, 2014. ISSN 00457930. Cited in page 21.

KARNIADAKIS, G.; SHERWIN, S. Spectral/hp Element Methods for Computational Fluid Dynamics: Second Edition. OUP Oxford, 2005. ISBN 9780198528692. Available from Internet: <https://books.google.com.br/books?id=mfpzYY4KsuwC>. Cited in page 36.

KIM, H. J.; VIGNON-CLEMENTEL, I. E.; FIGUEROA, C. A.; LADISA, J. F.; JANSEN, K. E.; FEINSTEIN, J. A.; TAYLOR, C. A. On coupling a lumped parameter heart model and a three-dimensional finite element aorta model. Annals of Biomedical Engineering, v. 37, n. 11, p. 2153-2169, 2009. ISSN 00906964. Cited in page 21.

KIM, H. J.; VIGNON-CLEMENTEL, I. E.; FIGUEROA, C. A.; JANSEN, K. E.; TAYLOR, C. A. Developing computational methods for three-dimensional finite element simulations of coronary blood flow. Finite Elements in Analysis and Design, Elsevier, v. 46, n. 6, p. 514-525, 2010. ISSN 0168874X. Cited in page 25.

KOO, B.-K.; ERGLIS, A.; DOH, J. H.; DANIELS, D. V.; JEGERE, S.; KIM, H. S.; DUNNING, A.; DEFRANCE, T.; LANSKY, A.; LEIPSIC, J.; MIN, J. K. Diagnosis of ischemia-causing coronary stenoses by noninvasive fractional flow reserve computed from coronary computed tomographic angiograms: Results from the prospective multicenter DISCOVER-FLOW (Diagnosis of Ischemia-Causing Stenoses Obtained Via Noni. Journal of the American College of Cardiology, Elsevier Inc., v. 58, n. 19, p. 1989-1997, 2011. ISSN 07351097. Cited in page 25.

LIANG, F.; LIU, H. A Closed-Loop Lumped Parameter Computational Model for Human Cardiovascular System. JSME International Journal Series C, v. 48, n. 4, p. 484-493, 2005. ISSN 1344-7653. Cited in page 20.

LOGG, A.; MARDAL, K. A.; WELLS, G. N. Automated Solution of Differential Equations by the Finite Element Method. [S.I.: s.n.], 2012. v. 84. 724 p. ISBN 978-3-642-23098-1. Cited 3 times in pages 36, 48, and 51 . 
MALEK, A. M.; ALPER, S. L.; IZUMO, S. Hemodynamic shear stress and its role in atherosclerosis. JAMA : the Journal of the American Medical Association, v. 282, n. 21, p. 2035-2042, 1999. ISSN 00987484. Cited in page 17.

MIN, J. K.; LEIPSIC, J.; PENCINA, M. J.; BERMAN, D. S.; KOO, B.-K.; MIEGHEM, C. van; ERGLIS, A.; LIN, F. Y. Diagnostic Accuracy of Fractional Flow Reserve From Anatomic CT Angiography. JAMA: The Journal of the American Medical Association, v. 308, n. 12, p. 1237-1245, 2012. ISSN 0098-7484. Cited in page 25.

MORRIS, P. D.; RYAN, D.; MORTON, A. C.; LYCETT, R.; LAWFORD, P. V.; HOSE, D. R.; GUNN, J. P. Virtual fractional flow reserve from coronary angiography: Modeling the significance of coronary lesions. Results from the VIRTU-1 (VIRTUal fractional flow reserve from coronary angiography) study. JACC: Cardiovascular Interventions, Elsevier Inc., v. 6 , n. 2, p. 149-157, 2013. ISSN 19368798. Cited in page 26.

MYERS, J. G.; MOORE, J. A.; OJHA, M.; JOHNSTON, K. W.; ETHIER, C. R. Factors influencing blood flow patterns in the human right coronary artery. Annals of Biomedical Engineering, v. 29, n. 2, p. 109-120, 2001. ISSN 00906964. Cited in page 24.

NØRGAARD, B. L.; LEIPSIC, J.; GAUR, S.; SENEVIRATNE, S.; KO, B. S.; ITO, H.; JENSEN, J. M. I.; MAURI, L.; De Bruyne, B.; BEZERRA, H. G.; OSAWA, K.; MARWAN, M.; NABER, C.; ERGLIS, A.; PARK, S. J.; CHRISTIANSEN, E. H.; KALTOFT, A.; LASSEN, J. F.; TKER, H. E. B.; ACHENBACH, S. Diagnostic performance of noninvasive fractional flow reserve derived from coronary computed tomography angiography in suspected coronary artery disease: The NXT trial (Analysis of Coronary Blood Flow Using CT Angiography: Next Steps). Journal of the American College of Cardiology, v. 63, n. 12, p. 1145-1155, 2014. ISSN 15583597. Cited in page 25.

PERKTOLD, K.; KARNER, G.; LEUPRECHT, A.; HOFER, M. Influence of non-newtonian flow behavior on local hemodynamics. Journal of Applied Mathematics and Mechanics, v. 79, n. S1, p. 187-190, 1999. ISSN 00442267. Cited in page 39.

PIJLS, N. H. J. Fractional flow reserve to guide coronary revascularization. Circulation Journal, v. 77, n. 3, p. 561-569, 2013. ISSN 1346-9843. Cited 3 times in pages 17, 18, and 67.

PIJLS, N. H. J.; SELS, J. W. E. M. Functional measurement of coronary stenosis. Journal of the American College of Cardiology, Elsevier Inc., v. 59, n. 12, p. 1045-1057, 2012. ISSN 07351097. Cited in page 18.

RAGHU, R.; TAYLOR, C. A. Verification of a one-dimensional finite element method for modeling blood flow in the cardiovascular system incorporating a viscoelastic wall model. Finite Elements in Analysis and Design, Elsevier, v. 47, n. 6, p. 586-592, 2011. ISSN 0168874X. Cited in page 20.

REDDY, J. N. An introduction to nonlinear finite element analysis. [S.I.]: Oxford University Press, 2004. 488 p. ISBN ISBN 0-19-852529-X 978-0-19-852529-5. Cited 4 times in pages $31,35,36$, and 37.

REYMOND, P.; CROSETTO, P.; DEPARIS, S.; QUARTERONI, A.; STERGIOPULOS, N. Physiological simulation of blood flow in the aorta: Comparison of hemodynamic indices as predicted by 3-D FSI, 3-D rigid wall and 1-D models. Medical Engineering and Physics, 
Institute of Physics and Engineering in Medicine, v. 35, n. 6, p. 784-791, 2013. ISSN 13504533. Cited 2 times in pages 22 and 41.

RIKHTEGAR, F.; WYSS, C.; STOK, K. S.; POULIKAKOS, D.; MüLLER, R.; KURTCUOGLU, V. Hemodynamics in coronary arteries with overlapping stents. Journal of Biomechanics, Elsevier, v. 47, n. 2, p. 505-511, 2014. ISSN 00219290. Cited in page 21.

ROBERTSON, A. M.; SEQUEIRA, A.; OWENSE, R. G. Rheological models for blood. In: FORMAGGIA, L.; QUARTERONI, A.; VENEZIANI, A. (Ed.). Cardiovasular Mathematics Modeling and simulation of the circulatory system. [S.I.]: Springer, 2009. Chap. 6, p. 211-241. Cited 3 times in pages 23, 28, and 30.

SAAD, Y.; SCHULTZ, M. H. GMRES: A Generalized Minimal Residual Algorithm for Solving Nonsymmetric Linear Systems. SIAM Journal on Scientific and Statistical Computing, v. 7, n. 3, p. 856-869, 1986. ISSN 0196-5204. Cited in page 50.

Staff Blausen.com. Blausen gallery 2014. Wikiversity Journal of Medicine, v. 1, n. 2, 2014. ISSN 20018762. Available from Internet: <https://en.wikiversity.org/wiki/Wikiversity Journal_of_Medicine/Blausen_gallery_2014>. Visited on: 2015-05-05. Cited 4 times in pages $15,16,18$, and 22.

STÜBEN, K. Algebraic multigrid (AMG): an introduction with applications. Computing, n. November, p. 1-127, 1999. Cited in page 50.

TAYLOR, C. A.; FIGUEROA, C. A. Patient-specific modeling of cardiovascular mechanics. Annual review of biomedical engineering, v. 11, n. April, p. 109-134, 2009. ISSN 1523-9829. Cited in page 24.

TAYLOR, C. A.; FONTE, T. A.; MIN, J. K. Computational fluid dynamics applied to cardiac computed tomography for noninvasive quantification of fractional flow reserve: Scientific basis. Journal of the American College of Cardiology, v. 61, n. 22, p. 2233-2241, 2013. ISSN 07351097. Cited in page 25.

U.S. Food and Drug Administration. FDA allows marketing of non-invasive device to help evaluate heart blood flow. 2014. Available from Internet: <http: //www.fda.gov/NewsEvents/Newsroom/PressAnnouncements/ucm424945.htm>. Visited on: 2015-07-08. Cited in page 25.

VALEN-SENDSTAD, K.; LOGG, A.; MARDAL, K. A.; NARAYANAN, H. A Comparison of Some Common Finite Element Schemes for the Incompressible Navier-Stokes Equations. In: LOGG, A.; MARDAL, K.-A.; WELLS, G. N. (Ed.). Automated Solution of Differential Equations by the Finite Element Method. [S.I.: s.n.], 2012. Chap. 21, p. 395-418. ISBN 9783642230981. Cited in page 33.

WALBURN, F. J.; SCHNECK, D. J. A constitutive equation for whole human blood. Biorheology, v. 13, n. 3, p. 201-210, 1976. ISSN 0006-355X. Cited in page 29.

WANG, D.; BERNSDORF, J. Lattice Boltzmann simulation of steady non-Newtonian blood flow in a 3D generic stenosis case. Computers and Mathematics with Applications, Elsevier Ltd, v. 58, n. 5, p. 1030-1034, 2009. ISSN 08981221. Cited in page 24.

WARNER, $\mathrm{H}$. The Use of an Analog Computer for Analysis of Control Mechanisms in the Circulation. Proceedings of the IRE, v. 47, n. 11, p. 1913-1916, 1959. ISSN 0096-8390. Cited in page 19. 
WELLNHOFER, E.; OSMAN, J.; KERTZSCHER, U.; AFFELD, K.; FLECK, E.;

GOUBERGRITS, L. Flow simulation studies in coronary arteries-Impact of side-branches. Atherosclerosis, Elsevier Ireland Ltd, v. 213, n. 2, p. 475-481, 2010. ISSN 00219150. Cited 2 times in pages 24 and 72.

WILSON, R. F.; WYCHE, K.; CHRISTENSEN, B. V.; ZIMMER, S.; LAXSON, D. D. Clinical Investigation Effects of Adenosine on Human Coronary Arterial Circulation. Circulation, v. 82 , n. 5, p. 1595-1606, 1990. Cited in page 40.

World Health Organization. The Global Burden of Disease: 2004 update. 2008. 146 p. Available from Internet: <http://www.who.int/healthinfo/global_burden_disease/2004_report_ update/en/>. Visited on: 2015-05-21. Cited in page 15.

XIAO, N.; HUMPHREY, J. D.; FIGUEROA, C. A. Multi-scale computational model of three-dimensional hemodynamics within a deformable full-body arterial network. Journal of Computational Physics, Elsevier Inc., v. 244, p. 22-40, 2013. ISSN 00219991. Cited in page 19.

XIE, X.; WANG, Y.; ZHOU, H. Impact of coronary tortuosity on the coronary blood flow: A 3D computational study. Journal of Biomechanics, Elsevier, v. 46, n. 11, p. 1833-1841, 2013. ISSN 00219290. Cited in page 24.

YAMABE, P. V. M.; DIANA, R. E. Y. Graduation Dissertation, Simulação Computacional 3D de Sistemas Arteriais. São Paulo: [s.n.], 2013. 95 p. Cited in page 25.

YEOW, Y. L.; WICKRAMASINGHE, S. R.; LEONG, Y. K.; HAN, B. Model-independent relationships between hematocrit, blood viscosity, and yield stress derived from Couette viscometry data. Biotechnology Progress, v. 18, n. 5, p. 1068-1075, 2002. ISSN 87567938. Cited in page 29. 


\section{APPENDIX A - CODE IMPLEMENTED}

Listing A.1 - Entire Code used in the computer simulations.

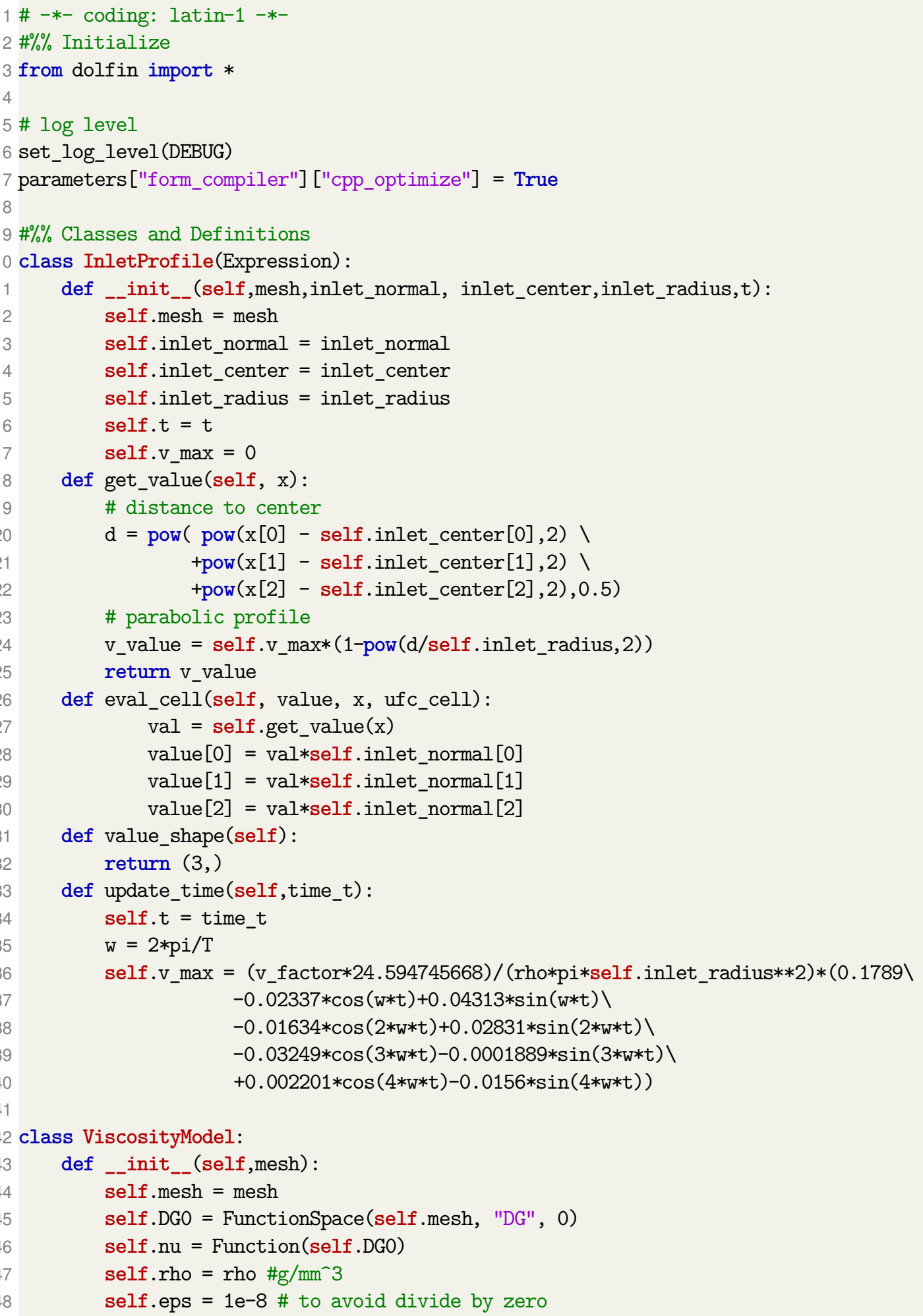




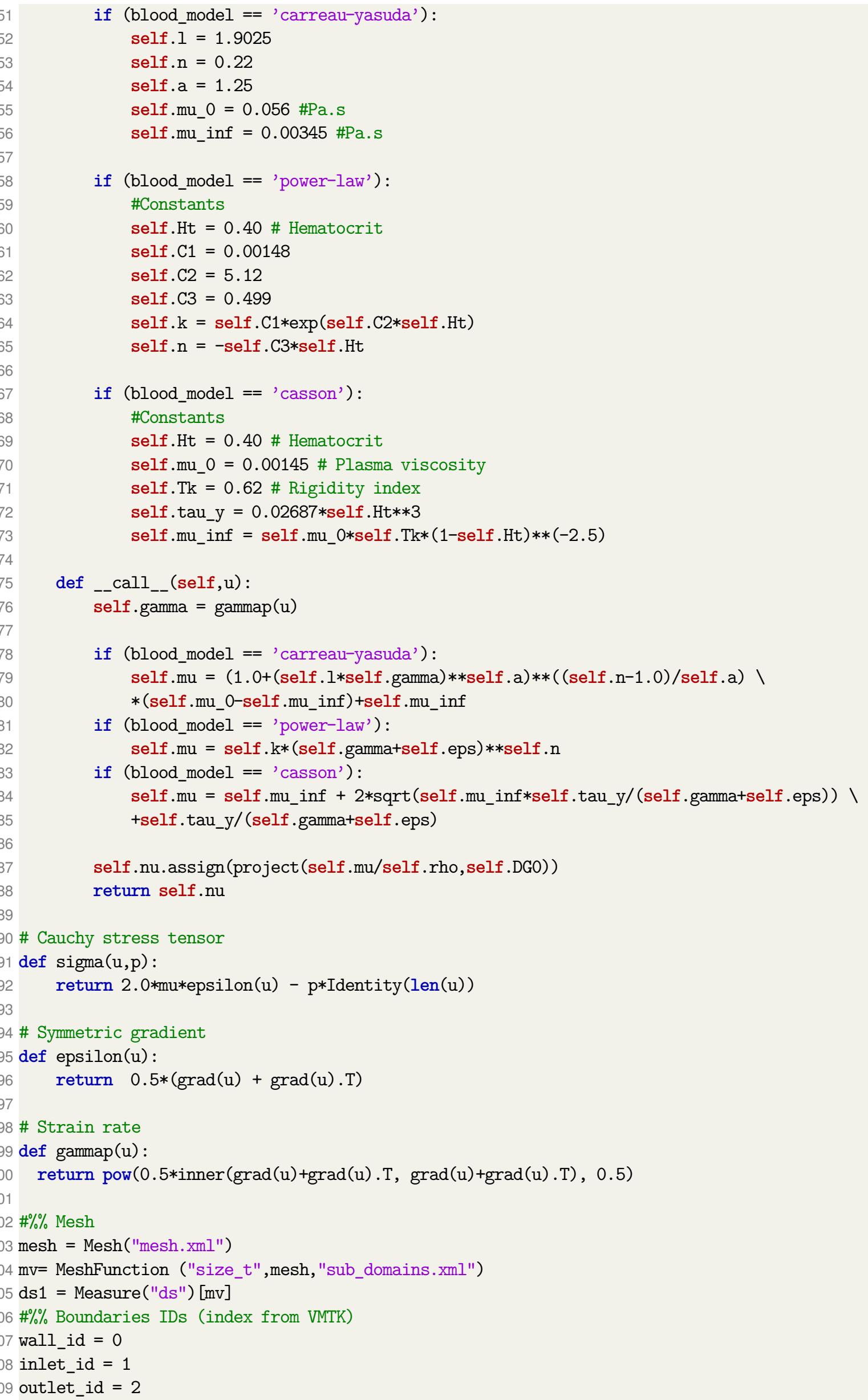




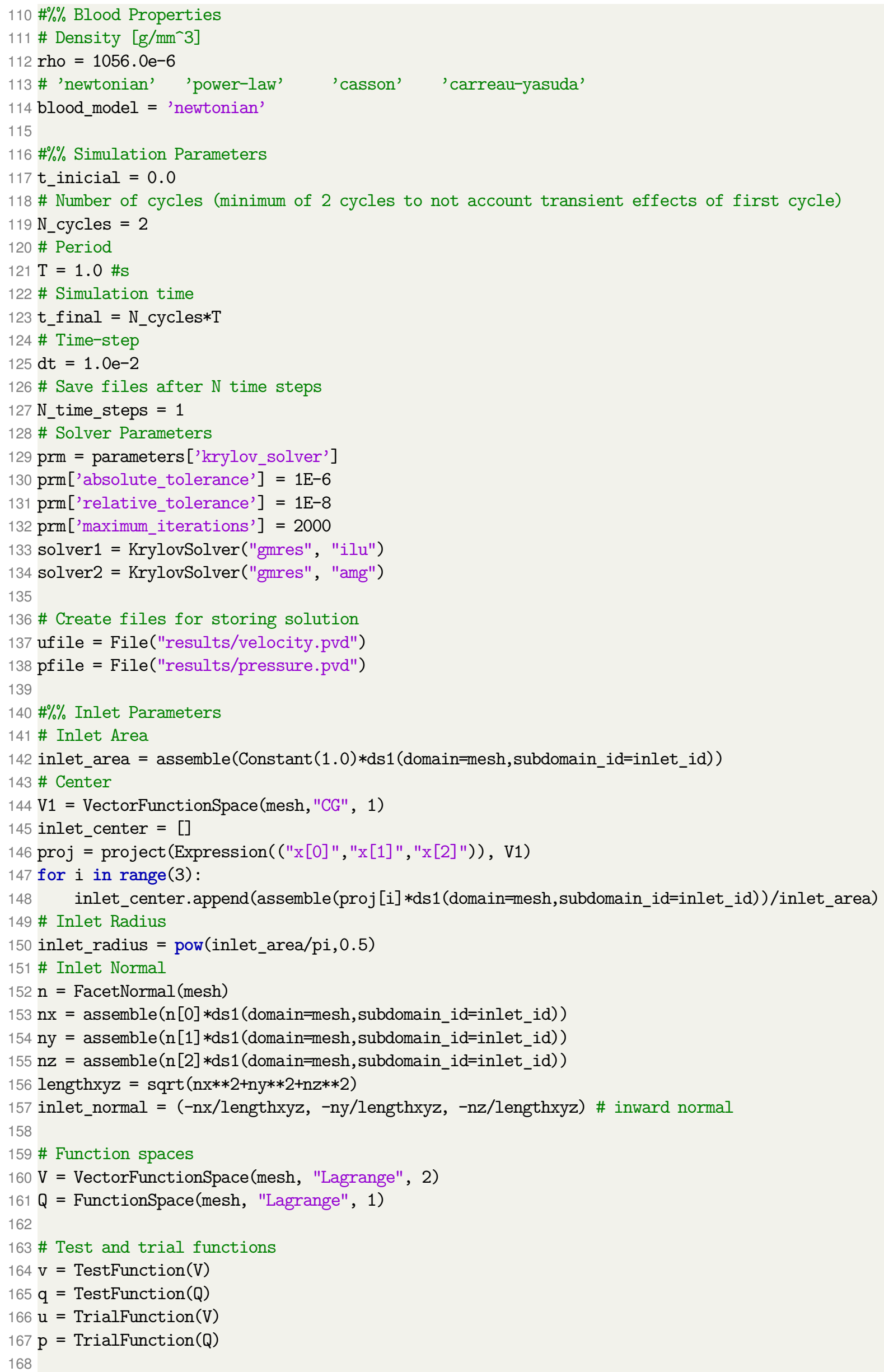




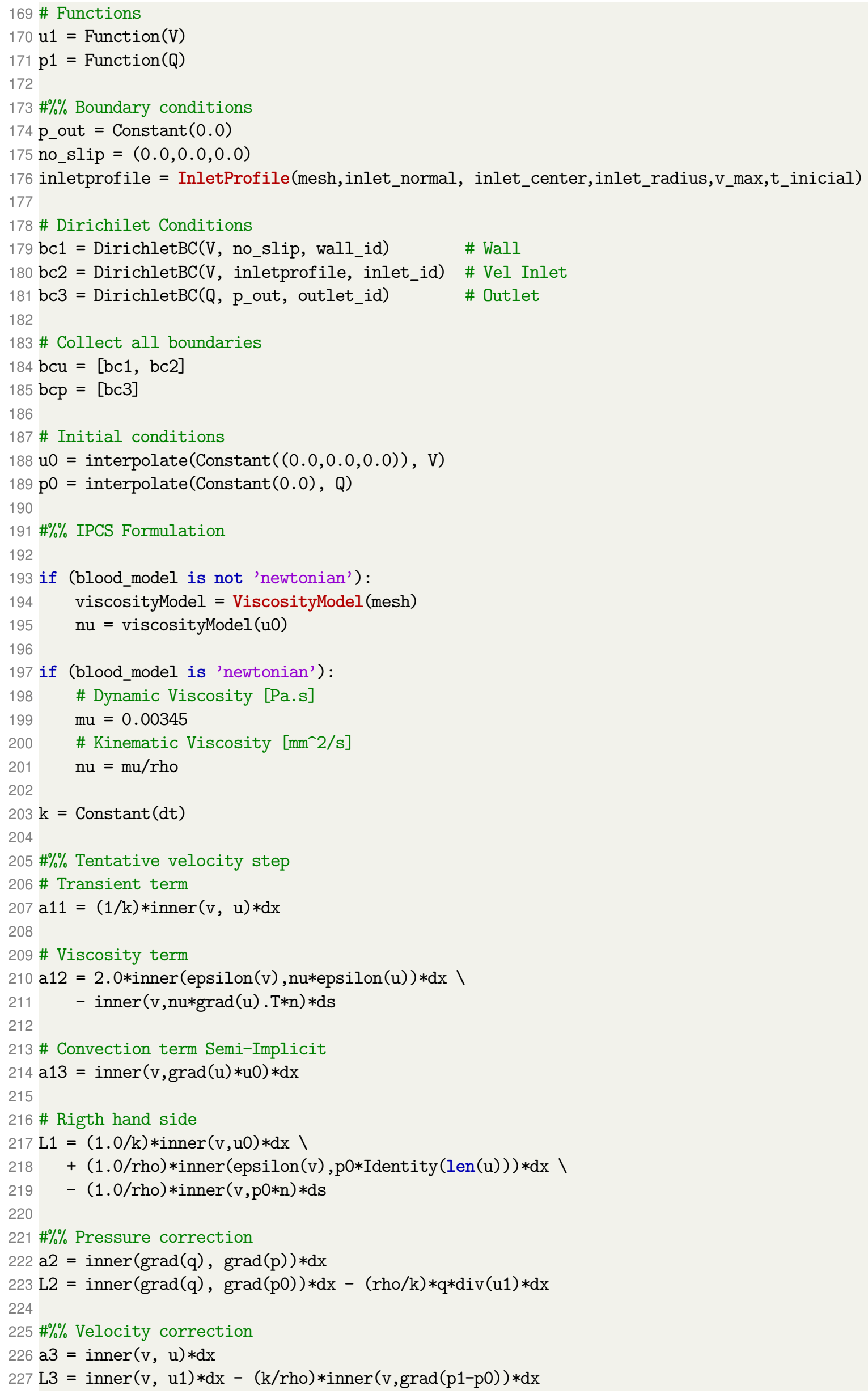




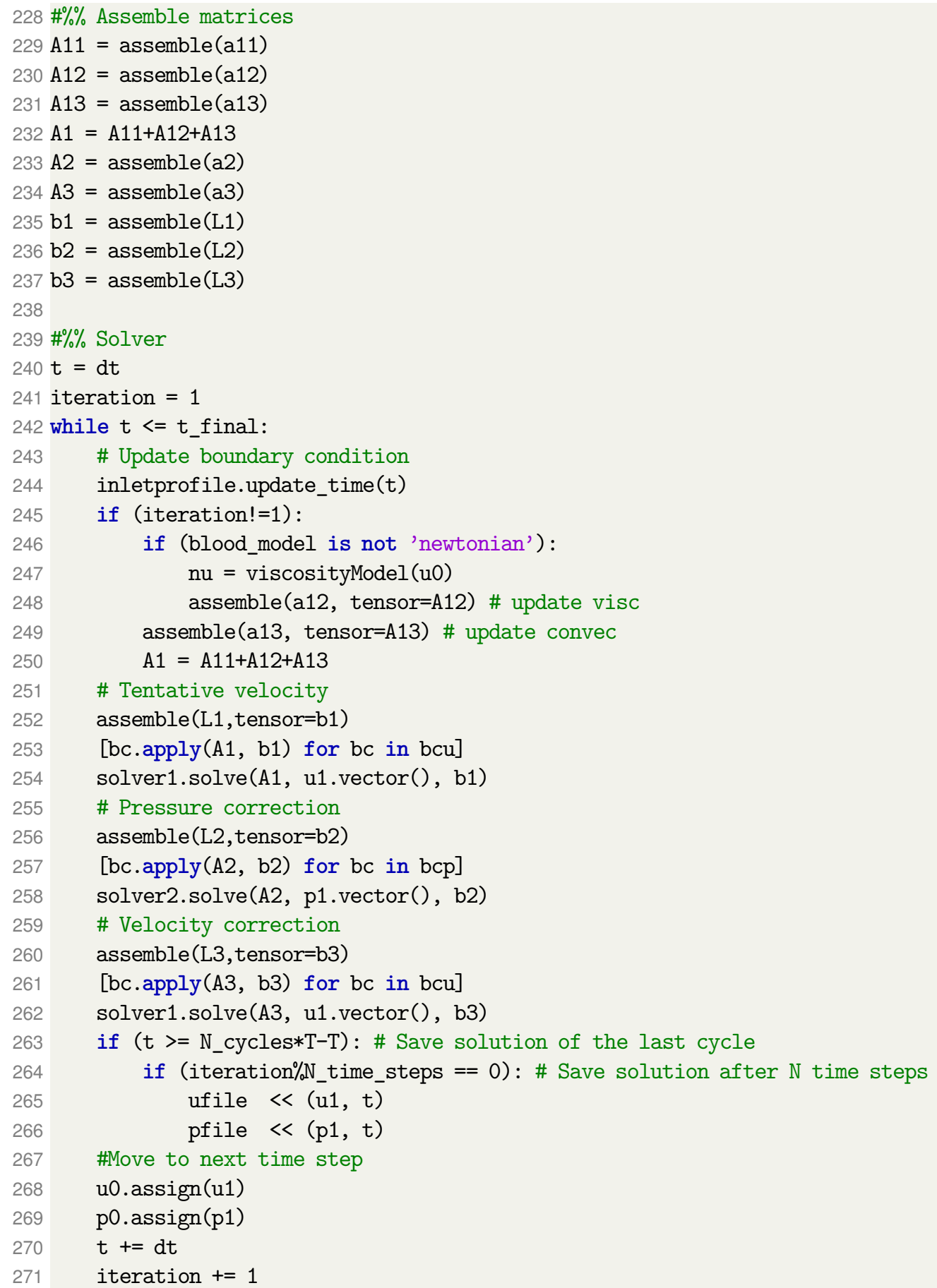

